\title{
WestVirginiaUniversity
}

THE RESEARCH REPOSITORY @ WVU

Graduate Theses, Dissertations, and Problem Reports

2006

\section{Investigation of techniques and effects of diesel particulate filter cleaning}

Nathaniel Moles

West Virginia University

Follow this and additional works at: https://researchrepository.wvu.edu/etd

\section{Recommended Citation}

Moles, Nathaniel, "Investigation of techniques and effects of diesel particulate filter cleaning" (2006). Graduate Theses, Dissertations, and Problem Reports. 4249.

https://researchrepository.wvu.edu/etd/4249

This Thesis is protected by copyright and/or related rights. It has been brought to you by the The Research Repository @ WVU with permission from the rights-holder(s). You are free to use this Thesis in any way that is permitted by the copyright and related rights legislation that applies to your use. For other uses you must obtain permission from the rights-holder(s) directly, unless additional rights are indicated by a Creative Commons license in the record and/ or on the work itself. This Thesis has been accepted for inclusion in WVU Graduate Theses, Dissertations, and Problem Reports collection by an authorized administrator of The Research Repository @ WVU. For more information, please contact researchrepository@mail.wvu.edu. 


\title{
Investigation of Techniques and Effects of Diesel Particulate Filter Cleaning
}

\author{
Nathaniel Moles
}

Thesis submitted to the

College of Engineering and Mineral Resources

at West Virginia University

in partial fulfillment of the requirements

for the degree of

\author{
Master of Science \\ In \\ Mechanical Engineering \\ Gregory J. Thompson Ph.D., Chair \\ Nigel N. Clark, Ph.D. \\ Mridul Gautam, Ph.D.
}

Department of Mechanical and Aerospace Engineering

\author{
Morgantown, West Virginia \\ 2006
}

Keywords: Diesel particulate filters, PM reduction, cleaning DPF's, filer cleaning 


\title{
ABSTRACT \\ Investigation of Techniques and Effects of Diesel Particulate Filter Cleaning
}

\author{
Nathaniel Moles
}

As the emissions standards placed on diesel engine exhaust become more stringent, the use of exhaust aftertreatment devices such as diesel particulate filters has become a more attractive means to meet those standards. During the use of these filters some of the particulate captured, usually ash, begins to restrict the flow through the filter. This increases the backpressure in the exhaust system and requires routine cleaning maintenance. This study reviewed engine technology used to reduce particulate emissions and investigated the effects of off-line cleaning of diesel particulate filters using compressed air and water flowing in the reverse direction of the exhaust flow. The resulting effects of these cleaning procedures were examined by measuring the weight lost and the pressure drop across the filters at varying air flow rates. Both the differential pressure and weight loss indicated that most of the particulate was removed during the initial stages of compressed air cleaning. A maximum of $92 \%$ of the total filter weight was removed from a single filter with a maximum decrease of $65 \%$ of the differential pressure across the filter. Flowing water in the reverse direction was found to be one of the most effective options in cleaning these filters, but many filters have matting materials that are damaged when exposed to water. Compressed air blown in the reverse direction for a thirty minute time period is recommended with a subsequent twenty minute water cleaning, if water is not restricted by the manufacturer. 


\section{ACKNOWLEDGMENTS}

I would like to take this opportunity to thank all of the people who have helped me in getting this far in my young professional career. First I would like to thank Dr. Greg Thompson who gave me this great opportunity to work on this research project and finish my course requirements so quickly; and John Nuszkowski who has helped me through every stage of this project and beyond. I could not have successfully made it through without their professional expertise and direction. Also, I extend my thanks to Fleetguard Emissions Solutions for funding this project. I would also like to thank Eric Taylor who persevered though all of the graduate courses along side me. I could not have

picked a better person to work along side of in the class room and at the laboratory. To all of my friends and coworkers at the ERC, I thank you and wish you the best of luck in your futures.

I would also like to thank my family and especially my Mom. She has been there for me throughout my life encouraging me to do my best. Without Her guidance and support I would not be the person I am today and have the opportunity to succeed in life. Last, and certainly not least I thank God, for without Him nothing in my life would be possible. 


\section{TABLE OF CONTENTS}

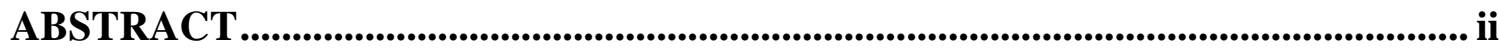

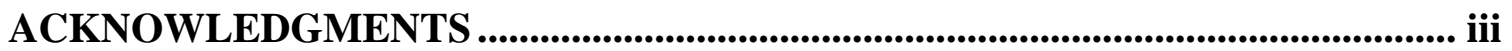

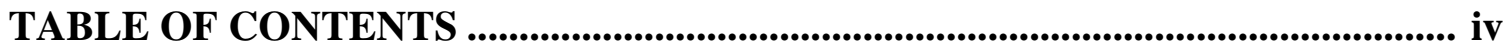

LIST OF TABLES ................................................................................................. vii

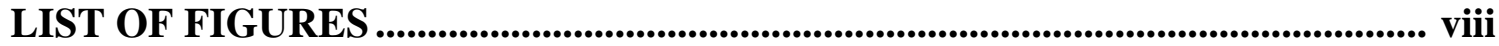

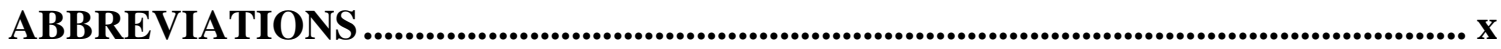

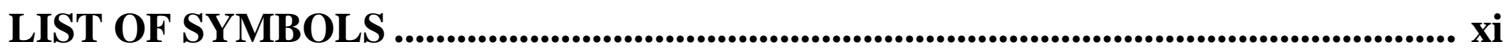

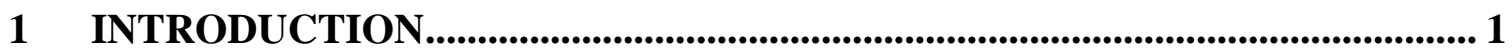

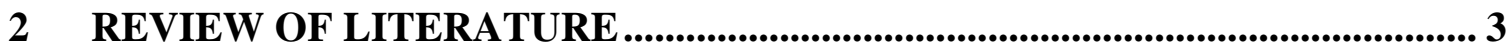

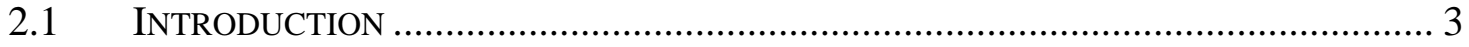

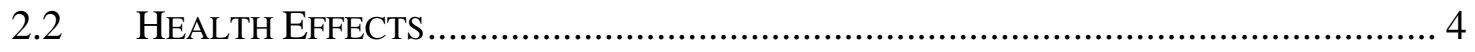

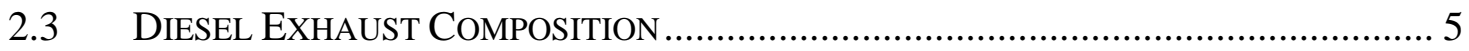

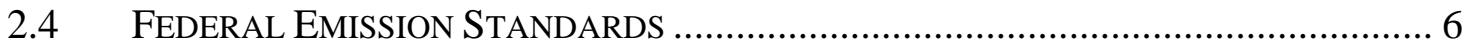

2.5 Improved Diesel Engine Emissions Reduction Methods........................... 9

2.5.1 Air Intake Improvements....................................................................... 10

2.5.2 Combustion Chamber Improvements......................................................... 12

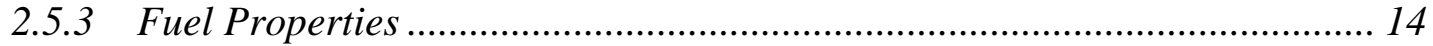

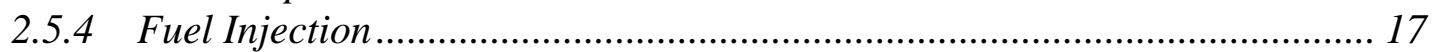

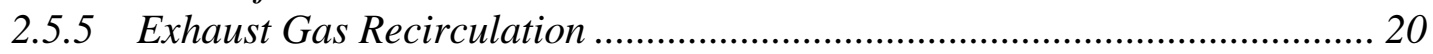

2.6 EXHAUST AFTERTREATMENT.................................................................... 21

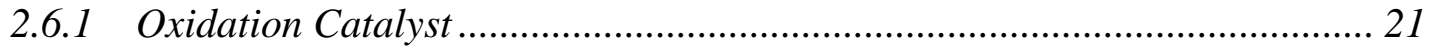

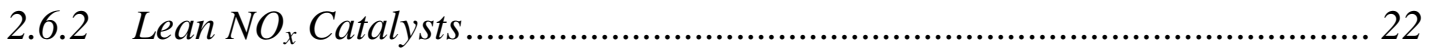

2.6.3 Urea-Selective Catalytic Reduction ......................................................... 24

2.6.4 Non-Thermal Plasma Catalyst............................................................... 25 
2.6.5 Diesel Particulate Filters.......................................................................... 26

2.6.6 Cleaning Diesel Particulate Filters ................................................................ 30

3 EXPERIMENTAL SETUP \& PROCEDURES ...................................................... 35

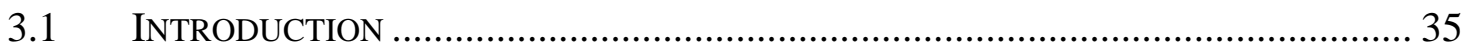

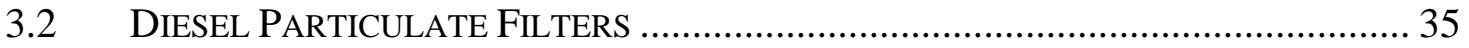

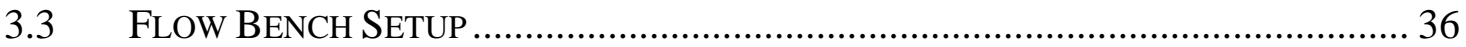

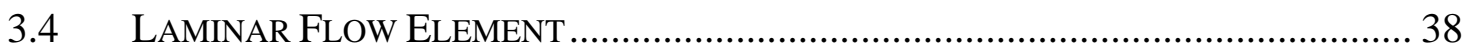

3.5 FLUKE THERMOCOUPLE CALIBRATOR ……………………................................ 39

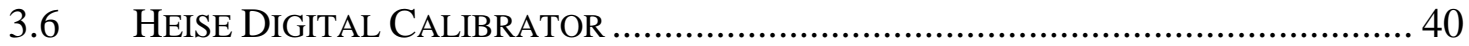

3.6.1 Filter Pressure Drop Modular Sensor ....................................................... 41

3.6.2 LFE Pressure Drop Modular Sensor .......................................................... 41

3.6.3 Absolute Air Pressure Modular Sensor ..................................................... 42

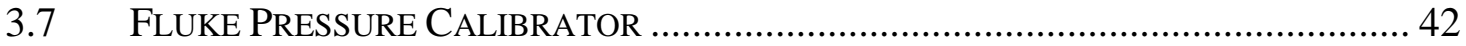

3.8 OMEgA Digital THERMO-HYGROMETER ………............................................ 43

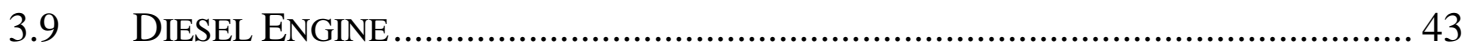

3.9.1 Diesel Engine Intake LFE .......................................................................... 45

3.9.2 Exhaust DPF Pressure Differential .......................................................... 46

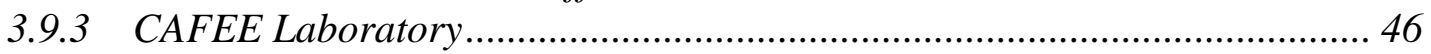

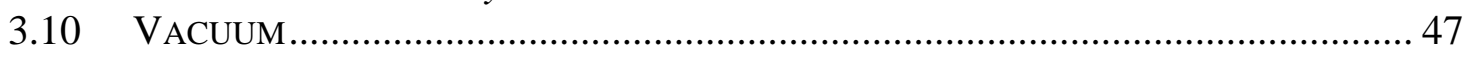

3.11 WEIGHT SCALE ........................................................................................... 48

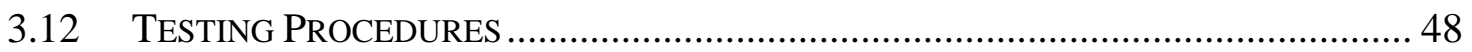

3.12.1 Filter Passage Profiles ............................................................................... 49

3.12.2 Data Logging for Flow Bench Testing......................................................... 52

3.12.3 Cleaning and Flow Bench Testing............................................................... 54

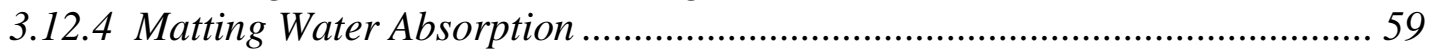

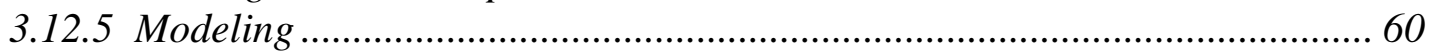

4 RESULTS AND DISCUSSION ……...................................................................... 63

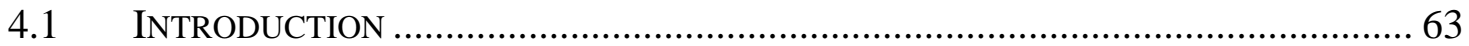

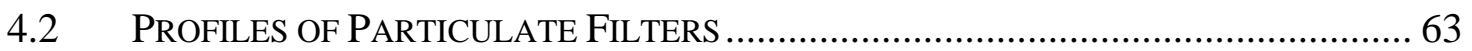

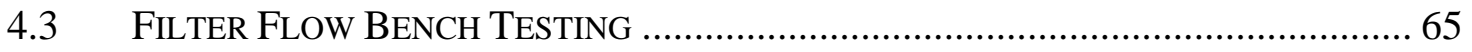

4.3.1 Initial Filters Pressure Drop ………………………………………….....6 66

4.3.2 Complete DPF Systems Pressure Drop ………………………………….... 67 


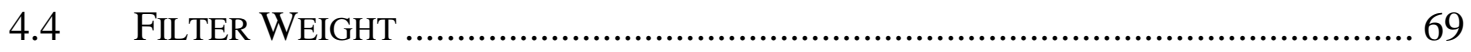

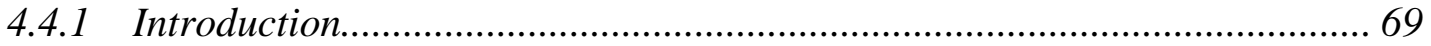

4.4.2 Initial Filters Weight............................................................................. 70

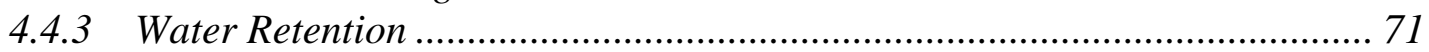

4.4.4 Complete DPF Weight .......................................................................... 73

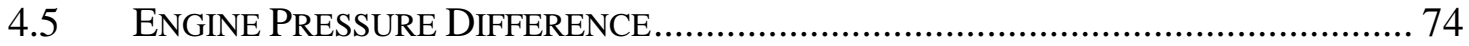

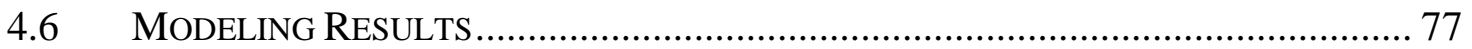

5 CONCLUSIONS AND RECOMMENDATIONS.............................................. 82

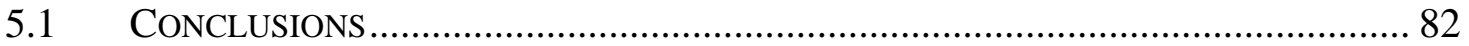

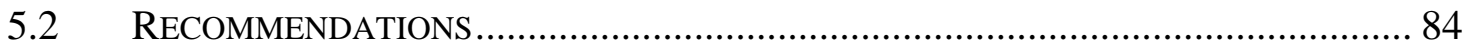

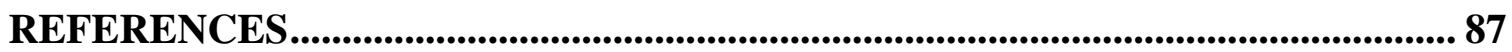

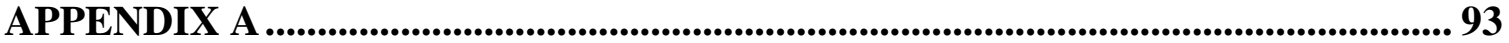

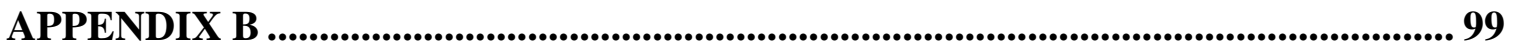

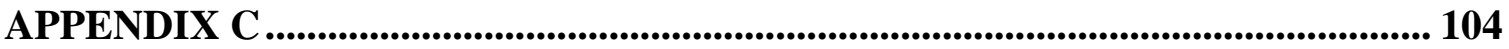

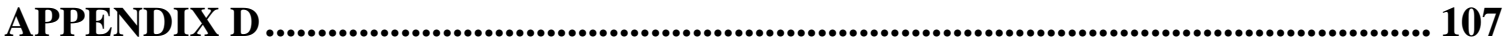




\section{LIST OF TABLES}

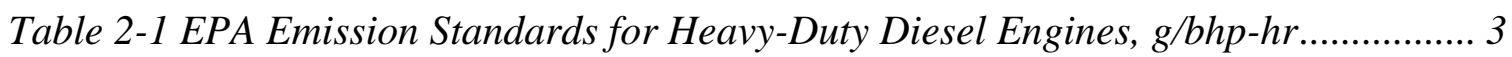

Table 2-2 EPA Tier 2 PM Emission Standards for Light Duty Vehicles [15] ................... 9

Table 3-1 Cummins ISM 370 Diesel Engine Specifications .......................................... 44

Table 3-2 Test Procedure for the First Five Filters ..................................................... 56

Table 3-3 Average Engine Performance........................................................................ 58

Table 3-4 Test Procedure for Two Engine Tested Filters................................................ 59

Table 4-1 Average Filter Passage Measurements for Each Filter ................................... 63

Table 4-2 Comparison of the Range of Modeling Parameters ....................................... 81 


\section{LIST OF FIGURES}

Figure 2-1 On-Highway Heavy Duty Diesel Engine Emissions Standards [1]................. 7

Figure 2-2 $\mathrm{NO}_{x}-\mathrm{PM}$ Trade-Off for Heavy Duty Diesel Engine Technology [16] ........... 10

Figure 2-3 Cordierite and Silicon Carbide Filter Bricks [46] ...................................... 28

Figure 3-1 Top Views Of A Small And Large Filter ...................................................... 36

Figure 3-2 Flow Bench Set-up for a 10 in Diameter Filter ........................................... 37

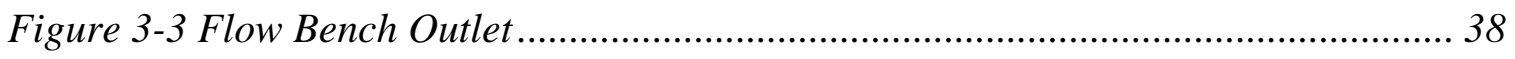

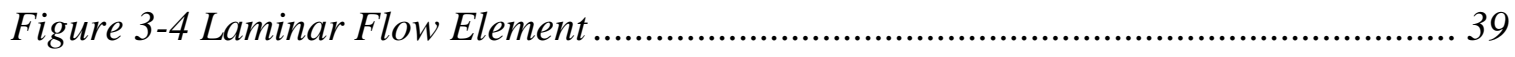

Figure 3-5 Heise Digital Calibrator and Sensor Module [65] ...................................... 40

Figure 3-6 Cummins ISM 370 Diesel Engine Set Up ................................................. 43

Figure 3-7 Complete DPF Flow Bench Set Up (Filter 6) ........................................... 45

Figure 3-8 12 inch Diameter Filter Connected to the Shop-Vac................................... 47

Figure 3-9 Compressed Air Blown Through Exhaust End of the Filter .......................... 48

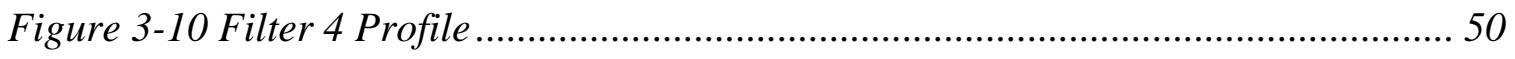

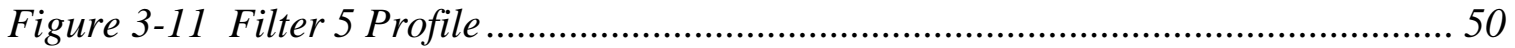

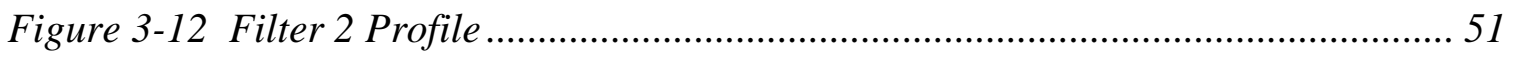

Figure 3-13 Rubber Reducer Used to Keep Water Away From Edge of Filter.............. 55

Figure 3-14 Filter 2 with Metal Sheath Removed ...................................................... 60

Figure 4-1 Filter Passage Measurements for Filter 4............................................... 65

Figure 4-2 Pressure Difference for Each Phase of Flow Bench Testing on Filter 4 ...... 67

Figure 4-3 Pressure Difference for Each Phase of Testing on Filter 6.......................... 68

Figure 4-4 Pressure Difference for Each Phase of Flow Bench Testing on Filter 7 ...... 69

Figure 4-5 Weight Lost During Each Stage of Testing for Initial Five Filters ............... 71

Figure 4-6 Inside View of Half the Metal Sheath Removed From Filter 2..................... 72

Figure 4-7 Mass Lost During Each Stage of Testing for Two Complete DPF Systems .. 74

Figure 4-8 Pressure Difference During Engine Testing for Filter 6............................ 75

Figure 4-9 Pressure Difference for the Initial Engine Testing for Filter 6.................... 76

Figure 4-10 Exhaust Temperature Difference During Engine Testing for Filter 6 ........ 77

viii 
Figure 4-11 Modeling Fit to Filter 6's Flow Bench Results ...................................... 78

Figure 4-12 Modeling Fit to Filter 6's Engine Test Results......................................... 79

Figure 4-13 Comparison of Modeled and Actual Pressure Drop for Both Filters ......... 80

Figure 4-14 Frequency of Percent Error of Predicted to Experimental Pressure Drop. 80

Figure A-1 Filter Passage Measurements for Filter 1 ................................................. 95

Figure A-2 Filter Passage Measurements for Filter 2 .............................................. 96

Figure A-3 Filter Passage Measurements for Filter 3 ............................................ 97

Figure A-4 Filter Passage Measurements for Filter 5 ............................................... 98

Figure B-1 Pressure Difference for Each Phase of Flow Bench Testing on Filter 1.... 101

Figure B-2 Pressure Difference for Each Phase of Flow Bench Testing on Filter 2... 101

Figure B-3 Pressure Difference for Each Phase of Flow Bench Testing on Filter 3.... 102

Figure B-4 Pressure Difference for Each Phase of Flow Bench Testing on Filter 5.... 102

Figure B-5 Pressure Difference for the Flow Bench Testing on the Muffler ................ 103

Figure C-1 Pressure Difference During Engine Testing for Filter 7 ........................... 106

Figure C-2 Pressure Difference During Engine Testing for the Muffler ...................... 106

Figure D-1 Modeling Fit to Filter 7’s Flow Bench Results......................................... 109

Figure D-2 Modeling Fit to Filter 7’s Engine Test Results........................................ 110 


\section{ABBREVIATIONS}

\begin{tabular}{|c|c|}
\hline CAAA & Clean Air Act Amendments \\
\hline CAFEE & Center for Alternative Fuels, Engines and Emissions \\
\hline CEPA & California Environmental Protection Agency \\
\hline CFR & Code of Federal Regulations \\
\hline $\mathrm{CO}$ & Carbon Monoxide \\
\hline $\mathrm{CO}_{2}$ & Carbon Dioxide \\
\hline DOC & Diesel Oxidation Catalysts \\
\hline $\mathrm{DPF}$ & Diesel Particulate Filter \\
\hline DPM & Diesel Particulate Matter \\
\hline EC & Electronic Control \\
\hline EGR & Exhaust Gas Recirculation \\
\hline EPA & Environmental Protection Agency \\
\hline FES & Fleetguard Emissions Solutions \\
\hline FTP & Federal Test Procedure \\
\hline $\mathrm{H}_{2} \mathrm{O}$ & Water \\
\hline $\mathrm{HC}$ & Hydrocarbons \\
\hline HDD & Heavy Duty Diesel \\
\hline LDT & Light Duty Trucks \\
\hline LDV & Light Duty Vehicles \\
\hline LFE & Laminar Flow Element \\
\hline $\mathrm{N}_{2}$ & Nitrogen \\
\hline NA & Naturally Aspirated \\
\hline NMHC & Non-Methane Hydrocarbon \\
\hline $\mathrm{NO}$ & Nitrous Oxide \\
\hline $\mathrm{NO}_{2}$ & Nitrogen Dioxide \\
\hline $\mathrm{NO}_{\mathrm{x}}$ & Oxides of Nitrogen \\
\hline $\mathrm{O}$ & Oxygen \\
\hline $\mathrm{O}_{2}$ & Oxygen Molecule \\
\hline $\mathrm{OH}$ & Hydroxide \\
\hline PM & Particulate Matter \\
\hline RPM & Revolutions per Minute \\
\hline SCFM & Standard Cubic Feet per Minute \\
\hline SCR & Selective Catalytic Reduction \\
\hline $\mathrm{SN}$ & Serial Number \\
\hline $\mathrm{SO}_{2}$ & Sulfur Dioxide \\
\hline $\mathrm{SO}_{\mathrm{x}}$ & Oxides of Sulfur \\
\hline SOF & Soluble Organic Fraction \\
\hline SUV & Sports Utility Vehicle \\
\hline TC & Turbocharged \\
\hline TCA & Turbocharged and Aftercooled \\
\hline $\mathrm{THC}$ & Total Hydrocarbons \\
\hline US & United States (of America) \\
\hline
\end{tabular}




\section{LIST OF SYMBOLS}

$\mathrm{F}$

$\mathrm{k}$

$\mathrm{k}_{\mathrm{p}}$

L

$\mathrm{P}$

$P_{\text {dry }}$

$\mathrm{P}_{\text {std }}$

Q

$\mathrm{Q}_{\text {std }}$

Qact

$\mathrm{T}$

$\mathrm{T}_{\text {std }}$

$\forall_{\text {trap }}$

$\mathrm{W}$

$\mathrm{w}_{\mathrm{p}}$

$\alpha$

$\beta$

$\Delta p_{\text {LFE Corrected }}$

$\Delta p_{\text {measured }}$

$\Delta p$

$\varsigma$

$\mu_{\text {dry air }}$

$\mu_{\text {std }}$

$\mu$

$\rho$

$\rho_{\text {water }} @ 20^{\circ} \mathrm{C}$
Friction Loss Factor, (28.454)

Filter Wall Permeability, $\left(i^{2}\right)$

Particulate Permeability, $\left(\mathrm{in}^{2}\right)$

Length of Filter, (in)

Measured Air Pressure, (in- $\mathrm{Hg}$ )

Dry Air Pressure, (in- $\mathrm{Hg})$

Standard Air Pressure, (in- $\mathrm{Hg}$ )

Volumetric Flow Rate, (ACFM)

Standard Flow Rate, (SCFM)

Actual Flow Rate, (CFM)

Temperature, $(R)$

Standard Temperature, $(R)$

Volume of Filter, $\left(\mathrm{in}^{3}\right)$

Filter Wall Thickness, (in)

Particulate Wall Thickness, (in)

Hydraulic Diameter of Channel, (in)

Forchheimer Coefficient, (Dimensionless)

LFE Pressure Difference at $4{ }^{\circ} \mathrm{C}$, $\left(\mathrm{in}-\mathrm{H}_{2} \mathrm{O}\right)$

Measured LFE Pressure Difference, $\left(\right.$ in $\left.-\mathrm{H}_{2} \mathrm{O}\right)$

Differential Pressure Across Filter, (in- $\mathrm{H}_{2} \mathrm{O}$ )

Inertial Losses Coefficient, (Dimensionless)

Dynamic Viscosity of Dry Air, $(\mu P)$

Standard Dynamic Viscosity of Air, $(\mu P)$

Dynamic Viscosity, (lb/in-s)

Filter Wall Density, $\left(\mathrm{lb} / \mathrm{in}^{3}\right)$

Water Density at $20{ }^{\circ} \mathrm{C},\left(\mathrm{kg} / \mathrm{m}^{3}\right)$ 


\section{INTRODUCTION}

The EPA is continually enforcing more stringent regulations on the emissions standards set for new diesel engines. PM regulations for model year 2007 and later heavy-duty highway engines are set as $0.01 \mathrm{~g}$-bhp- $h \mathrm{r}$. These regulations are spurred by the environment concerns and possible health hazards caused by the large amounts of PM emitted into the atmosphere by both on-road and off-road diesel engines. Diesel particulate filters are becoming an intriguing option in reducing particulate matter emitted by diesel engine exhaust to meet these standards. EPA's review of industry progress shows that diesel particulate filters that reduce harmful PM emissions by more than $90 \%$ will be used by all manufacturers by 2007 [1].

Particulate filters capture both organic and inorganic ash particles contained in the diesel exhaust. The inorganic particles cannot be removed through thermal regeneration since they are incombustible and accumulate in the filter. This ash accumulation gradually increases the pressure difference across the filter which results in an increased engine backpressure during operation [2].

Since these diesel particulate filters have finite life-spans due to the build up of noncombusted particles, an economical cleaning procedure must be developed to keep these filters a viable emissions reduction choice. The EPA requires cleaning the DPFs after a minimum of 100,000 miles of operation for the initial cleaning and every 150,000 miles for any subsequent cleanings. Filter manufacturers are suggesting filters be cleaned every 12 to 24 months or $60,000-100,000$ miles depending on engine lubrication consumption, duty cycle and vehicle/engine vocation [2]. 
DPFs have been developed and are already being used for city buses in several cities. There are several reasons as to why DPF systems for city buses have been chosen as the first developments. One is for hygienic reasons since reducing visible smoke is a priority for vehicles operated primarily in city traffic. Another reason is that city buses return to bus stations for routine maintenance [2].

These filters have only recently been considered for large scale use in the diesel engine industry in the US. Although some manufacturers have developed in-house cleaning systems, little research has been performed on possible cleaning methods and their effects. Some of these cleaning systems use water at some stage in the cleaning cycle which may not be suitable for the material used to make some DPF's.

The objective of this work was to investigate the effects of different cleaning methods that can be used to remove the build up of PM in DPFs. Seven filters were provided by Fleetguard Emissions Solutions to the West Virginia University CAFEE. The history of the filters used was unknown as to the number of hours or miles in use or the application in which they were used. At the CAFEE laboratory the filters underwent compressed air cleaning cycles of various time lengths followed by water cleaning cycles. The effectiveness of each cleaning cycle was evaluated by recording the change in weight and differential pressure across the filters following each cleaning cycle. 
Due to health and environmental concerns, the exhaust emitted from mobile sources has faced increasingly stringent regulations. In particular the PM and $\mathrm{NO}_{\mathrm{x}}$ emitted from diesel engines. Improvements in engine technology, alternative fuels and exhaust aftertreatment have reduced the amount of PM and other regulated emissions produced by diesel engines. Many of these improvements have enhanced engine performance and reduced emissions with minimal disadvantages while others like the diesel particulate filter have some drawbacks.

DPF systems remove the particulates from the filter using a process called "regeneration," performed either periodically or continuously, to restore the filters capacity. Particulate filters also capture inorganic ash which cannot be removed by typical thermal regeneration. This causes a gradual increase in pressure drop across the filter. Although this process is very slow it does require the filters to be cleaned on a prescribed maintenance schedule [5].

\subsection{Health Effects}

There has been an increasing concern over potential health hazards caused by diesel engine emissions. The residence time of the smaller PM (.1-10 $\mu$ m diameter) can average around one week [6]. With an increasing number of diesel powered vehicles, health and environmental effects are becoming increasingly important. The need to determine the extent of potential health hazards and how to reduce the amount of PM is of utmost importance [7].

Based upon human and animal evidence, the EPA categorizes human health effects to include acute (short-term exposure) effects, chronic (long-term exposure) non- 
carcinogenic respiratory effects and chronic carcinogenic effects. Acute effects include irritation, allergic responses and respiratory and neurophysiologic symptoms. Chronic effects include inflammation and histopathological changes in the lung as well as an increased risk of lung cancer [8].

Both the EPA and the CEPA studies of the effects of diesel exhaust exposure concluded that the results of animal studies can be used to infer a hazard for humans [8, 9]. These results are not definite because the high doses exposed to the animals may not be relevant to the low ambient concentrations exposed to humans [10]. Exhaustive studies and literature can be found on the debate over the level of risk to the general public from diesel exhaust and the validity of the epidemiologic studies.

\subsection{Diesel Exhaust Composition}

Diesel exhaust consists of both gaseous and solid components. The major gaseous components include carbon dioxide, oxygen, nitrogen, water vapor, carbon monoxide, nitrogen compounds and sulfur compounds as well as several molecular weight hydrocarbons. Diesel particulate matter is defined by the EPA as the particle-phase compounds emitted in diesel exhaust $[8,11]$. Heavy duty vehicles emissions vary a considerable amount and are not always predictable from the fuel properties [12]. Diesel particulates are composed of elemental carbon particles which agglomerate and absorb other organic compounds as well as small amounts of solid material such as metallic ash and sulfate $[13,14]$. The composition of particulate matter greatly depends on engine technology, test conditions and the type of fuel used [7, 8]. DPM is generally broken into two fractions called soluble and insoluble. The soluble, or wet fraction, contains organic 
material derived from fuel and lubricating oil which can be dissolved in an organic solution. The insoluble, or dry soot fraction, contains elemental carbon and a small amount sulfate particles which cannot be dissolved in an organic solution [13].

Diesel particulate is emitted in the range of 5-1000 nanometers (nm). Most of the mass exists in the range of $300-1000 \mathrm{~nm}$ in diameter, while the largest number of particles resides in the range of 5-50 $\mathrm{nm}$ in diameter [7]. There has been concern over the modal distribution of DPM because current standards regulate mass allowing newer engines to produce more particles at a smaller diameter and still meet these regulations. The residence time for smaller particles is also greatly increased with up to one week for the particles in the range of .1-10 $\mu \mathrm{m}$ in diameter. Additional health concerns associated with smaller particles raise even more concern; i.e. the fact that the pulmonary deposition increases with decreasing particle size. This can cause smaller particles to become toxic, which may be non-toxic at a larger size diameter [7].

\subsection{Federal Emission Standards}

The EPA began regulating mobile emission sources in the late 1960's with the 1963 Clean Air Act. This was followed by the 1970 Clean Air Act that regulated six pollutants: PM, sulfur dioxide, carbon monoxide, nitrous oxides, ozone and lead. Diesel powered vehicles built today emit $60 \%$ to $80 \%$ less pollutants (depending on the pollutant) than those built in the 1960s. Cars and trucks still account for almost half the emissions of the ozone precursors and up to $90 \%$ of the CO emissions in urban areas; despite the fact that the federal standards have become increasingly stringent on regulating mobile emissions sources. Figure 2-1 below illustrates a timeline of the 
reduction of on road HDD engine emissions standards from model year 1974-2007 [1]. In 1997 diesel engines powered nearly 100\% of heavy duty trucks sold and contributed $66 \%$ of the PM (2.5 $\mu \mathrm{m}$ diameter or less) emitted by on-road engines [8].

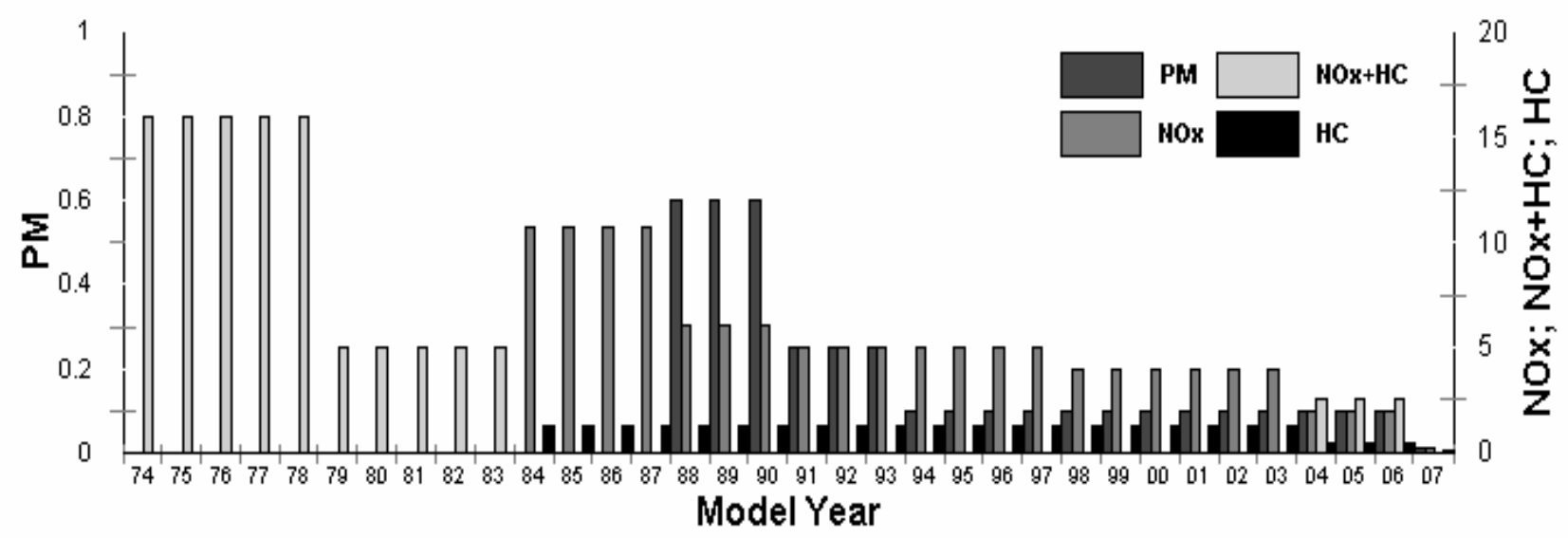

Figure 2-1 On-Highway Heavy Duty Diesel Engine Emissions Standards [1]

Heavy-duty vehicles are defined as vehicles of gross vehicle weight rating above 8,500 lbs. Heavy-duty vehicles are subdivided into light, medium and heavy categories by the gross vehicle weight rating. Compliance with the model year emissions standards has to be demonstrated over the useful life of the engine. The useful life of the light medium and heavy-heavy duty engines is 110,000 miles, 185,000 miles and 435,000 miles or 10 years, respectively, for 2004 and later models [1].

In addition to further restricting emissions for 2007 and later model heavy duty engines, the sulfur content for on-highway diesel fuel is reduced to $15 \mathrm{ppm}$ beginning June 2006. The regulations on the sulfur content in diesel fuel is being introduced to allow aftertreatment technologies such as DPFs and $\mathrm{NO}_{\mathrm{x}}$ catalysts that are adversely affected by sulfur in the exhaust gases. Crankcase emissions for turbocharged heavy duty 
diesel engines, which were previously unregulated, are included as exhaust emissions in the 2007 model year engines [1].

The Clean Air Act Amendment of 1990 introduced two sets of standards, Tier 1 and Tier 2. Tier 1 standards apply to light duty vehicles and light duty trucks of a gross vehicle weight rating below 8,500 lbs. These vehicles were further divided into subcategories according to weight. Each sub-category was assigned separate standards that were phased in from 1994 to the 1997 model year. A more detailed account of these standards can be found in section 203 of the 1990 CAAA [1].

Tier 2 standards are being phased in from 2004 to 2009. The Tier 2 emission standards apply to all vehicle weight categories including passenger cars, light duty trucks and larger passenger vehicles (such as SUV's and passenger vans) operated on any fuel. This requires larger engines to use more advanced emission control technologies to meet the standard. Tier 2 standards also include improved fuel quality requirements that are necessary for the emissions aftertreatments [15].

The Tier 2 standards are divided into 8 levels or “certification bins" in which manufacturers chose to certify particular vehicles in any of the 8 bins. Two additional temporary certification bins with more relaxed standards are provided during the transition period up to the 2008 model year. The particulate matter standard for each bin is shown in Table 2-2 below. As shown in Table 2-2, the temporary bins permit higher levels of PM, up to $0.12 \mathrm{~g} / \mathrm{mi}$, while the permanent bins limit PM to $0.02 \mathrm{~g} / \mathrm{mi}$ or less [15]. 
Table 2-2 EPA Tier 2 PM Emission Standards for Light Duty Vehicles [15]

\begin{tabular}{|l|c|}
\hline \multirow{2}{*}{$\begin{array}{l}\text { Certified } \\
\text { Bin }\end{array}$} & $\begin{array}{c}120,0000 \\
\text { Number }\end{array}$ \\
\cline { 2 - 2 } & $\begin{array}{c}\text { PM } \\
\text { (grams/mile) }\end{array}$ \\
\hline \multicolumn{2}{|l|}{ Temporary Bins } \\
\hline 10 & 0.12 \\
\hline 9 & 0.08 \\
\hline \multicolumn{2}{|l|}{ Permanent Bins } \\
\hline 8 & 0.02 \\
\hline 7 & 0.02 \\
\hline 6 & 0.01 \\
\hline 5 & 0.01 \\
\hline 4 & 0.01 \\
\hline 3 & 0.01 \\
\hline 2 & 0.01 \\
\hline 1 & 0.00 \\
\hline
\end{tabular}

\subsection{Improved Diesel Engine Emissions Reduction Methods}

Over the past few decades several new techniques and devices have been developed in order to meet EPA emissions standards. These technologies typically focus on one of the three areas: reduced $\mathrm{NO}_{\mathrm{x}}$ emissions, reduced $\mathrm{PM}$ emissions or improved fuel economy. Figure 2-2 below shows how several of these technologies lowered emissions and the trade off between lowering $\mathrm{NO}_{\mathrm{x}}$ and $\mathrm{PM}$ emissions and the evolution of $\mathrm{NO}_{\mathrm{x}}$ and $\mathrm{PM}$ standards for heavy duty engines in the US and European Union. As shown in Figure 2-2, the advancement in engine technology has been able to reduce emissions within acceptable ranges without the use of diesel particulate filters. In the following subsections several of the more prominent emission control techniques will be discussed. 


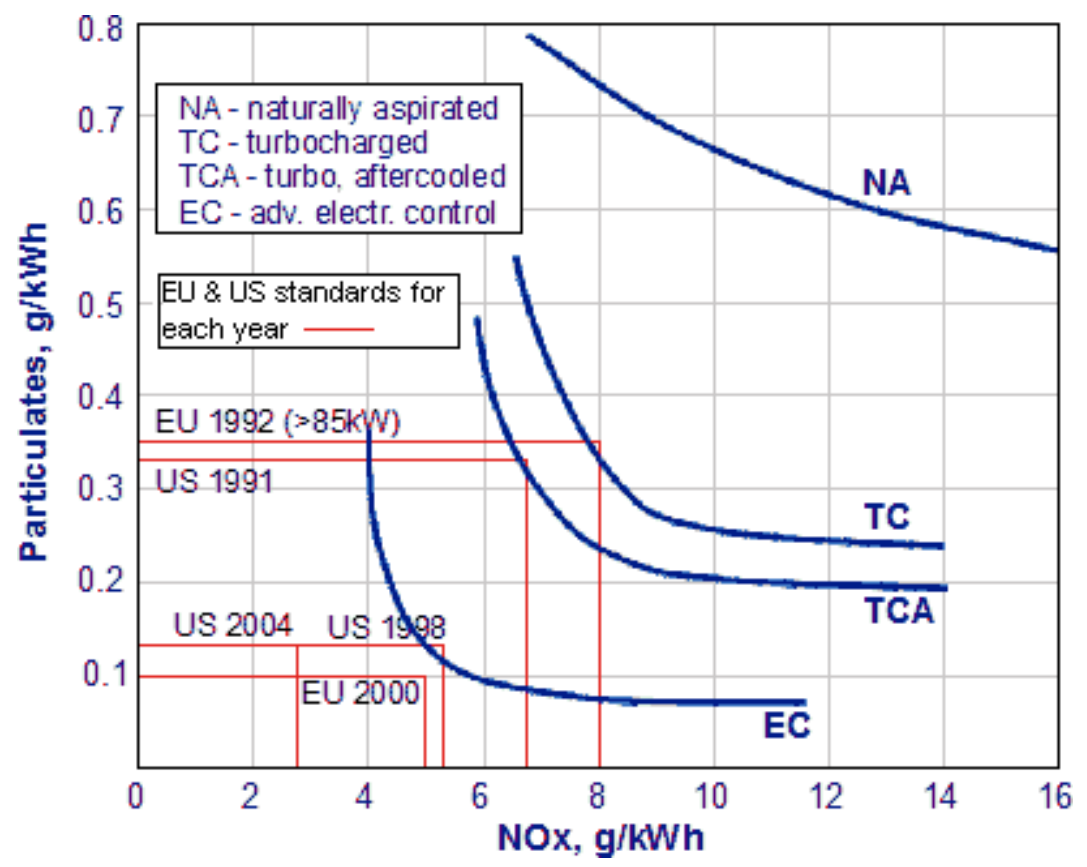

Figure 2-2 NO$_{x}-P M$ Trade-Off for Heavy Duty Diesel Engine Technology [16]

\subsubsection{Air Intake Improvements}

Many of the advancements in diesel engine technology have come through air intake improvements. The use of turbochargers has dramatically improved engine performance and reduced emissions. Along with redesigned intake manifolds, variable geometry turbochargers and the use of inter- and aftercoolers; improvements made in the air intake technology have produced some of the largest improvements in emissions reductions to date.

\subsubsection{Intake Air Oxygen Enrichment}

Although not utilized due to a lack of practicality, increased oxygen concentration in intake air is a fundamental variable in most combustion processes. Studies performed on a direct injection diesel engine by Karim and Ward [17] and an indirect injection 
diesel by Hillard and Levendis [18], show many advantages to oxygen enrichment. Both studies show a large decrease in ignition delay and a reduction in smoke, CO and HC emissions. As with most emission reductions methods the trade off for PM reduction is a substantial gain in $\mathrm{NO}_{\mathrm{x}}$. Despite the implementation of oxygen enrichment not being viable, it did lead to several other emissions reduction techniques that were implemented to produce the same results $[17,18]$.

\subsubsection{Turbochargers}

Virtually all modern diesel engines use a turbocharger. The increase in airflow from a turbocharger improves combustion and reduces the amount of PM produced at high load conditions. A conventional turbocharger is generally unable to produce adequate air flow at low speeds (under approximately $1000 \mathrm{rpm}$ ) [19, 20]. The boost pressure does have an upper limit where fuel liquid spray and vapor penetration lengths are reduced [20]. Most diesel engines use a wastegate to solve this problem which allows some exhaust gas to bypass the turbocharger at high loads and speeds. This allows the boost pressure to be effective at low speeds and not exceedingly high at higher engine loads and speeds. A disadvantage to using wastegates is a decrease in efficiency and higher fuel consumption at high engine loads and speeds [19, 20].

There are several other means of producing higher boost pressure at lower loads and speeds such as two-stage turbochargers, variable geometry turbochargers and variable speed superchargers [20, 21]. Variable geometry turbochargers use variable area turbines, variable nozzle geometry or movable vanes to produce the optimal boost pressure for a given speed and load condition [20]. Variable speed superchargers are used 
in conjunction with a turbocharger to provide additional boost pressure at low engine speeds. At higher speeds when the supercharger is not needed the airflow bypasses the supercharger and is disengaged by the use of a clutch. This prevents the supercharger from drawing power from the engine when not in use [19].

\subsubsection{Combustion Chamber Improvements}

The main goal in combustion chamber design is to optimize the mixing of fuel and air before combustion. In order to reduce the PM produced there must be good fuel atomization, which is evenly distributed, with minimal cylinder wall wetting [22]. The main modifications to the combustion chamber include increasing the compression ratio, altering the piston bowl shape, the number and placement of the cylinder valves and reducing oil consumption [21].

\subsubsection{Compression Ratio}

The compression ratio strongly affects combustion and provides a great deal of control over engine performance [23]. Increasing the compression ratio in diesel engines aids in cold starting and reduces the ignition delay period which reduces the amount of fuel burned in the premixed region. A high compression ratio is most effective at reducing emissions at high speed light load conditions when the ignition delay is longest. Major reductions in HC are achieved during these operating conditions [21].

A variable compression ratio engine is also an attractive possibility for future production. Variable compression allows control over peak cylinder pressure which permits considerable increase of specific power output through supercharging without 
reducing the engines durability. Variable compression ratio also improves overall fuel efficiency and reduces $\mathrm{HC}$ and $\mathrm{NO}_{\mathrm{x}}$ emissions [23].

\subsubsection{Piston Bowl Shape}

The shape of the piston bowl in direct injection diesel engines is critical to air-fuel mixing. Bowl design can be used to increase swirl to promote better mixing or decrease swirl for quiescent combustion systems, where air-fuel mixing is produced by high pressure fuel injection (fuel spray momentum) rather than air motion. Piston bowl shape design is also used to reduce PM emissions by minimizing the amount of cylinder wall wetting from fuel [24]. Bowl design must be matched with the proper injector spray pattern and pressure in order to optimize emissions [21].

\subsubsection{Cylinder Valves}

Most heavy-duty engine manufacturers and many medium and light-duty engine manufacturers employ four valves per cylinder (2 intake and 2 exhaust valves) which provides better fuel economy and emissions benefits [21]. Early engines mounted the valves in the engine block close to the crank shaft, but as technology progressed valves were moved to the cylinder head [25]. Other improvements include variable valve timing to improve air intake at high loads and increase swirl at low loads [21]. Also a fifth valve is implemented in some engines to increase the air intake for higher loads. Because intake valves provide the greatest restriction to incoming air, their design and function can greatly affect the overall efficiency of the engine [25]. 


\subsubsection{Reduced Oil Consumption}

Engine oil left on the cylinder during the expansion stroke or introduced into the combustion chamber by other means significantly contributes to PM emissions [21, 22]. One of the predominate sources of lube oil consumption is bore distortion [22]. Thus precise bore honing and enhanced ring pack design have been utilized to reduce the amount of PM emissions caused from lube oil. Other components such as valve guides and seals also play a major role in reducing the lube oil consumption. It is important to note that there is a fine balance that must be maintained while enhancing these designs to prevent too little lube oil remaining on the cylinder walls [21].

\subsubsection{Fuel Properties}

The most important properties of fuel include aromatics, cetane number, oxygenates, density and sulfur content. The effects of the fuel properties are not definite because variations in engine technology and testing procedures make it difficult to compare individual studies. The properties of fuel are codependent making it difficult to isolate specific changes in the fuel properties to determine their effects [26].

\subsubsection{Aromatics}

The effect on emissions by aromatics has been debated. This is due to the difficulty of separating the effects of other fuel properties to those that may be caused by aromatics. Recent results show that aromatics have little effect on combustion characteristics and emissions. Decreasing the total aromatics has been shown to slightly reduce $\mathrm{NO}_{\mathrm{x}}(<5 \%)$ which is most likely due to the higher flame temperature associated with aromatic compounds $[27,28]$. Reducing aromatics has been shown to decrease PM 
in older engines with reductions in poly-aromatics contributing more to the PM reductions than reductions in mono-aromatics [26, 27, 28].

\subsubsection{Cetane Number}

Increasing the cetane number of a fuel reduces the ignition delay and the size of the premixed combustion. Increasing the cetane number has been found to reduce all regulated emissions $\left(\mathrm{NO}_{\mathrm{x}}, \mathrm{HC}, \mathrm{CO}\right.$ and $\left.\mathrm{PM}\right)$ [29, 30]. The effects of naturally higher cetane number verses additive improved show similar results. The beneficial effects of increasing the cetane number are becoming smaller and even nonexistent as new low emissions engines are designed to have little premix burn thus negating the decrease in premix combustion by increasing the cetane number [30]. The effect of increasing cetane number on PM emissions varies with engine technology. In most engines, the cetane number has no influence on PM emissions. However, in some engines a small but beneficial effect has been observed. Yet in others, increasing the cetane number leads to increased PM emissions [30].

\subsubsection{Oxygenates}

The addition of oxygenates to diesel fuel has had an increased interest in recent years. This is mostly due to the availability of oxygenates from biomass feed stocks. Most studies however, have failed to decouple the dilution and lowered fuel density among other changes in fuel properties that occur when oxygenates are added [30]. Thus the results found are tentative but show a decrease in PM and a slight decrease in CO. There appears to be little or no effect on $\mathrm{NO}_{\mathrm{x}}$ emissions while $\mathrm{HC}$ emissions increase slightly [26, 30]. 


\subsubsection{Density}

The density of diesel fuel is an important characteristic with respect to the volumetric fuel economy and maximum power. It has also been shown that the density is an important parameter for regulated diesel emissions in particular PM. The effects of fuel density must be carefully studied to ensure that its effects are decoupled from other fuel properties like aromatic content. It is also critical that the engine shaft work is held constant since lower density fuels would generally produce lower peak power and thus lower overall emissions [30].

Reducing the fuel density by $6 \%$ has been shown to reduce PM emissions by $20 \%$ in older high emissions engines; however, these effects are almost negligible with modern low emissions engines. Reducing density also produces a small reduction in $\mathrm{NO}_{\mathrm{x}}$ but a large increase in $\mathrm{HC}$ emissions and a small increase in CO. The increase in HC is especially well pronounced in older high emitting engines [30].

\subsubsection{Sulfur Content}

The effects of the sulfur content of fuel are restricted to the PM emissions and do not have any observable effects on the regulated gaseous emissions. The sulfur in fuel is converted to sulfate PM. The sulfur fuel content was lowered from 3,000 ppm to 500 ppm by US legislation in 1994 and is being further reduced to 15 ppm in 2006 [1, 30]. Further reducing the sulfur content to $15 \mathrm{ppm}$ has negligible effects on reducing PM emissions but is instead being implemented to enable exhaust aftertreatment technology. In order for most regenerative DPF systems to be efficient, ultra low sulfur fuel is required. Some catalyst used in the regenerative process produce sulfate from fuel sulfur 
increasing the PM. In other catalysts $\mathrm{SO}_{\mathrm{x}}$ and $\mathrm{NO}_{\mathrm{x}}$ are both absorbed by the catalyst thus reducing the efficiency of the catalyst by reducing the $\mathrm{NO}_{\mathrm{x}}$ absorption capabilties [30].

\subsubsection{Fuel Injection}

Fuel injection system improvements have had a great impact on combustion and thus emissions. Injection timing, pressure, duration, rate, nozzle configuration and design determine ignition delay and combustion rate through their effects on air-fuel mixing. The design of the fuel injection system in conjunction with the design of the combustion chamber can be used to optimize diesel engine performance, fuel economy and emissions [21].

\subsubsection{Injection Pressure}

Higher injection pressure is beneficial because it aids in fuel atomization by giving more energy to the fuel and producing faster spray tip penetration. Increasing the injection pressure provides a more homogeneous fuel density distribution and increases turbulence intensity improving the air-fuel mixing [31]. A higher fuel injection pressure is especially important for quiescent combustion engines which depend on the fuel spray momentum to achieve proper air-fuel mixing [24]. By increasing the fuel injection pressure the particulate emissions are reduced and fuel economy is improved, but it also causes an increase in $\mathrm{NO}_{\mathrm{x}}$ and combustion noise [31]. Fuel economy is improved, even though increasing the injection pressure places an increased load on the engine to power accessories. However, the improved combustion counters this effect. This problem is reduced further by the additional help of an electronically controlled fuel injection unit to reduce the injection pressure at lighter loads [21]. 


\subsubsection{Electronic Fuel Injection System}

Electronically controlled fuel injection systems provide control over the PM-NO trade-offs as a function of speed, load and ambient conditions [22]. Using an electronic fuel injection system offers control of injection timing and duration that is independent of engine speed. These electronic unit injection systems are usually cam-driven or common rail. In the common rail system fuel is distributed to the injectors through a high pressure manifold and injection pressure is controlled by a pressure sensor in the rail. This type of system is advantageous since it does not require an additional engine cam-shaft. However, a common rail fuel injection system usually has a lower peak injection pressure $[32,21]$.

For full engine load and peak torque, increasing the injection pressure results in increased atomization and air-entrainment which improves smoke, combustion period and ignition delay as well as specific fuel consumption. However, at light engine loads in order to optimize the fuel consumption and HC emissions a reduced fuel injection and advanced injection timing is required [32].

\subsubsection{Fuel Injectors}

The design of the fuel injector has a great affect on the performance of a diesel engine and its emissions. The design and number of fuel injectors, in large bore engines, must be correlated with the geometry of the combustion chamber and the injection pressure. Several of the parameters that are considered in order to optimize the design of a fuel injector are briefly discussed below [21]. 
Different types of engines require different strategies to reduce emissions. In sac type nozzles, minimizing the sac volume is critical to reduce leakage of fuel into the combustion chamber which increases HC emissions [21]. In a quiescent combustion, smoke reduces by decreasing the nozzle hole diameter without increasing $\mathrm{NO}_{\mathrm{x}}$ production [33]. In a swirl type combustion a double injection strategy was shown to lower both $\mathrm{NO}_{\mathrm{x}}$ and PM [31].

\subsection{Nozzle Inlet Conditions}

The use of a sharp-edge inlet tip nozzles produces less emissions than a roundinlet nozzle tips when the fuel droplet sizes are kept the same. With a constant mass flux the round-inlet tip yields slightly lower $\mathrm{NO}_{\mathrm{x}}$ emissions but much higher PM. This is caused by the larger droplets with a narrower spray angle produced by the round-inlet tip nozzle at a constant mass flux. The PM produced by the round-inlet tip can be as much as 2.5 times greater than the sharp-edge inlet tip under the same injection delivery, injection duration and same size [31].

\subsection{Nozzle Injection Angle}

Changing the injection angle effects the internal flow pattern and velocity distribution. The injection angle in conjunction with the combustion chamber design can help improve combustion by producing desired spray characteristics. However, different injection angles have shown little affect on $\mathrm{NO}_{\mathrm{x}}$ and $\mathrm{PM}$ levels. This may be a result of spray impingement on the cylinder wall [31]. 


\subsection{Nozzle Hole Size}

It was already stated that a smaller nozzle hole diameter reduces smoke emissions, but also, the reduction percentage increases as the injection pressure increases. The PM reduction is associated with only a slight increase in $\mathrm{NO}_{\mathrm{x}}$ production. A smaller hole size nozzle produces shorter spray tip penetration but wider spray angles. It also produces smaller overall average droplet size thus improving fuel atomization.

\subsection{Rate Shaping and Multiple Injections}

Rate shaping is used to reduce the injection rate during the initial injection period. Because peak combustion temperatures are mainly determined by the premix phase of combustion, limiting the amount of fuel injected at the beginning of the injection period can reduce $\mathrm{NO}_{\mathrm{x}}$ emissions dramatically. Multiple injections can also be used to achieve the same result [21]. A double injection has been shown to decrease the spray droplet average diameter and reduce both $\mathrm{NO}_{\mathrm{x}}$ and $\mathrm{PM}$ at the same time [31].

\subsubsection{Exhaust Gas Recirculation}

Exhaust gas recirculation (EGR) has been used on both spark ignited and diesel engines for its effective means of reducing $\mathrm{NO}_{\mathrm{x}}$ emissions. Two types of EGR systems are used, the high pressure loop and the low pressure loop EGR. The high pressure loop EGR takes recirculated gas upstream of the turbocharger and mixes it with compressed intake air downstream of the aftercooler. The low pressure loop EGR takes recirculated gas downstream of the turbocharger and mixes it with low pressure intake air. Most manufacturers of heavy-duty truck and bus engines use cooled EGR to reduce $\mathrm{NO}_{\mathrm{x}}$ emissions [34]. Cooled EGR is used because, depending on flow rate and temperature, 
EGR can increase PM emissions and brake specific fuel consumption. Cooling the EGR decreases the charge air temperature reducing PM, brake specific fuel consumption and also further reducing $\mathrm{NO}_{\mathrm{x}}$ emissions [21]. The dominant factor in reducing $\mathrm{NO}_{\mathrm{x}}$ with an EGR is the dilution of the intake air with inert gases. This decreases the oxygen concentration and the increase in the heat absorbing capacity of $\mathrm{CO}_{2}$ and $\mathrm{H}_{2} \mathrm{O}$ which reduces combustion temperatures and pressures [35].

\subsection{Exhaust Aftertreatment}

In spite of the advances in diesel engine design, manufacturers are looking to aftertreatment to bring the emission levels to within regulated limits. As emission regulations become more stringent, especially for $\mathrm{NO}_{\mathrm{x}}$ and $\mathrm{PM}$, exhaust aftertreatment is becoming a primary method to produce certifiable engines. Several types of aftertreatment systems included diesel oxidation catalysts, lean $\mathrm{NO}_{\mathrm{x}}$ catalysts, selective catalytic reduction, exhaust gas recirculation, non-thermal plasma catalysts, and diesel particulate filters will be discussed in the following subsections. There are advantages and disadvantages for each system which must be considered when selecting an

aftertreatment system. Many manufacturers have implemented a combination of aftertreatment systems to overcome some of the limitations each has, such as a catalyst combined with a DPF [21].

\subsubsection{Oxidation Catalyst}

Diesel oxidation catalysts are very effective in reducing CO, HC, aldehydes, and the soluble organic fraction; however, they have little effect on $\mathrm{NO}_{\mathrm{x}}$ and insoluble 
fraction emissions [22]. The catalyst has little effect at low exhaust temperatures. As exhaust temperature increases the oxidation of $\mathrm{CO}$ and $\mathrm{HC}$ increases rapidly and then levels off at approximately $350{ }^{\circ} \mathrm{C}$, depending on the chemical reaction kinetics in the catalyst. Additionally, oxidation catalysts release sulfates through the oxidation of sulfur in the diesel fuel at higher exhaust temperatures. This disadvantage is of little importance since it has lead to the introduction and mandated use of ultra-low sulfur diesel fuel by 2006 [21].

Given the sizable emission reductions in HC, CO, and aldehydes, DOCs are good candidates for aftertreatment systems to be combined with another form of aftertreatment (i.e. DPFs) or with fuel-borne catalysts. The undesired oxidation of $\mathrm{NO}$ to $\mathrm{NO}_{2}$ by an oxidation catalyst can be used as an oxidizing gas for the regeneration process in a DPF. A study performed by the Southwest Research Institute saw PM reductions from 0.073 g/bhp-hr to $0.042 \mathrm{~g} / \mathrm{bhp}-\mathrm{hr}$, a $42 \%$ reduction, using a fuel-borne catalyst. However this study also reported that for a diesel oxidation catalyst to be most effective, it must be approximately equal in volume to the engine displacement, meaning that for large diesel engines, the catalyst would be too large for practical use [36, 37].

\subsubsection{Lean $\mathrm{NO}_{x}$ Catalysts}

Lean $\mathrm{NO}_{\mathrm{x}}$ catalysts provide a catalytic reduction of $\mathrm{NO}_{\mathrm{x}}$ through a lean fuel environment. Copper zeolite catalysts use hydrocarbons in the exhaust stream to reduce $\mathrm{NO}_{\mathrm{x}}$ emission at high temperatures through the reaction shown in Equation 2-1 below.

$$
\{\mathrm{HC}\}+\mathrm{NO}_{x}=\mathrm{N}_{2}+\mathrm{CO}_{2}+\mathrm{H}_{2} \mathrm{O}
$$

Equation 2-1 
This system has two major problems; the system requires a significant amount of hydrocarbons in the exhaust stream to reduce NO substantially, approximately a HC to NO ratio of $4: 1$ and the system is very sensitive to sulfur poisoning from the absorption of $\mathrm{SO}_{2}$ and water inhibition [21]. It has been determined that sulfur degrades the oxygen storage media, which in turn inhibits the formation of hydrogen in the water gas shift reaction. This, in turn, detracts from the catalyst's efficiency and requires a desulfation process to recover some of the lost efficiency. The catalysts never fully regenerate to 100\% capacity, which gives the system a finite life [38].

Another type of lean $\mathrm{NO}_{\mathrm{x}}$ catalyst utilizes a platinum based catalyst. This systems reaction occurs at a lower temperature than the copper zeolite catalysts (200-300 $\left.{ }^{\circ} \mathrm{C}\right)$ and requires less $\mathrm{HC}$ to reduce the $\mathrm{NO}_{\mathrm{x}}$ (2:1 ratio). However, the platinum in this system releases sulfates from the fuel sulfur, increasing the PM emissions [21]. As previously mentioned this increase in PM from sulfates is reduced with low sulfur fuels.

The significant problem with any lean $\mathrm{NO}_{\mathrm{x}}$ catalyst is the need for large amounts of hydrocarbons. Several systems have been developed to supplement the exhaust stream with the necessary HC's. The first strategy is to place an additional fuel injector into the exhaust pipe up-stream of the catalyst and inject diesel fuel directly into the exhaust stream. This system, however, encourages tampering since removal of the injector would not influence engine performance and would enhance fuel economy. Some promise has been shown utilizing this injection method, but with the substitution of urea for the diesel fuel injected into the exhaust [39]. The use of urea poses its own set of drawbacks which will be discussed in the following section. 
Another possible method of fuel supplementation is to increase the fuel volume being injected into combustion chamber during the normal injection process. Potential tampering is lessened, but large fuel penalties and increased HC emissions are likely. Alternatively, and most feasibly, fuel can be injected into the cylinder during the exhaust stroke. This would require a more complex electronic fuel injection system and an estimated five percent increase in fuel consumption would be necessary to provide enough hydrocarbons for sufficient $\mathrm{NO}_{\mathrm{x}}$ reduction [21].

\subsubsection{Urea-Selective Catalytic Reduction}

Selective catalytic reduction is an aftertreatment system used commercially for stationary diesel installations. It is also being used by some European heavy-duty diesel engine manufacturers as an on-road $\mathrm{NO}_{\mathrm{x}}$ reduction method. This system injects ammonia in the form of a urea solution into the raw exhaust in order to supplement the exhaust hydrocarbons [40]. The use of ammonia has been practically ruled out, due to safety concerns, and urea (in water solution) is the preferred alternative. The urea injection forces the chemical reactions necessary for the $\mathrm{NO}_{\mathrm{x}}$ in the exhaust to convert to harmless nitrogen and water. The process has demonstrated $\mathrm{NO}_{\mathrm{x}}$ reductions as high as $90 \%$ in both the EPA’s Federal Test Procedure cycle and the New European Driving Cycle [41].

SCR systems, in combination with DPFs, have also shown promise in simultaneously reducing $\mathrm{PM}$ and $\mathrm{NO}_{\mathrm{x}}+\mathrm{NMHC}$ emissions. Southwest Research Institute reported PM emissions of $0.01 \mathrm{~g} / \mathrm{bhp}-\mathrm{hr}$ and $\mathrm{NO}_{\mathrm{x}}+\mathrm{NMHC}$ emissions of $1.1 \mathrm{glbhp}-\mathrm{hr}$ using $368 \mathrm{ppm}$ sulfur fuel, an $86 \%$ and $73 \%$ reduction over the baseline measurements 
respectively. These data were recorded while testing a 1998 Detroit Diesel Series 60 12.7L turbocharged engine rated at $400 \mathrm{hp}$ at $1800 \mathrm{rpm}$. [36].

As promising as this system appears, it is not without its drawbacks. SCR systems produce highly elevated levels of $\mathrm{N}_{2} \mathrm{O}$ when compared to a standard diesel and over injection of urea leads to ammonia emissions called "ammonia slip." Commercial introduction of SCR systems would require establishing a urea distribution infrastructure. The implementation of such system poses a number of logistics and regulatory emission compliance challenges. Urea solutions would need to be distributed along with the diesel fuel throughout the fuel distribution network. The fueling system should prevent, or at least minimize, the possibility of operating the vehicle with an empty urea tank. Computerized fueling terminals have been proposed, which would communicate with the vehicle's electronic control unit and simultaneously dispense the required amount of fuel and urea through a special dual fueling nozzle [42].

\subsubsection{Non-Thermal Plasma Catalyst}

Non-thermal plasma catalysts are aftertreatment systems that are still in the experimental stages. In these systems, exhaust gases pass through an intense field of charged particles, a plasma field, and are dissociated and ionized into more reactive particles. These particles are easily catalyzed downstream. A pair of electrodes is used to generate the plasma field with at least one electrode covered by a dielectric barrier such as alumina. A high voltage alternating current is placed across the electrodes causing the gas in the gap between them to break down resulting in the formation of discharge streamers. The streamers rapidly travel across the gap creating electrons with a mean 
energy of three to four electron volts. When the streamers reach the barrier, charge accumulates on the surface and cancels the electric field so that the streamers are extinguished [43].

In addition to $\mathrm{NO}_{\mathrm{x}}$ conversion, plasma catalysts can also be utilized for particulate removal. Since the plasma creates $\mathrm{O}$ and $\mathrm{OH}$ radicals and converts $\mathrm{NO}$ to $\mathrm{NO}_{2}$, it can be expected that soot particles will also be oxidized provided they remain in the plasma for a sufficient period of time, much longer than is required for gaseous species. To increase the residence time without increasing the reactor size beyond reasonable limits, the particulate has to be removed from the gas stream and held in the reactor until its oxidation is completed. Although little research has been conducted to this point, laboratory experiments have shown that this can greatly reduce the size of particles being released from the engine exhaust [43].

Plasma catalysts systems have shown high $\mathrm{NO}_{\mathrm{x}}$ removal, as high as $80 \%$ when combined with a suitable oxidation catalysts, and high particulate removal rates. They can also function well over a wide temperature range, $150-500{ }^{\circ} \mathrm{C}$. However, these systems have only been demonstrated in laboratory environments and are still much too large for practical use [41]. A better understanding of the reaction mechanisms in plasma catalysts especially pertaining to the presents of PM, as well as, many other aspects need to be further investigated before plasma catalysts can be implemented [43].

\subsubsection{Diesel Particulate Filters}

Diesel particulate filters are one of the most effective means for controlling PM emissions. In 1991, DPFs showed great promise to meet the reduced standard of 0.10 
g/bhp-hr of PM for urban buses [21]. However, concerns over the durability, useful life of and the complexity of regeneration combined with the development of engines that meet the new standard without the use of DPFs discontinued their use. With the even more stringent standards today, manufacturers are now reconsidering the use of DPFs. Improved regeneration systems and durability issues resolved; DPFs in combination with oxidation catalysts have become an effective exhaust aftertreatment option [43, 45].

The most common DPF design uses a wall-flow monolith where alternating channel ends are plugged to force exhaust gasses to flow through the porous walls which filter out PM. This design was chosen because of its high surface area per unit volume and high filtration efficiencies. The filtration mechanism on wall-flow DPFs is a combination of PM cake and depth filtration. On a clean filter the particulates are trapped in the porous wall material. As the soot accumulates, a layer of PM develops and cake filtration becomes an important filtration mechanism [46].

DPFs are made of specialized ceramic materials that can withstand high temperatures and high temperature gradients. The two most commonly used materials are cordierite and silicon carbide shown in Figure 2-3 below. Aluminum titanate has also been introduced for use in passenger car applications [46]. 

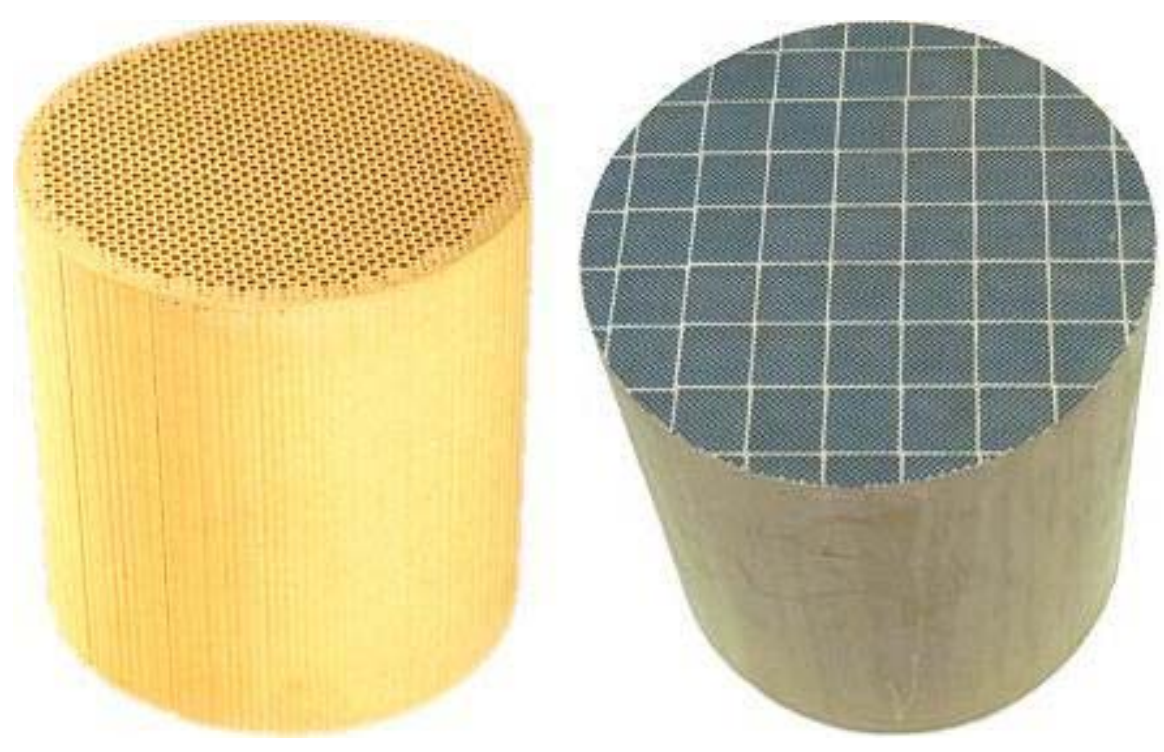

Figure 2-3 Cordierite and Silicon Carbide Filter Bricks [46]

Left: cordierite; Right: silicon carbide

Cordierite $\left(2 \mathrm{MgO}-2 \mathrm{Al}_{2} \mathrm{O}_{3}-5 \mathrm{SiO}_{2}\right)$ filters are manufactured by extrusion using precision dies then cut to the desired length before being fired in an oven. Combustible substances are added to the raw material which is oxidized during the firing process and create the pores within the walls. Cordierite filters are mostly used in heavy duty engine applications and is characterized by superior thermal shock resistance and lower cost then its silicon carbon counterpart. However, cordierite filters have a poor resistance to sulfuric acid and a lower melting point temperature which is insufficient to protect the material during an uncontrolled regeneration process [46].

Silicon carbon filters are made of several longitudinal segments as can be seen on the right side of Figure 2-3 above. This design is used to cope with the high thermal expansion and high degree of brittleness of the material. The segments are joined with material that has both good adhesion and elastic properties to absorb the thermal strain from the segments. Silicon carbon filters are characterized by having greater heat 
capacity and conductivity providing a greater margin of safety for uncontrolled regeneration. Silicon carbide filters also have a more uniform distribution of pores providing a higher permeability and lower pressure drop across the filter. The filter capacity for silicon carbide filters is limited by the thermal gradient rather than the maximum temperature [46].

Several liters of soot per day can be produced by heavy-duty diesel engines. The PM collected by the DPFs would quickly clog and create a high pressure drop across the filter adversely affecting the engines performance. Thus, the DPF systems must create a way to remove the particulates and restore its efficiency through a process called regeneration [47]. In most cases thermal regeneration is performed where the particulates are removed from the trap by oxidation into gaseous forms, usually $\mathrm{CO}_{2}$. To produce this regeneration process the filter must operate at a sufficient temperature and be supplied with oxidizing gasses such as $\mathrm{O}_{2}$ and $\mathrm{NO}_{2}$ [48].

DPFs have limited effectiveness in controlling nonsolid fractions of PM, such as the soluble organic fraction or sulfate particles [48]. Many DPFs are combined with a platinum catalyst ahead of the filter which allows combustion of soot to drop from approximately $650{ }^{\circ} \mathrm{C}$ down to about $300{ }^{\circ} \mathrm{C}$. The platinum catalyst converts $\mathrm{NO}$ and $\mathrm{O}_{2}$ in the exhaust to $\mathrm{NO}_{2}$ and also reduces the amount of hydrocarbons, carbon monoxide and soluble organic fraction. The $\mathrm{NO}_{2}$ then reacts with the carbon particulate to form $\mathrm{NO}$ and $\mathrm{CO}_{2}$ [21]. This regeneration process can occur after a predetermined amount of soot is accumulated or continuously (continuously regenerating trap or CRT). As was true with the engine technology the DPF also yields to the $\mathrm{NO}_{\mathrm{x}}-\mathrm{PM}$ trade-off; greatly reducing $\mathrm{PM}$ but has no effect on $\mathrm{NO}_{\mathrm{x}}$ emissions [48]. Thus the use of a DPF system 
would be most effective in combination with engine technology focused on reducing $\mathrm{NO}_{\mathrm{x}}$ emissions.

\subsubsection{Cleaning Diesel Particulate Filters}

Particulate filters also capture inorganic ash particles contained in the diesel exhaust. These particles cannot be removed through thermal regeneration since they are incombustible. This ash accumulation gradually increases the pressure difference across the filter which results in an increased backpressure during operation [2]. The build up of the exhaust backpressure allows extra exhaust gases to remain in the cylinder during valve overlap. The volumetric efficiency is lowered because the residual gases dilute the combustion chamber in the next cycle, functioning like an uncontrolled internal EGR. The amount of residual gas can be a very important factor in burn velocity and ignition delay [49-52]. Filter or engine manufacture's set a maximum backpressure level that when reached, requires the filter to be cleaned or replaced. Research has been recently focused on increasing filters ash collection capacity in order to reduce the frequency of routine maintenance. Even though the ash is a very small fraction of the total PM its accumulation requires the filter to go through a routine cleaning procedure. The EPA has set a minimum of 100,000 miles for the initial cleaning and every 150,000 miles for any subsequent cleanings [2]. Filter manufacturers are suggesting filters be cleaned every 12 to 24 months or $60,000-100,000$ miles depending on engine lubrication consumption, duty cycle and vehicle/engine vocation [2]. 


\subsubsection{Reverse Flow In-situ Regeneration}

The use of reverse flow regeneration is not only an alternative to the conventional means of thermal regeneration but may also eliminate the need to have routine cleaning procedures performed to the DPFs. Reverse flow regeneration uses compressed air blown opposite of the exhaust flow to clean the particulate accumulated on the filter wall. The particulate is then collected either in a heated vessel to burn the particulate or collected in a disposable filter bag $[53,54]$.

Several systems have been designed to accomplish reverse flow regeneration, utilizing different cleaning methods as well as collection of the particulate blown off. In a system developed by Northeastern University two ceramic filters operate alternatively; while one filters the engine exhaust the other regenerates. The removed particulate was then collected in an electric burner. [55]. A similar system was developed by Asahi Glass Co. which broke a single filter into two segments which could alternatively be regenerated [53]. Another system developed at Northeastern University rotated a filter and blew compressed air through a small slot at a fixed location opposite to the exhaust flow. This system also used deposable vacuum cleaner bags to collect the removed particulates. A potential problem could arise during on-road use, if the collection bags require frequent replacement [54].

\subsubsection{Filter Cleaning Procedures and Equipment}

Currently there are limited numbers of filter cleaning systems because the use of DPFs is still limited. The general cleaning procedures used are similar, with a few variations in cleaning time, air pressure and use of heat. Once the filter is removed from 
the vehicle, pressurized air is used to remove the ash. Filters with catalytic coatings should be provided with a recommended air pressure to avoid damaging the coating. The ash is then collected at the exit side of the filter in an industrial vacuum with an appropriate filter to collect the ash. Some systems include a heating step before or after the pressurized cleaning to regenerate any remaining soot in the filter. Once the cleaning process is finished it is inspected and reinstalled [2].

\subsection{Compressed Air Cleaning}

In compressed air cleaning systems, compressed air is blown through the filter opposite to the flow of exhaust. Systems developed by Cleaire, Fleetguard Emisssion Solutions and Lubrizol all utilize compressed air cleaning systems [56, 57, 58]. Most of these systems are coupled with an industrial vacuum on the inlet side of the filter which collects the ash and unburnable soot. The high pressure air is delivered through a nozzle or nozzles which isolates a small area of the filter and moves along the surface to clean the entire filter $[56,57,58]$. The pressurized air is usually below 100 psi to avoid damaging the catalytic coatings on the filters [2]. Cleaning times range from a half hour for the Fleetguard system and up to three hours (eight hours for cordierite filters) for the Lubrizol system which also incorporates a regenerative cycle [57, 58].

\subsection{Pulse Air Cleaning}

The pulse air cleaning system is similar to the compressed air system but only provides short bursts or "pulses" of high pressure air to the filter. These pulses last for only a few seconds followed by a short time to recompress the air stored in an air tank, usually a few minutes. Both SPx (in collaboration with Cummins) and Donaldson have 
developed pulse air type cleaning systems [59, 60]. The SPx system empties an 80 psi, 40 gallon tank over 1-2 seconds through a 3 in orifice diffuser during a 30 minute cleaning cycle [59]. The Donaldson system has an operating cycle of 15 minutes with an additional thermal regeneration cycle if required [60].

\subsection{Water Cleaning}

Water based filter cleaning systems utilize a three stage process consisting of regeneration, water cleaning and drying $[2,61]$. The wash water must be treated to remove the ash before being returned to a local sewer system. These procedures have only been used on uncatalyzed filter systems that have mounting materials compatible with the water cleaning operation. Some ceramic filter substrate mounting materials, such as intumescent-base mats deteriorate when exposed to water [2]. This type of mounting material is primarily being used for DPFs in the United States despite its limitations for cleaning. Faurecia has developed a three stage water cleaning process for silicone-carbide filters, capable of remanufacturing 250 filters per day. Each filter is weighed before and after each stage of the processes and then viewed by an endoscope to ensure proper cleanliness [61].

\subsection{Regenerative Cleaning}

Regenerative cleaning uses a baking or heating process to burn off any organic PM remaining in the filter, but has no effect on the inorganic ash. This process uses the oxidation reaction that occurs during normal operation of the DPF to "burn” off the soot. Temperatures for this cycle range from 450 to $800{ }^{\circ} \mathrm{C}$ with cycle times from 3 to 12 hours. These cycles use controlled heat-up and cool-down schedules to minimize thermal 
stress on the filter [2]. The systems developed by Donaldson, Lubrizol and Faurecia all utilize a regenerative cleaning cycle although Donaldson's system does not require a regenerative cycle for every filter $[60,58,61]$. 


\section{EXPERIMENTAL SETUP \& PROCEDURES}

\subsection{Introduction}

The following section outlines the experimental equipment used during the evaluation of DPF cleaning techniques. Several cleaning techniques were tested and evaluated at the WVU CAFEE. Compressed air and water cleaning methods were evaluated with varying compressed air cleaning times. The effectiveness of each cleaning cycle was determined by measuring the weight loss and pressure drop across the DPFs on a flow bench.

\subsection{Diesel Particulate Filters}

A total of seven retrofit diesel particulate filers were sent by FES to the CAFEE laboratory for testing. The history of the filters use was unknown and each filter was assumed to be fully loaded. Initially five filters were sent consisting of the filter canisters only while the final two contained the entire DPF system. Of the initial five filters, three (filters 1, 2 and 3 ) appeared to have uncatalyzed filter bricks with a diameter of 10 inches (8.5 in filter surface area) with $0.06 \times 0.06$ inch filter passage openings and a length of 11.5 inches. A representative picture of the uncatalyzed filters is shown on the left side of Figure 3-1 below. The remaining two filters (filters 4 and 5) did appear to have catalyzed filter brick and were larger with a diameter of 12 inches (10.5 in filter surface area) with 0.085x0.085 inch filter passage openings and a length of 13.5 inches. A representative picture of the catalyzed filters is shown on the right side of Figure 3-1 below. 


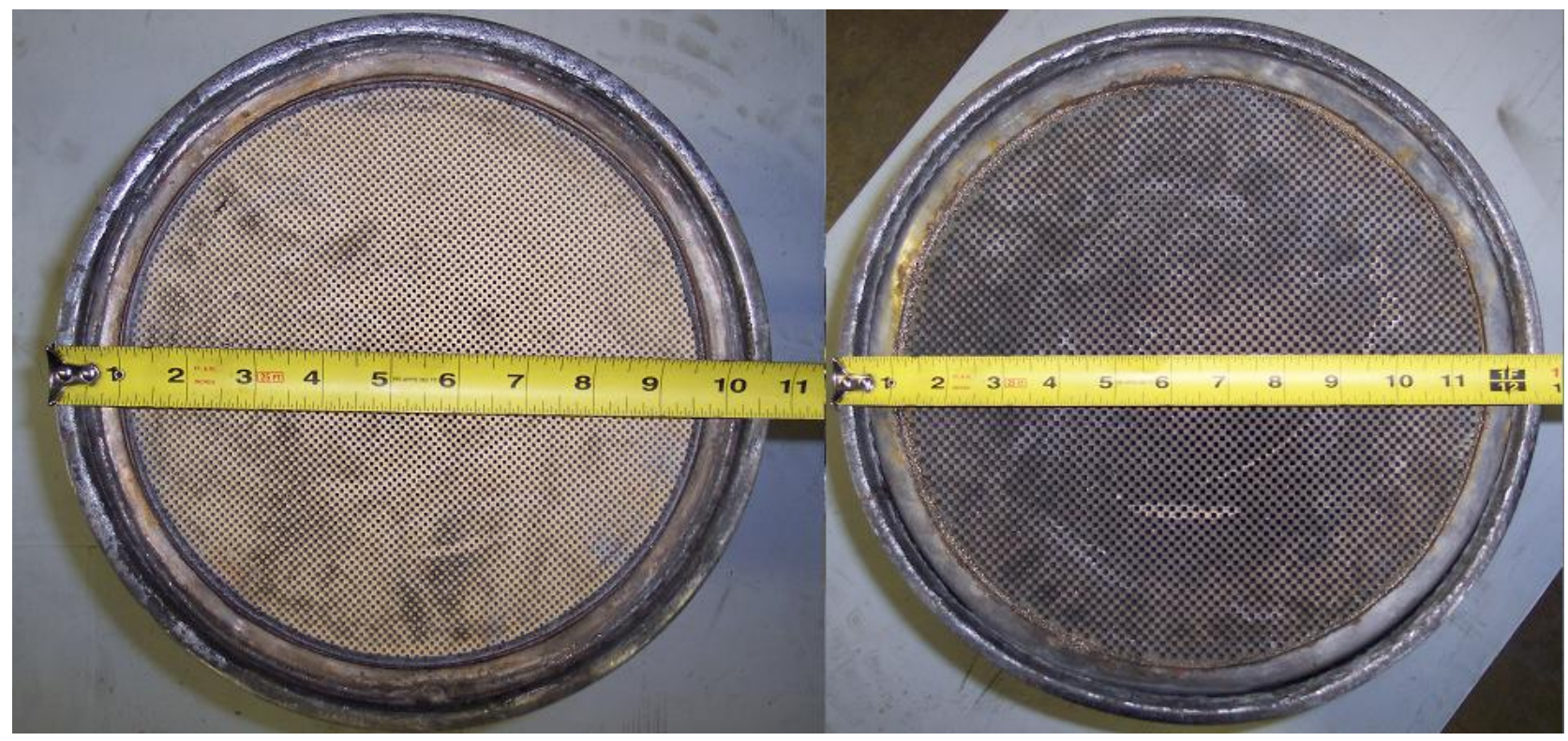

Figure 3-1 Top Views Of A Small And Large Filter

Left: uncatalyzed filter; Right: catalyzed filter

The final two filters consisted of one uncatalyzed and the other catalyzed filter, filters 6 and 7, respectively. With filters 6 and 7 the entire retrofit system was received to directly connect to a 5 inch exhaust, which included the pre-filter catalyst for filter 6 . The inference made to the catalyzation of the filters was made based on the relative size of the filters and the additional pre-catalyst included in the complete system for the smaller filters.

\subsection{Flow Bench Setup}

A flow bench was used to measure the pressure drop across each of the filters before and after each cleaning cycle. The flow bench consisted of a low pressure air source, a LFE for measuring the flow and pressure transducers to measure the pressure drop across the filter. Figure 3-2 below shows the flow bench set-up and labels each data 
logging instrument used in the flow bench test. Figure 3-3, below, shows the flow bench outlet outside the laboratory area and the location of the digital thermo-hygrometer. Low pressure air (approximately atmospheric pressure) with a maximum flow rate of 1200 SCFM was blown through an 8 in pipe into a laminar flow element (LFE) where temperature and pressure reading were taken. The locations of the pressure and temperature taps can be seen in Figure 3-2. The filters were placed down stream of the LFE and the pressure taps were inserted 4 inches and 14 inches up/down stream for the 10 in and 12 in diameter filters, respectively. The air flow was then piped outside where the relative humidity was measured as shown in Figure 3-3.

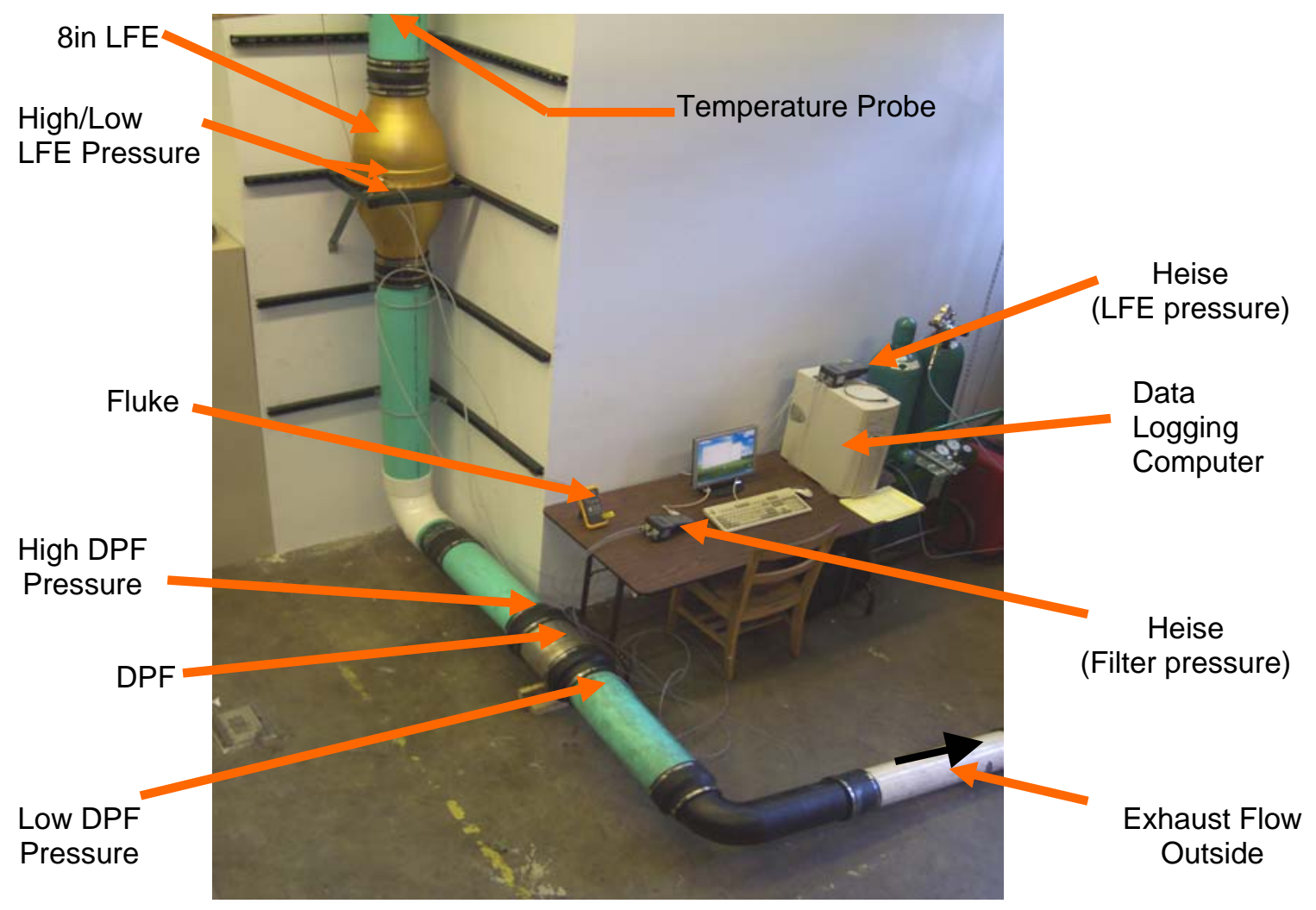

Figure 3-2 Flow Bench Set-up for a 10 in Diameter Filter 


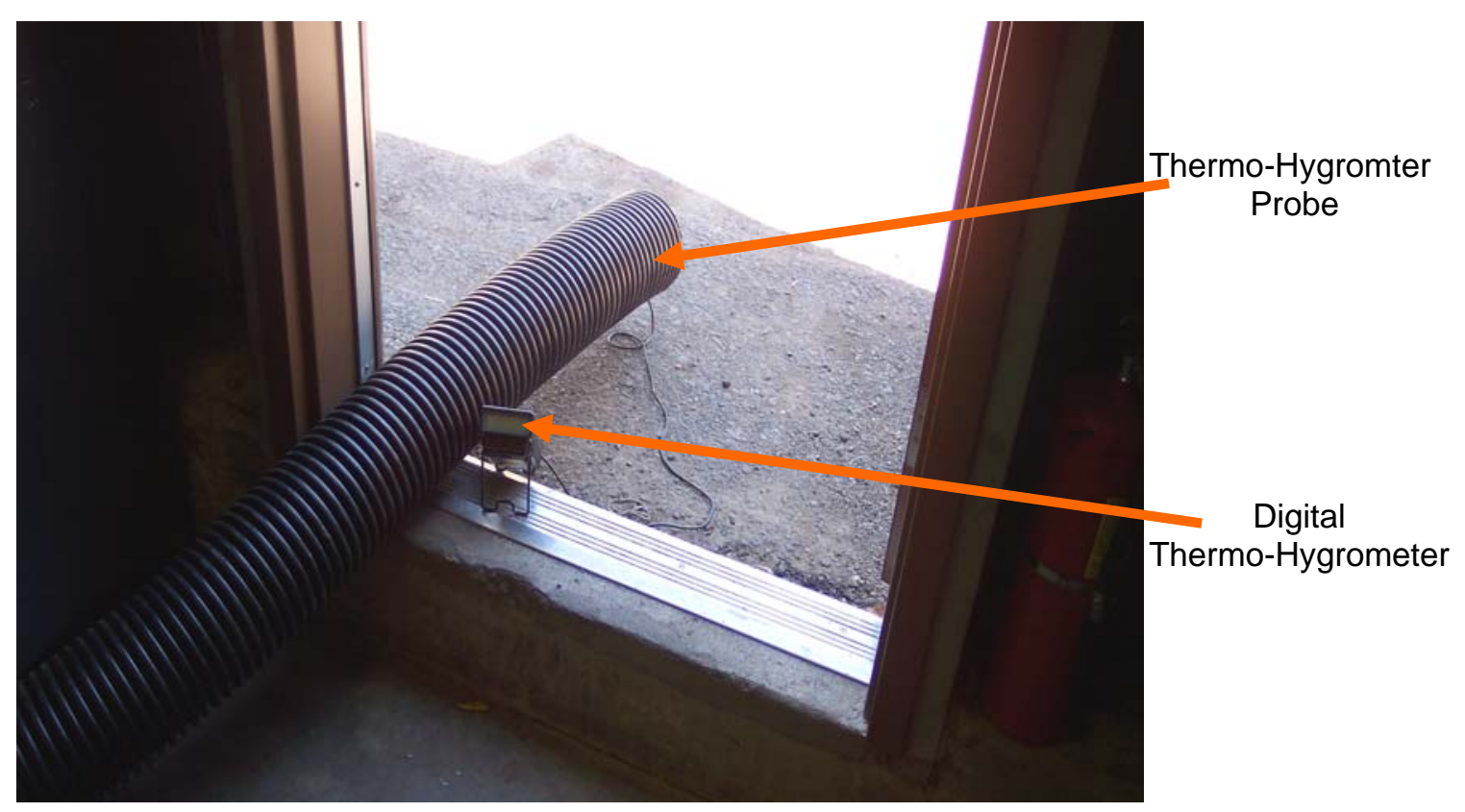

Figure 3-3 Flow Bench Outlet

\subsection{Laminar Flow Element}

A laminar flow element was used to measure the volumetric flow rate of air flow through the filters on the flow bench. A LFE is a device that will generate a differential pressure that is nearly a linear function of the volumetric flow passing through it. Each passage has a small cross-sectional area causing the Reynolds number of the flow through each passage to be low enough to maintain laminar flow throughout [62]. The LFE selected for the flow bench was an 8 in model 50MC2-8 manufactured by Meriam Process Technologies shown in Figure 3-4 below. This LFE has a flow rate range of 2250 SCFM with a standard accuracy of $+/-0.86 \%$ of a reading and a repeatability of $0.1 \%$ [63]. 


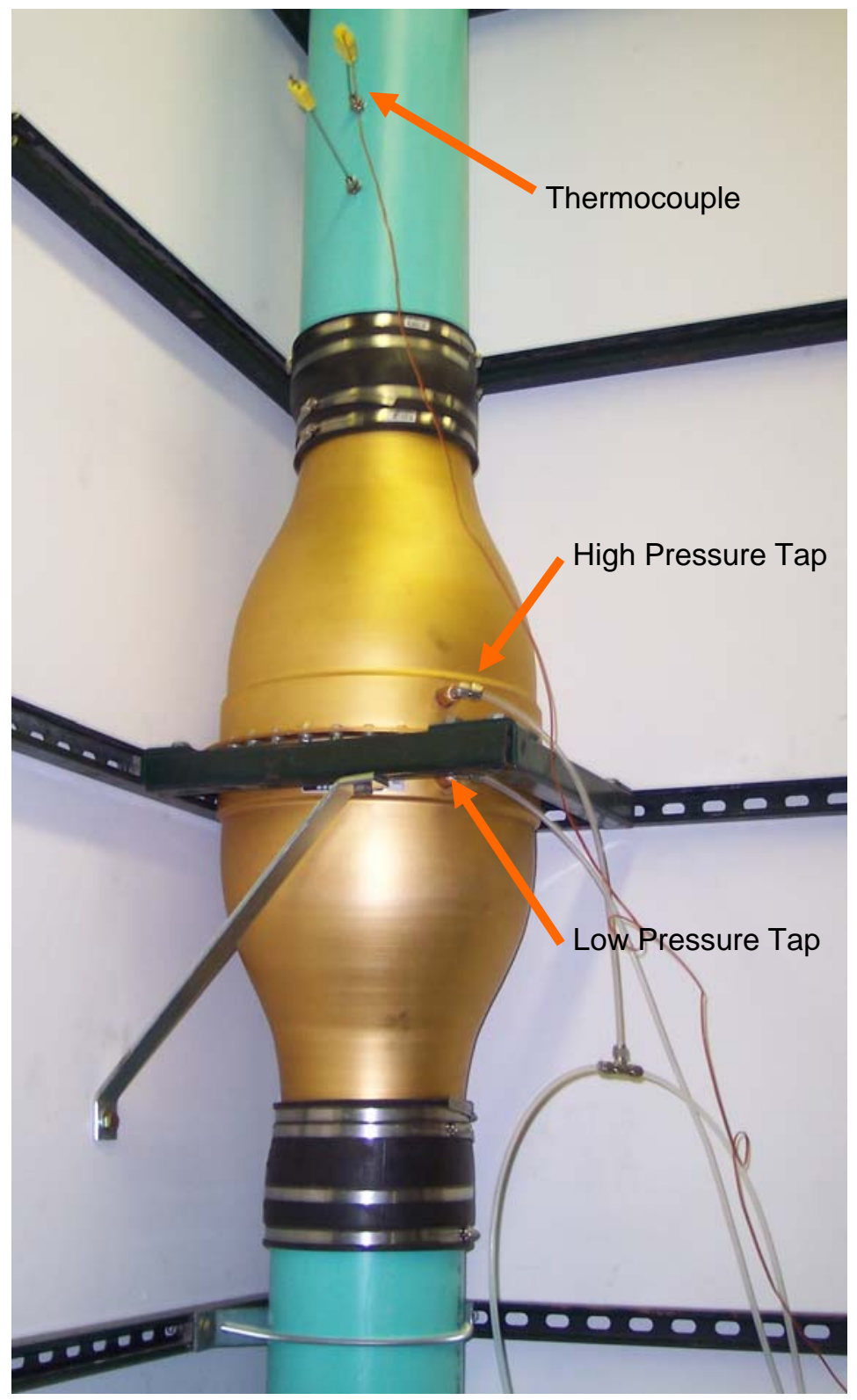

Figure 3-4 Laminar Flow Element

\subsection{Fluke Thermocouple Calibrator}

A thermocouple was placed upstream of the LFE, as shown in Figure 3-4 above, to measure the air temperature entering the LFE. A Fluke thermocouple calibrator, model 714, was used to display the temperature from a $\mathrm{K}$ type thermocouple. The temperature 
was recorded at the beginning and end of each test and the average was used for calculations and data reduction. The thermocouple calibrator had an operating range of 200 to $1800{ }^{\circ} \mathrm{C}$ with an accuracy of $0.3^{\circ} \mathrm{C}$ and a resolution of $0.1{ }^{\circ} \mathrm{C}$ [64].

\subsection{Heise Digital Calibrator}

To measure the pressure drop across both the filters and the LFE a Heise digital calibrator, model number PTE-1, was used. The Heise digital calibrator and a sensor module is depicted in Figure 3-5 below [65]. The collected data for the two minute duration of each flow rate was recorded and an average value was used for calculations and data reduction. Three modular sensors were used for the three separate pressure values recorded. Each of the modular sensors are discussed in the following subsections.

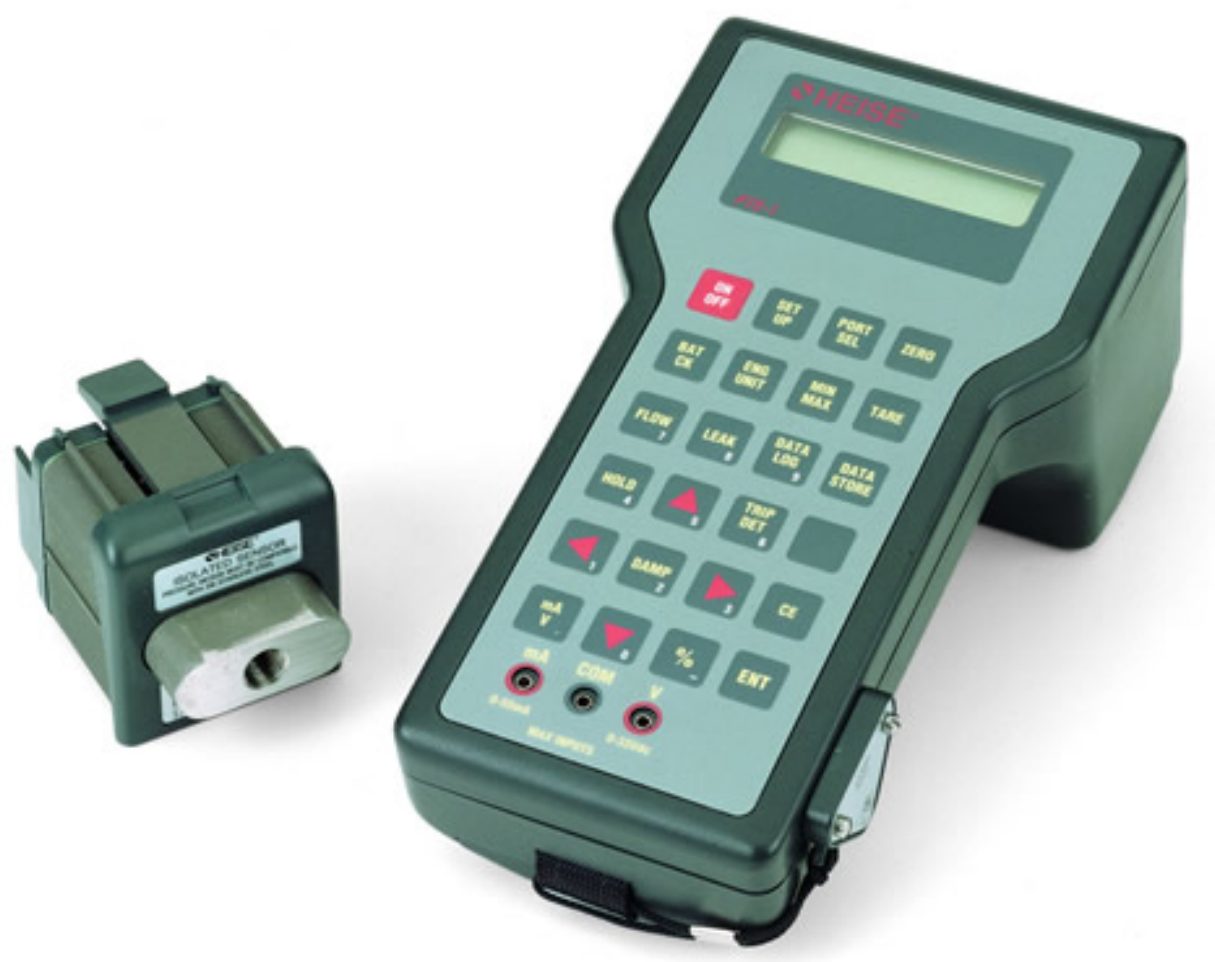

Figure 3-5 Heise Digital Calibrator and Sensor Module [65] 


\subsubsection{Filter Pressure Drop Modular Sensor}

The pressure sensor module used to measure the pressure drop across the filter was an HQS-1 with a range of $0-50 \mathrm{in}-\mathrm{H}_{2} \mathrm{O}$. This sensor had an accuracy of $0.06 \%$ of full scale and a repeatability of $+/-0.01 \%$ of span. The HQS-1 pressure modules are designed for low pressure measurements [65].

Inside the sensor is a silicon diaphragm between two fixed metal plates. The air between the plates and diaphragm acts as an insulator for a capacitor. When both the high and low pressure ports are at equal pressure the distance between the fixed plates and the diaphragm is equal. In this case, the signal to the top plate is capacitively coupled to the equal and opposite signal of the bottom plate. Thus no signal current flows through the diaphragm. When a pressure or vacuum is applied to the sensor the diaphragm moves, changing the capacitance of the sensor. This current flows through the diaphragm and is correlated to a pressure or vacuum reading [65]. A few of the more heavily clogged filters at higher flow rates produced a pressure drop exceeding the 50 in $-\mathrm{H}_{2} \mathrm{O}$ capability of this module and a Fluke 713 G30, to be discussed in a later section, was utilized.

\subsubsection{LFE Pressure Drop Modular Sensor}

The pressure sensor module used to measure the pressure drop across the LFE was an HQS-1 with a range of $0-10 \mathrm{in}-\mathrm{H}_{2} \mathrm{O}$. This sensor had an accuracy of $0.06 \%$ of full scale and a repeatability of $+/-0.01 \%$ of span [65]. This is the same module model used for the filter pressure measurement with a lower range. 


\subsubsection{Absolute Air Pressure Modular Sensor}

The absolute air pressure tap was split off the high pressure tap on the LFE. The pressure sensor module used to measure this pressure was an HQS-2 with a range of 0-30 psi. This sensor had an accuracy of $0.025 \%$ of full scale and a repeatability of $+/-0.01 \%$ of span [65].

These modules used a piezoresistive strain gage sensor. Resistors are deposited in a silicon substrate typically in a wheatstone bridge orientation. When no pressure is applied the output is near zero, and as pressure or vacuum is applied and increased the output also increases almost linearly. The flexing of the diaphragm under pressure or vacuum causes the resistive properties to change which is correlated to a pressure or vacuum reading [65].

\subsection{Fluke Pressure Calibrator}

A second device was needed to measure the pressure drop across the more heavily clogged filters at high flow rates because the pressure differential exceeded that of the Heise pressure sensor modules available at the CAFEE laboratory. For these instances a Fluke pressure calibrator, model number 713 G30, was used. This device had a range of 0-30 psi and an accuracy of $0.05 \%$ of full scale [66]. Since this device was not connected to the data logger that the Heise's used, the average pressure readings were obtained visually and recorded. Thus, some accuracy may have been lost in comparison to the data recorded by the Heise. 


\subsection{Omega Digital Thermo-hygrometer}

A hygrometer was used to measure the moisture content in the air flowing through the filters on the flow bench. An Omega digital thermo-hygrometer, model number RH411, was used for this process. This device had a temperature range of $0-120{ }^{\circ} \mathrm{F}$ and a moisture range of 2-98\% relative humidity. The thermo-hygrometers accuracy was $3 \%$ at $25{ }^{\circ} \mathrm{C}$ between $20-90 \%$ range and $5 \%$ at $25{ }^{\circ} \mathrm{C}$ below $20 \%$ or above $90 \%$ of the range [67].

\subsection{Diesel Engine}

The diesel engine used to operate with the filters was a Cummins ISM 370 manufactured in 2004 shown in Figure 3-6 below.

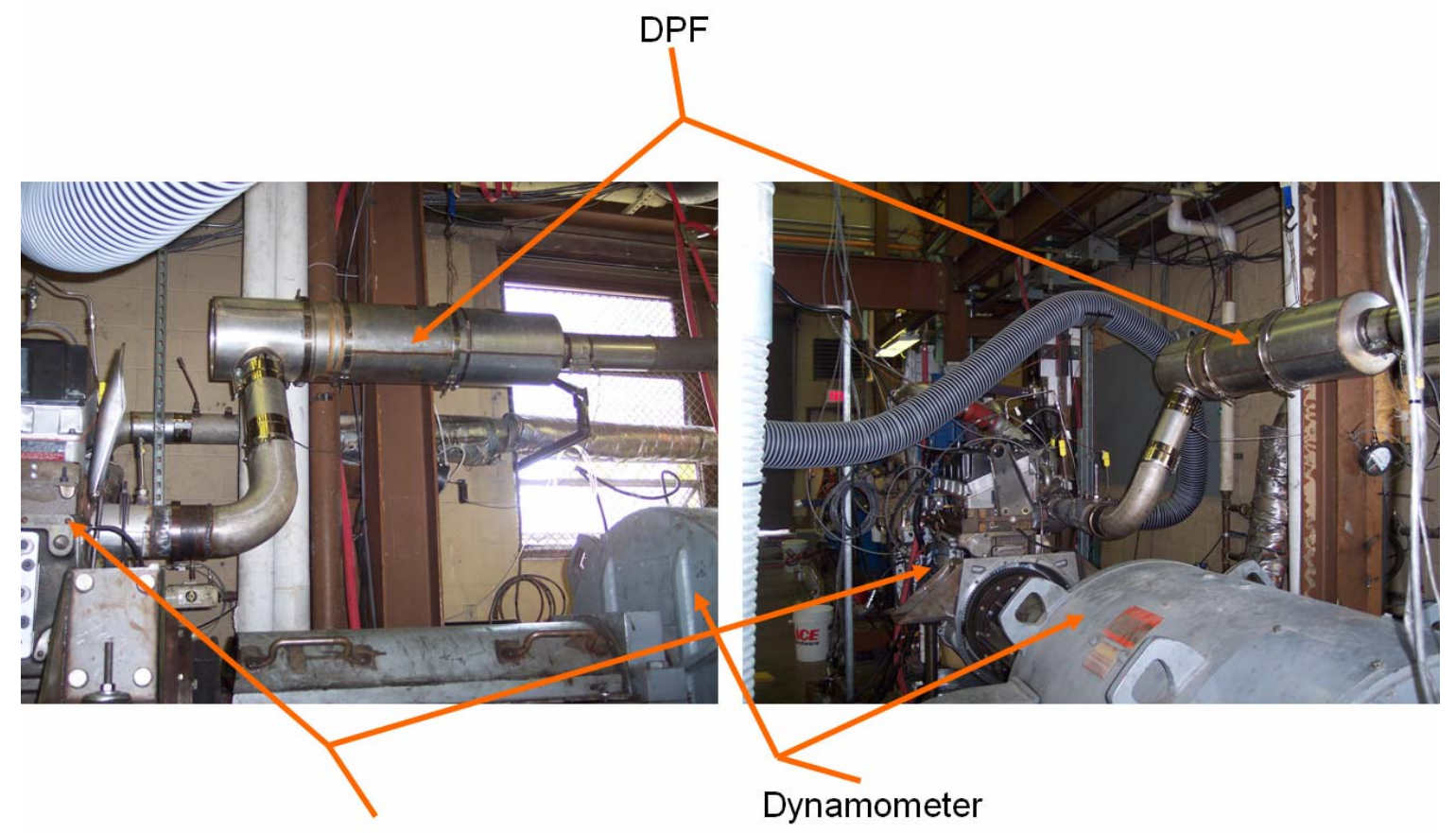

Cummins ISM 370 Diesel Engine

Figure 3-6 Cummins ISM 370 Diesel Engine Set Up 
The engine was operated on low sulfur diesel fuel with a sulfur content of $15 \mathrm{ppm}$. Table 3-1 below contains the engine specifications. It is important to note that the DPFs used were designed for smaller engine applications ( $270 \mathrm{hp}$ ) however the Cummins engine was used based on availability [59].

\section{Table 3-1 Cummins ISM 370 Diesel Engine Specifications}

\begin{tabular}{|l|r|}
\hline Engine Number & 35108713 \\
\hline Family & 4CEXH0661MAT \\
\hline Model & ISM 370 \\
\hline Manufacture Date & Sep-04 \\
\hline Advert $h p$ & 370 \\
\hline Peak Torque $(f t-l b)$ & 1450 \\
\hline Displacement $(L)$ & 10.8 \\
\hline NOx+NMHC $(g / b h p-h r)$ & $2.4+2.4$ \\
\hline PM $(g / b h p-h r)$ & 0.10 \\
\hline
\end{tabular}

Figure 3-7 below shows the flow bench setup of filter 6 , indicating the location of the pressure taps and the pre-filter catalyst. Filter 7 had a similar set up however the system did not have a pre-filter catalyst since the filter brick itself was catalyzed. This was system was designed so no alterations had to be made from the engine to the flow bench during the alternating test cycles. 


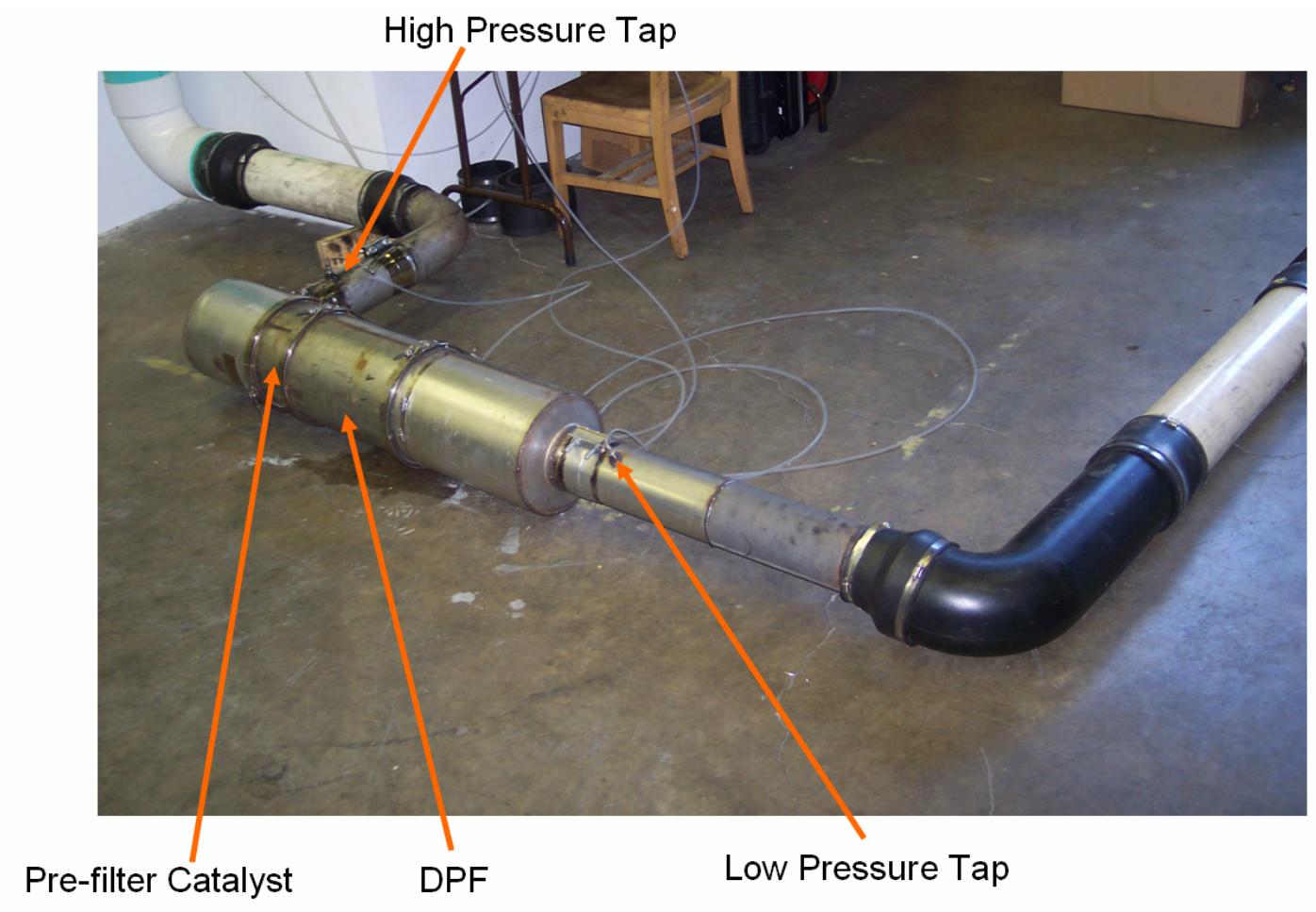

Figure 3-7 Complete DPF Flow Bench Set Up (Filter 6)

\subsubsection{Diesel Engine Intake LFE}

A laminar flow element was used to measure the volumetric flow rate of air entering the intake of the diesel engine. The LFE selected for this application was a 6 in model 50MC2-6 manufactured by Meriam Process Technologies. This is the same model of LFE that was used for the flow bench with a smaller inlet and outlet diameter. This LFE had a flow rate range of 1000 SCFM with a standard accuracy of $+/-0.86 \%$ of a reading and a repeatability of $0.1 \%$ [63].

To measure the differential pressure across the LFE an Omega model PX65310D3V pressure transducer was used. This model had a range of $10 \mathrm{in}-\mathrm{H}_{2} \mathrm{O}$ with an output of 1-5 VDC. The repeatability of the transducer was $0.05 \%$ of full scale [68]. The 
absolute pressure was measured by a Viatran model 1042ACA pressure transducer with a range of 0-15 psi. The repeatability of this transducer was $0.25 \%$ of full scale [69].

\subsubsection{Exhaust DPF Pressure Differential}

To measure the pressure drop across the DPF system while operating on the diesel engine, a Validyne model P305D differential pressure transducer was used. The range for this transducer was 80 in $-\mathrm{H}_{2} \mathrm{O}$ with an accuracy of $+/-0.25 \%$ of full scale [70]. A Dwyer Magnehelic Series 2000, model 2150, differential pressure gage was used when the Validyne transducer was over ranged. This occurred for one of the test modes to be discussed later. This differential pressure gage had a range of 150 in- $\mathrm{H}_{2} \mathrm{O}$ with minor divisions of 5 in- $\mathrm{H}_{2} \mathrm{O}$. The accuracy of this gage was $+/-2 \%$ of full scale [71].

\subsubsection{CAFEE Laboratory}

The experiments conducted for this work were performed in the CAFEE laboratory at West Virginia University’s Evansdale Campus. The CAFEE uses an engine dynamometer to simulate the loads placed on the engine during on-road driving. The diesel engine exhaust is run through a full flow dilution tunnel to simulate the dilution that occurs when exhausted into the atmosphere. The exhaust gases from the dilution tunnel are then analyzed by hydrocarbon, $\mathrm{NO}_{\mathrm{x}}, \mathrm{CO}_{2}$ and $\mathrm{CO}$ analyzers. $\mathrm{PM}$ is measured in real time and as a total at the end of each test run. See references for more information on the WVU CAFEE laboratory and engine test set-up [72, 73]. 


\subsection{Vacuum}

A vacuum cleaner was used to collect the particulate removed from each filter as it was cleaned. The vacuum cleaner used was an $18 \mathrm{gal}, 6.5 \mathrm{hp}$ peak Shop-Vac with a standard cartridge filter. The inlet side of the filter was connected to the vacuum using PVC pipe while compressed air was blown through the exit side of the filter as shown in Figure 3-8 and Figure 3-9 below. The air used was 120 psi with the outlet orifice of the nozzle measuring 0.1 inches.

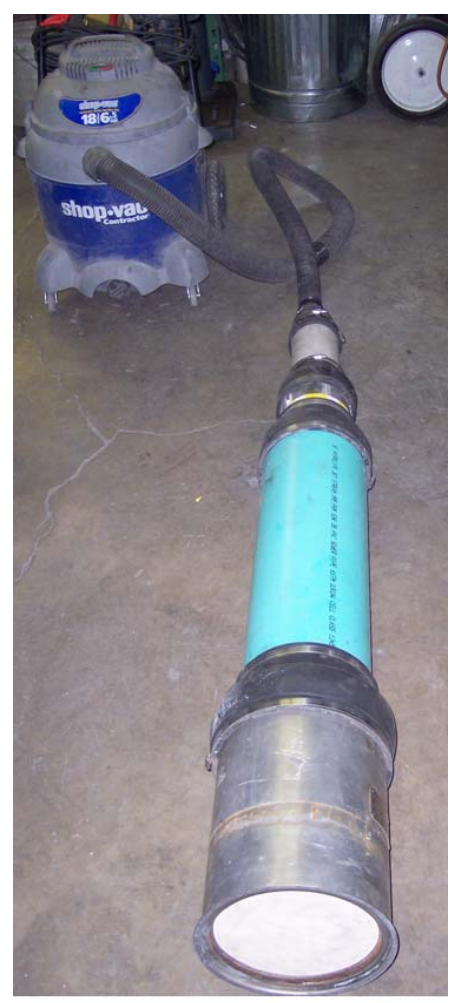

Figure 3-8 12 inch Diameter Filter Connected to the Shop-Vac 


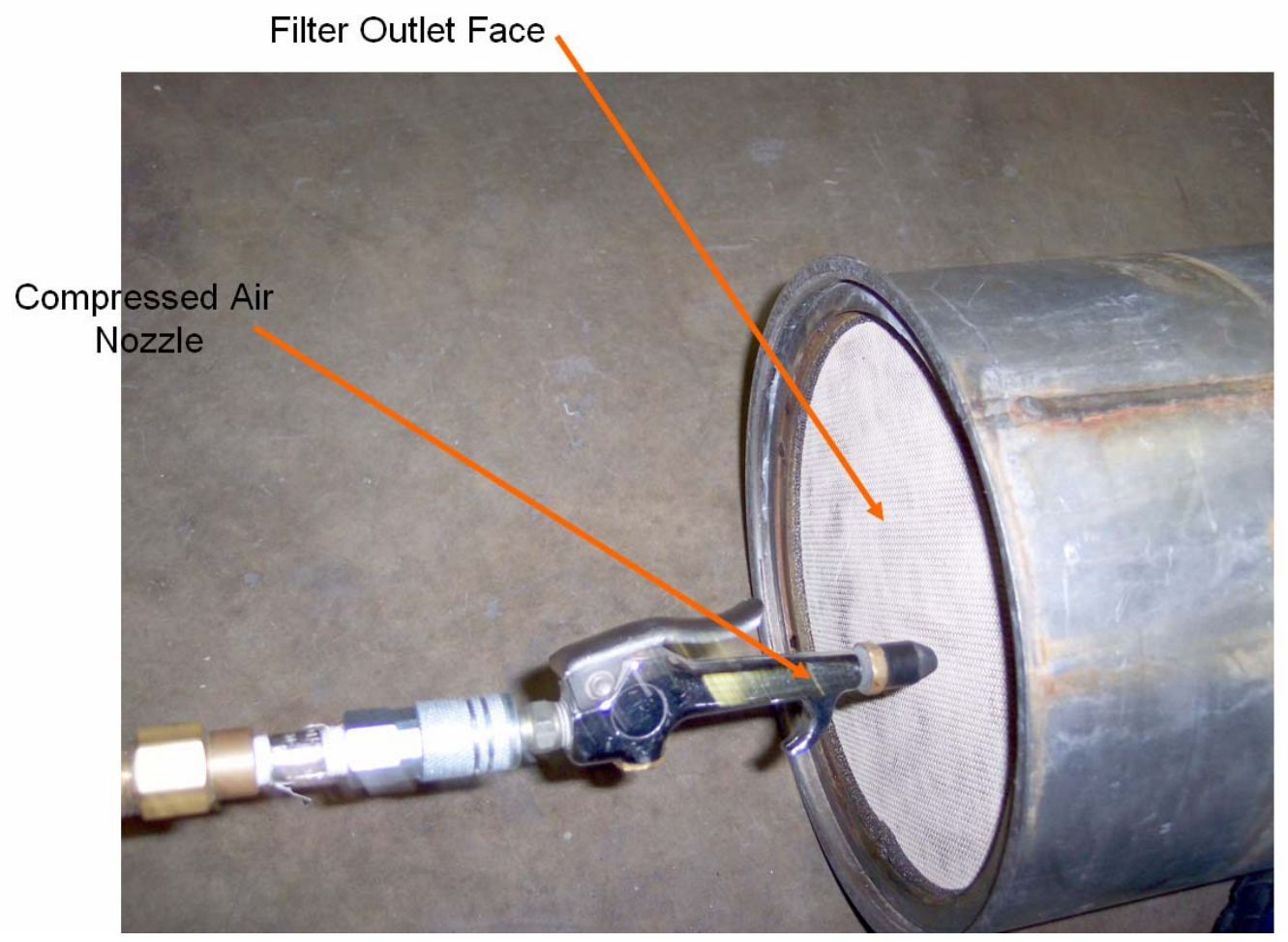

Figure 3-9 Compressed Air Blown Through Exhaust End of the Filter

\subsection{Weight Scale}

To weigh the filters between each testing cycle an Ohaus, model CD-11, scale was used. The accuracy of the scale was $0.02 \%$ of full scale with a repeatability of $+/-0.01 \%$ [74]. The scale was checked by a $50 \mathrm{lb}$ weight and for zero load before and after each filter was weighed.

\subsection{Testing Procedures}

Each of the initial five filters underwent a series of tests consisting of weighing, cleaning and flow bench testing. The two filters with the complete DPF systems, were 
placed on an engine exhaust in addition to the other testing procedures. The subsections below outline the procedures performed on each filter.

\subsubsection{Filter Passage Profiles}

The first procedure performed on two of the first five filters received was to examine the profile of the clogged filter passes. Stainless steel welding rods with a diameter of 0.6 in were cut into 18 in sections and dropped into each filter pass for the two 14 in diameter filters as shown in Figure 3-10 and Figure 3-11 below, to visualize the entire profile. Each of the first five filters profiles were measured along two rows of filter passes perpendicular to each other labeled north to south and east to west. An example of this can be seen in Figure 3-12 below. However, the 0.032 in diameter carbon steel wire used in Figure 3-12 was found to be too flexible. All the measurements were taken using 0.042 in diameter 304 stainless steel tubing cut into $1.5 \mathrm{ft}$ sections. 

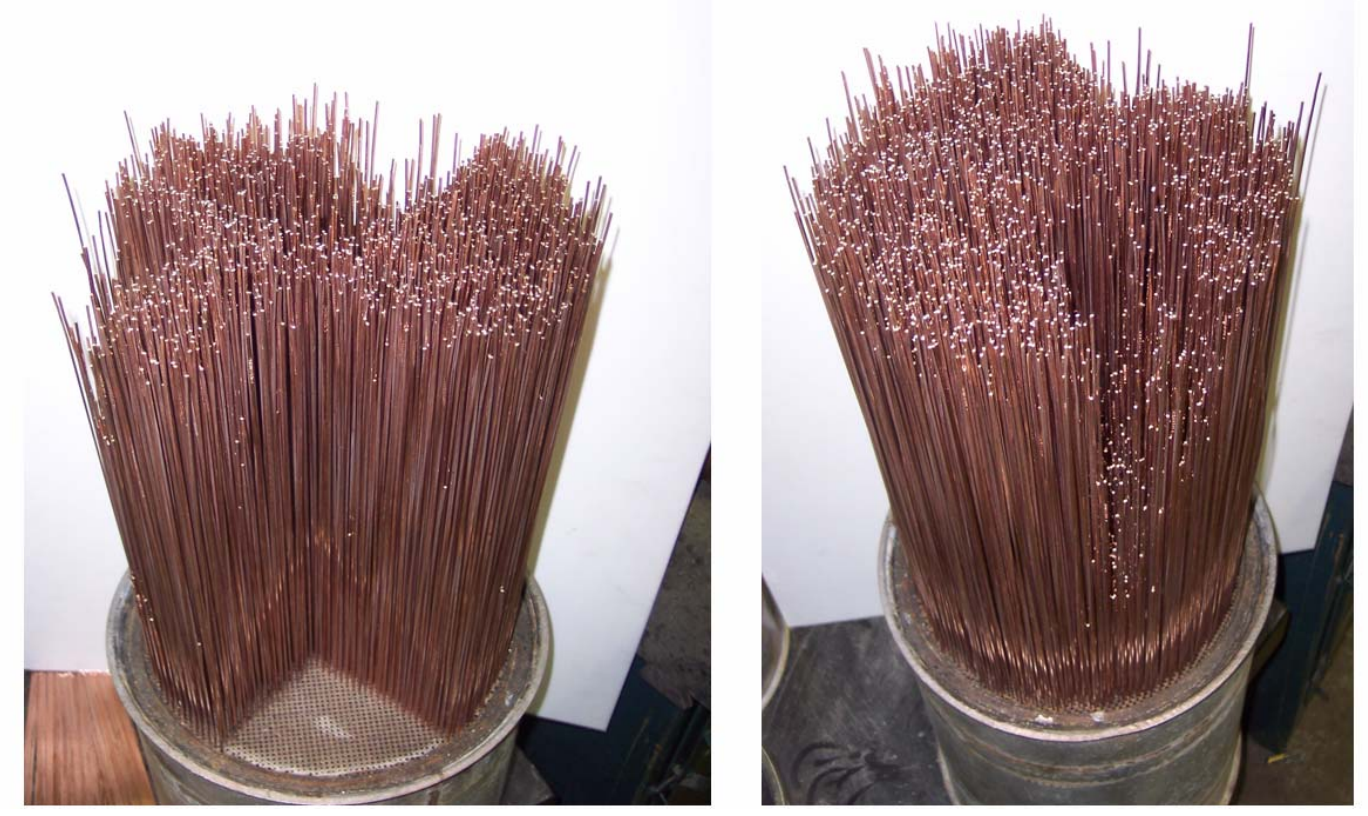

Figure 3-10 Filter 4 Profile
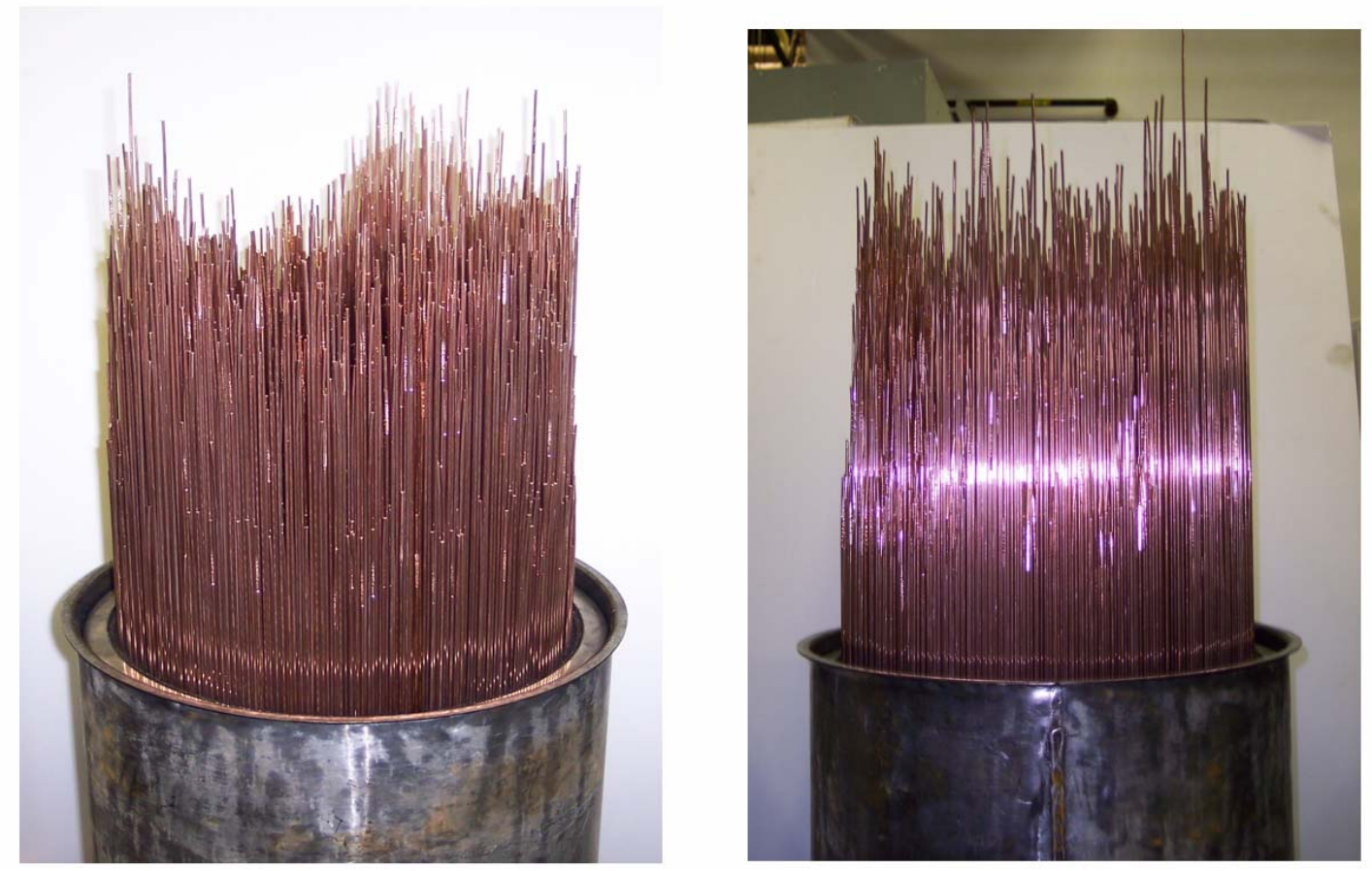

Figure 3-11 Filter 5 Profile 


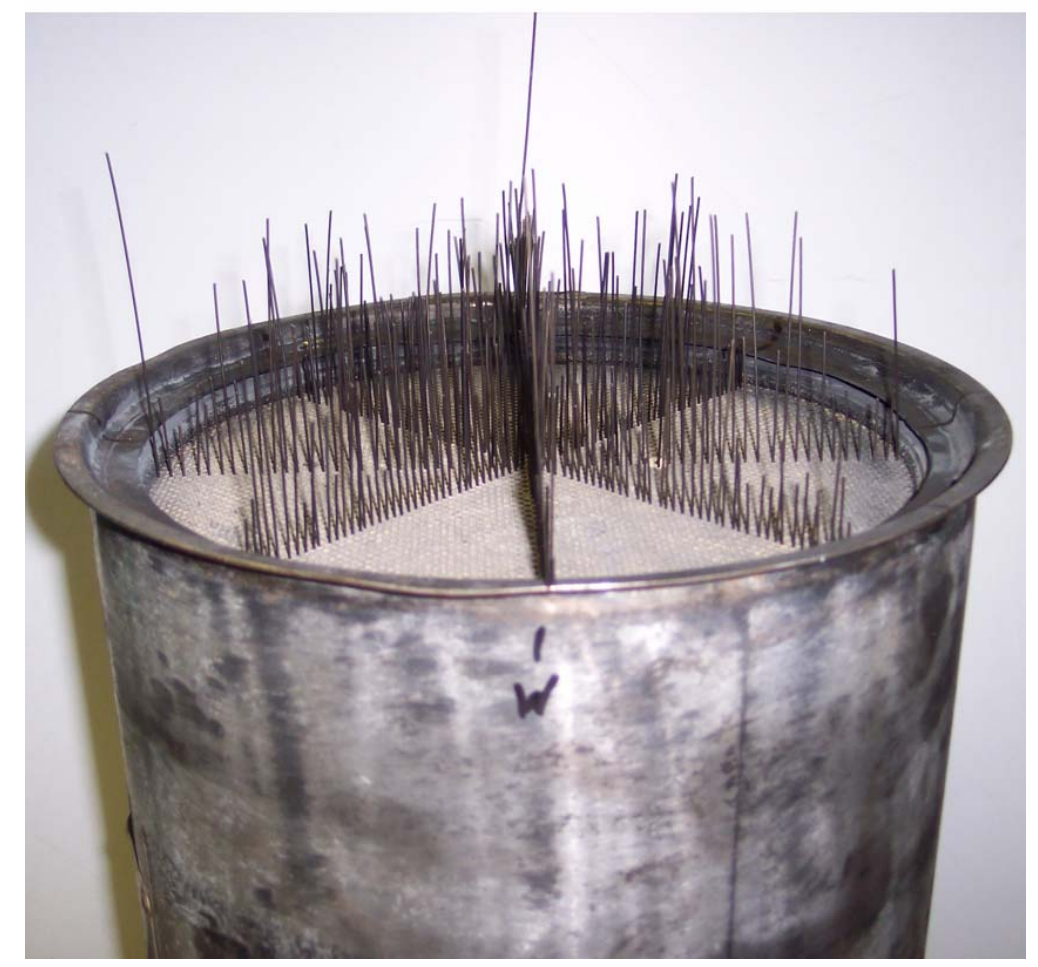

Figure 3-12 Filter 2 Profile

The view shown in Figure 3-10 on the right shows the small area of lighter loading apparent from the dip in the profile. The even distribution is apparent in both Figure 3-10 and Figure 3-11 with random peaks and lows in the profile clearly shown in Figure 3-11. This trend can also be observed in Figure 3-11 which displays the pattern used to measure the filter pass measurements discussed in the results section. The profiles obtained may not be representative of the ash loading to due the variation in the passage sizes during manufacturing. However, it does give an indication as to the evenly distributed loading profile of the filters. 


\subsubsection{Data Logging for Flow Bench Testing}

The flow bench was used to record pressure drop across each filter at several flow rates. The pressure was measured for approximately two minutes and then averaged at eight different flow rates for the initial five filter, and four flow rates for the two complete DPF systems. The flow rates were determined by incrementing the measured pressure drop across the laminar flow element by $0.5 \mathrm{in}-\mathrm{H}_{2} \mathrm{O}$ and $1 \mathrm{in}-\mathrm{H}_{2} \mathrm{O}$ respectively, with a maximum of 4 in $-\mathrm{H}_{2} \mathrm{O}$. The flow rate was calculated from the pressure drop measured across the LFE using the procedure provided in the Meriam LFE instruction manual [63]. All the flows were corrected to $4{ }^{\circ} \mathrm{C}$ using Equation 4-1.

$$
\Delta p_{\text {LFE }} @ 4^{\circ} C=\Delta p_{\text {measured }}\left[\frac{\rho_{\text {water }} @ 20^{\circ} \mathrm{C}}{\rho_{\text {water }} @ 4^{\circ} \mathrm{C}}\right]
$$

The viscosity was corrected for the varying moisture content in the air supply. This was used in correlation to the humidity measurements to determine the actual viscosity of the air being used at a given temperature and humidity level. This correction only changed the differential pressure value an average of $0.2 \%$. The viscosity is given by the temperature relation shown in the following Equation 4-2.

$$
\mu_{\text {dry air }}=\frac{14.58\left(\frac{459.67+{ }^{o} F}{1.8}\right)^{3 / 2}}{110.4+\left(\frac{459.67+{ }^{o} F}{1.8}\right)}
$$

Equation 3-2

The standard viscosity of air was also found using Equation 4-2 by using a standard temperature of $70{ }^{\circ} \mathrm{F}$. The "wet" air viscosity was found by multiplying the "dry" air 
viscosity by the ratio of wet to dry viscosity. This ratio was given in Table A-35500 on page 5 of the Meriam LFE Manual found by referencing the recorded temperature and relative humidity of the air being used [63].

The actual and standard volumetric flow rates were obtained by using a formula particular to the LFE used which contains the unique constants B and C stamped on the nameplate of the LFE. The values of the constants for the LFE used in the flow bench testing were 283.699 and .0973527 for B and C, respectively. Equation 3-3 below was used to calculate the actual volumetric flow rate.

$$
Q_{a c t}=\left(B\left(\Delta P_{L F E \text { corrected }}\right)+C\left(\Delta P_{L F E \text { corrected }}\right)^{2}\right)\left(\frac{\mu_{\text {std }}}{\mu_{d r y}}\right)
$$

Equation 3-3

The standard volumetric flow rate was found using the same relation and multiplying by a temperature and pressure ratio as shown in Equation 3-4 below.

$$
Q_{\text {std }}=\left(B\left(\Delta P_{\text {LFE corrected }}\right)+C\left(\Delta P_{L F E \text { corrected }}\right)^{2}\right)\left(\frac{\mu_{\text {std }}}{\mu_{d r y}}\right)\left(\frac{T_{\text {std }}}{T_{\text {act }}}\right)\left(\frac{P_{\text {act }}}{P_{\text {std }}}\right)
$$

Because the air contained moisture, each flow rate had to be multiplied by a relative humidity correction factor given by the ratio of wet to dry air density. This humidity correction factor was also provided in the Meriam LFE Manual in table A-35600 on page 5 which correlated the correction factor to the temperature and relative humidity of the air being used. The results of the calculations obtained for each filter will be discussed in the results section. 


\subsubsection{Cleaning and Flow Bench Testing}

The initial five filters underwent similar testing procedures which were performed from August 16 to September 12, 2005. Initial weights and measurements were taken on each filter before testing began. Then each filter was placed on the flow bench to determine the pressure drop on each filter and weighed again. The first cleaning for all five filters used pressurized air with cleaning times from 2.5 minutes to 10 minutes. Pressure cleaning was performed by blowing high pressure air at 120 psi in the reverse direction through the filter which was connected to a vacuum cleaner at the opposite end. After the first cleaning cycle the filters were weighted and placed on the flow bench to reevaluate the pressure loss across each filter. The filters were weighed again and underwent the same cleaning procedure as each had been given previously. Each filter was then weighed and run on the flow bench a third time.

For the third cleaning cycle two filters were cleaned using water while the remaining three were cleaned with pressurized air for thirty minutes. As mentioned previously, the matting for these filters deteriorate when exposed to water. A rubber coupling was used to pour water in, to attempt to prevent water from reaching the outer edge of the surface as shown in Figure 3-13 below. This problem was investigated further and will be discussed in more detail later. After the water cleaning the two filters were dried by placing them on the flow bench for one hour. The moisture level of the exiting air flow was monitored during this drying cycle to ensure that $0 \%$ relative humidity was reached at the outlet of the flow bench. After the drying cycle the filters were weighed, run on the flow bench and weighed again. 


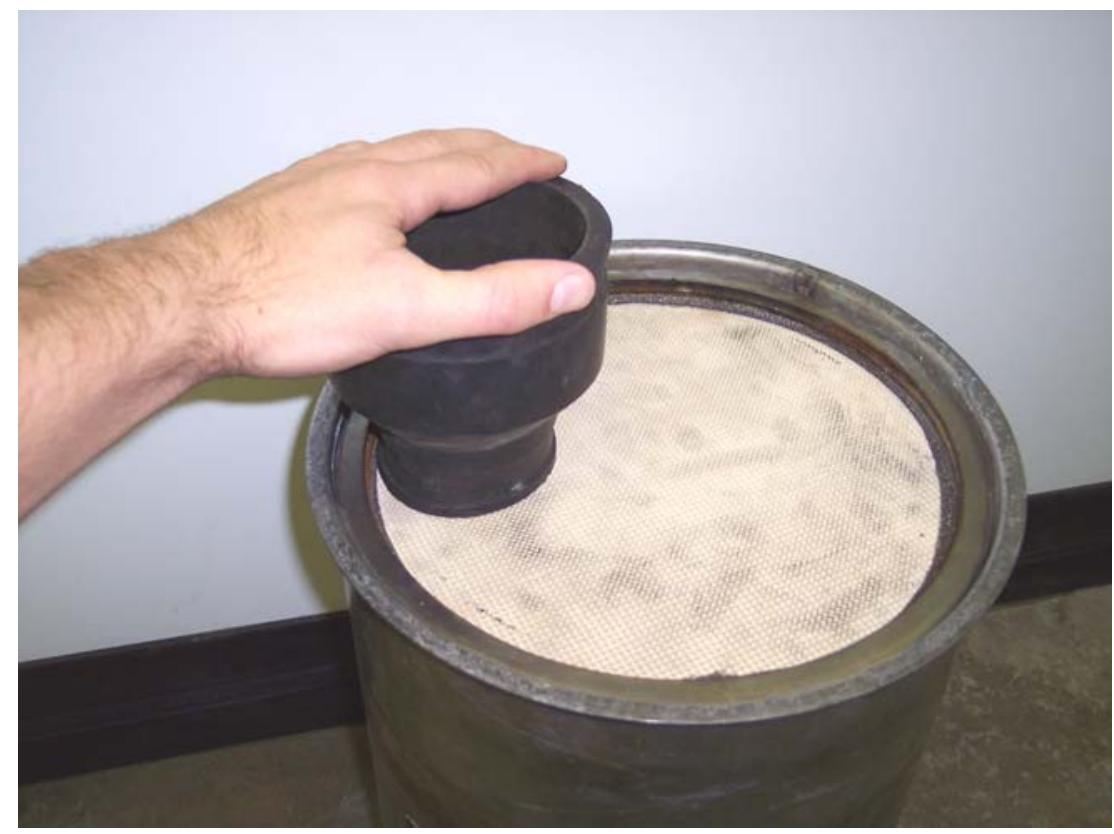

Figure 3-13 Rubber Reducer Used to Keep Water Away From Edge of Filter

The remaining three filters that underwent the thirty minute cleaning cycle were weighed and then placed on the flow bench a fourth time. Each filter was weighed again and two were given the same water cleaning cycle as previously mentioned including the drying cycle, weighing and flow bench testing. Each filter, except filter 2, had a final weighing four months after the testing was completed. The outline of each of the first five filters testing procedures is given in Table 3-2 on the following page. 


\section{Table 3-2 Test Procedure for the First Five Filters}

\begin{tabular}{|c|c|c|c|c|}
\hline Filter 1 & Filter 3 & Filter 2 & Filter 5 & Filter 4 \\
\hline initial weight & initial weight & initial weight & initial weight & initial weight \\
\hline 1st flow bench test & 1st flow bench test & 1st flow bench test & 1st flow bench test & 1st flow bench test \\
\hline post 1st flow bench weight & post 1st flow bench weight & post 1st flow bench weight & post 1st flow bench weight & post 1st flow bench weight \\
\hline 3 min pressurized air cleaning & $\begin{array}{l}10 \text { min pressurized air } \\
\text { cleaning }\end{array}$ & $\begin{array}{l}3.5 \text { min pressurized air } \\
\text { cleaning }\end{array}$ & 3 min pressurized air cleaning & $\begin{array}{l}2.5 \text { min pressurized air } \\
\text { cleaning }\end{array}$ \\
\hline post cleaning weight & post cleaning weight & post cleaning weight & post cleaning weight & post cleaning weight \\
\hline 2nd flow bench test & 2nd flow bench test & 2nd flow bench test & 2nd flow bench test & 2nd flow bench test \\
\hline post 2nd flow bench weight & post 2nd flow bench weight & post 2nd flow bench weight & post 2nd flow bench weight & post 2nd flow bench weight \\
\hline 3 min pressurized air cleaning & $\begin{array}{l}10 \text { min pressurized air } \\
\text { cleaning }\end{array}$ & $\begin{array}{l}3.5 \text { min pressurized air } \\
\text { cleaning }\end{array}$ & 3 min pressurized air cleaning & $\begin{array}{l}2.5 \text { min pressurized air } \\
\text { cleaning }\end{array}$ \\
\hline post cleaning weight & post cleaning weight & post cleaning weight & post cleaning weight & post cleaning weight \\
\hline 3rd flow bench test & 3rd flow bench test & 3rd flow bench test & 3rd flow bench test & 3rd flow bench test \\
\hline post 3rd flow bench weight & post 3rd flow bench weight & post 3rd flow bench weight & post 3rd flow bench weight & post 3rd flow bench weight \\
\hline 20 min water cleaning & 20 min water cleaning & $\begin{array}{l}30 \text { min pressurized air } \\
\text { cleaning }\end{array}$ & $\begin{array}{l}30 \text { min pressurized air } \\
\text { cleaning }\end{array}$ & $\begin{array}{l}30 \text { min pressurized air } \\
\text { cleaning }\end{array}$ \\
\hline drying on flow bench $60 \mathrm{~min}$ & drying on flow bench $60 \mathrm{~min}$ & post cleaning weight & post cleaning weight & post cleaning weight \\
\hline post cleaning weight & post cleaning weight & 4th flow bench test & 4th flow bench test & 4th flow bench test \\
\hline 4th flow bench test & 3 days later weight check & $\begin{array}{l}\text { post 4th flow bench test } \\
\text { weight }\end{array}$ & $\begin{array}{l}\text { post 4th flow bench test } \\
\text { weight }\end{array}$ & $\begin{array}{l}\text { post 4th flow bench test } \\
\text { weight }\end{array}$ \\
\hline $\begin{array}{l}\text { post 4th flow bench test } \\
\text { weight }\end{array}$ & 4th flow bench test & 20 min water cleaning & & 20 min water cleaning \\
\hline \multirow[t]{5}{*}{ next day weight check } & $\begin{array}{l}\text { post 4th flow bench test } \\
\text { weight }\end{array}$ & drying on flow bench $60 \mathrm{~min}$ & & drying on flow bench $60 \mathrm{~min}$ \\
\hline & & post cleaning weight & & post cleaning weight \\
\hline & & next day weight check & & 3 days later weight check \\
\hline & & 5th flow bench test & & 5th flow bench test \\
\hline & & $\begin{array}{l}\text { post 5th flow bench test } \\
\text { weight }\end{array}$ & & $\begin{array}{l}\text { post 5th flow bench test } \\
\text { weight }\end{array}$ \\
\hline
\end{tabular}


The final two filters with the complete DPF system were tested from September 17-21, 2005. The testing procedure was similar to the previous filters but included operating on an engine dynamometer test stand. This was done to observe the differential pressure across the filters under operational conditions and to see the affects of the particulates gained. A muffler was also run on the flow bench and engine to compare the differential pressures measured with those from the particulate filters. The muffler and DPF systems were assembled to exhaust pipe so each would directly fit to the engine without any modification. Each engine run included six modes: idle, I50, I100, R50, R100 and high idle. Each mode was 2.5 minutes long, with data collection the last 60 seconds, for a total of 20-25 minutes per run including approximately 5-10 minutes for warm up time. The average engine performance for each of the six modes is included in Table 3-3 below. Each engine test cycle performed the six mode run three separate times to obtain a repeated average. During each mode the pressure difference across the filter was recorded, as well as the exhaust flow rate, temperature and back pressure. The fifth test mode, named R100 in Table 3-3 below, over ranged the Validyne model P305D differential pressure transducer and the Magnehelic Series 2000, model 2150, differential pressure gage was used. 
Table 3-3 Average Engine Performance

\begin{tabular}{|c|c|c|c|c|c|c|}
\hline Mode & $\begin{array}{l}\text { Engine } \\
\text { Speed } \\
\text { (RPM) }\end{array}$ & $\begin{array}{l}\text { Engine } \\
\text { Torque } \\
\text { (ft-lbs) }\end{array}$ & $\begin{array}{l}\text { Exhaust } \\
\text { Flow } \\
\text { (SCFM) }\end{array}$ & $\begin{array}{l}\text { Exhaust } \\
\text { Flow } \\
\text { (ACFM) }\end{array}$ & $\begin{array}{l}\text { Post } \\
\text { Turbo } \\
\text { Exhaust } \\
\text { Back } \\
\text { Pressure } \\
\text { (psig) }\end{array}$ & $\begin{array}{l}\text { Post Turbo } \\
\text { Exhaust } \\
\text { Temperature } \\
\left({ }^{\circ} \mathrm{C}\right)\end{array}$ \\
\hline idle & 702 & 10 & 66 & 94 & 0.63 & 154 \\
\hline 150 & 1253 & 660 & 366 & 772 & 0.66 & 356 \\
\hline 1100 & 1253 & 1277 & 547 & 1291 & 1.77 & 483 \\
\hline R50 & 2104 & 416 & 554 & 1064 & 2.83 & 382 \\
\hline R100 & 2104 & 830 & 787 & 1688 & 3.8 & 501 \\
\hline high idle & 2295 & 10 & 548 & 806 & 2.73 & 227 \\
\hline
\end{tabular}

Both of the complete DPF systems underwent the same testing procedures. Each were weighed, tested on the flow bench and then run on the engine. The first cleaning cycle consisted of a 30 minute pressurized air cleaning. Another set of flow bench tests were run and another engine cycle was performed followed by a 20 minute water cleaning cycle. Filter 7 did not receive a drying cycle following the water cleaning due to time constraints. The drying cycle for the complete DPFs was not as essential as it was for the first five filters since the hot engine exhaust removed the moisture. Then a final set of flow bench tests and an engine cycle was performed. The outline of the two complete DPF systems testing procedure is given in Table 3-4 below. 


\section{Table 3-4 Test Procedure for Two Engine Tested Filters}

\begin{tabular}{|l|l|}
\hline Filter 7 & Filter 6 \\
\hline initial weight & initial weight \\
\hline 1st flow bench test & 1st flow bench test \\
\hline post 1st flow bench weight & post 1st flow bench weight \\
\hline 1st engine run & 1st engine run \\
\hline post 1st engine run weight & post 1st engine run weight \\
\hline 2nd flow bench test & 2nd flow bench test \\
\hline post 2nd flow bench weight & post 2nd flow bench weight \\
\hline $\begin{array}{l}\text { 30 min pressurized air } \\
\text { cleaning }\end{array}$ & $\begin{array}{l}\text { 30 min pressurized air } \\
\text { cleaning }\end{array}$ \\
\hline post cleaning weight & post cleaning weight \\
\hline 3rd flow bench test & 3rd flow bench test \\
\hline 2nd engine run & 2nd engine run \\
\hline post 2nd engine run weight & post 2nd engine run weight \\
\hline 4th flow bench test & 4th flow bench test \\
\hline $\begin{array}{l}\text { post 4th flow bench test } \\
\text { weight }\end{array}$ & $\begin{array}{l}\text { post 4th flow bench test } \\
\text { weight }\end{array}$ \\
\hline 20 min water cleaning & 20 min water cleaning \\
\hline post cleaning weight & drying on flow bench 60 min \\
\hline 5th flow bench test & post cleaning weight \\
\hline 3rd engine run & 5th flow bench test \\
\hline post 3rd engine run weight & 3rd engine run \\
\hline 6th flow bench test & post 3rd engine run weight \\
\hline & 6th flow bench test \\
\cline { 2 - 2 } &
\end{tabular}

\subsubsection{Matting Water Absorption}

The filter systems investigated were not designed for water cleaning. Great care was taken to prevent water from reaching the outer edges of the filter face during the water cleaning. To further investigate this matter, filter 2's metal sheath was cut in half and removed as shown in Figure 3-14 below. With the filter removed from the metal sheath, approximately 0.5 liters of water was poured into the rubber coupling held at the center of the filter to observe the amount of water that propagated through the filters substrates. This allowed the inspection of the matting material to determine if water had reached and damaged it during the water cleaning cycle. The water propagation showed 
that any water cleaning cycle, despite efforts to prevent the edges from getting wet, could allow water to reach the matting material and damage it.

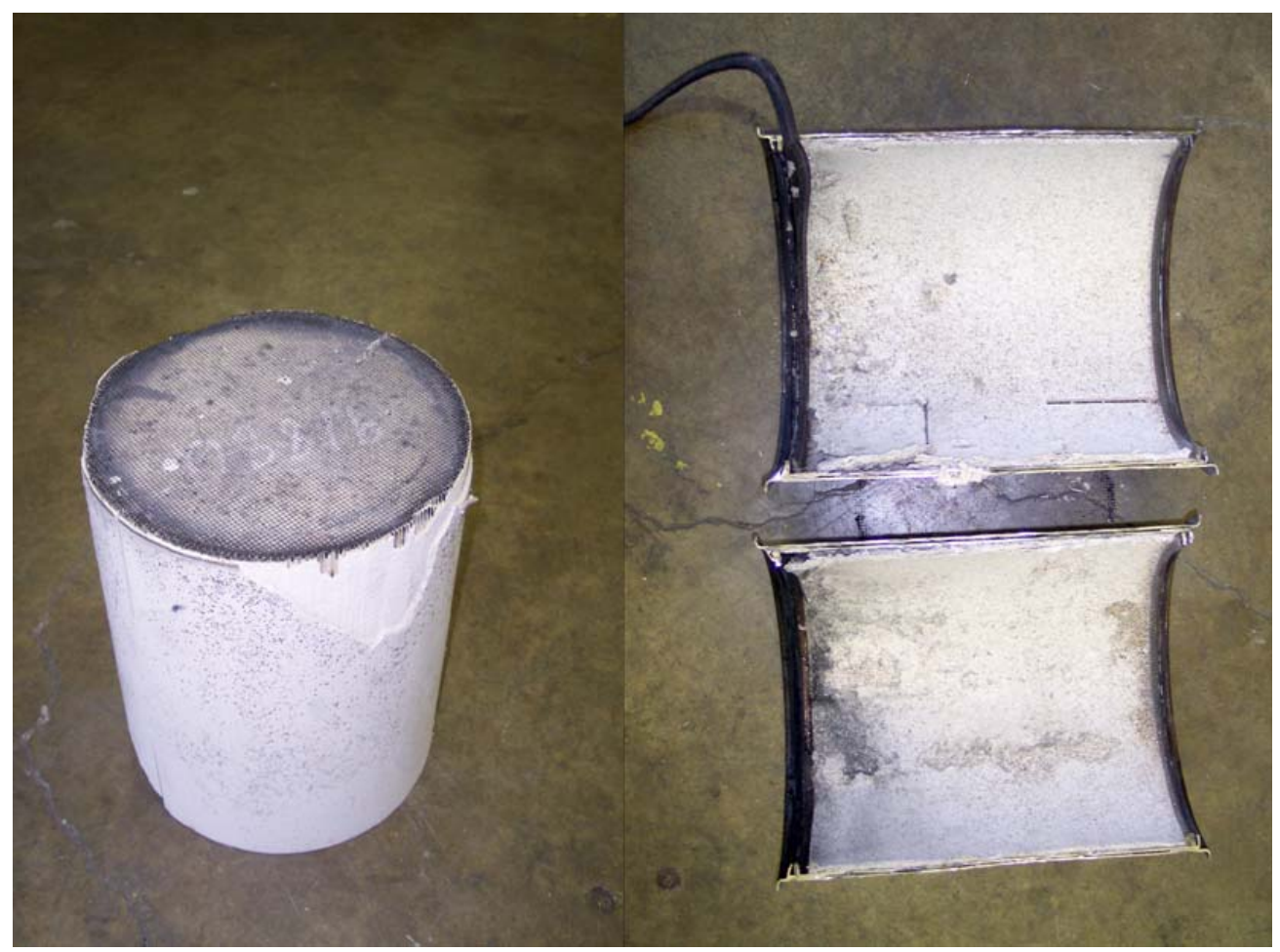

Figure 3-14 Filter 2 with Metal Sheath Removed

\subsubsection{Modeling}

A one dimensional model was performed for the two complete DPF systems to compare analytical results to experimental data. This model was obtained from a paper submitted to SAE in May 2006, by WVU's CAFEE, which compared the experimental data and modeling of the initial five DPFs [75]. The modeled pressure drop was determined by four major contributors: wall permeability, particulate permeability, channel wall friction and inlet and outlet conditions.

Equation 3-5 below was utilized to model the pressure drop across a clean filter. The four terms summed together represent: pressure losses in the filter wall, pressure drop due 
to friction effects, second order effects of flow through a porous wall and pressure drop due to inlet and outlet conditions, respectively.

$$
\Delta p=\frac{\mu Q}{2 \forall_{\text {trap }}}(\alpha+w)^{2}\left[\frac{w}{k \alpha}+\frac{8 F L^{2}}{3 \alpha^{4}}\right]+\frac{\rho Q^{2}(\alpha+w)^{4}}{\forall_{\text {trap }}^{2} \alpha}\left[\frac{\beta w}{4}+2 \varsigma\left(\frac{L}{\alpha}\right)^{2}\right] \text { Equation 3-5 }
$$

Equation 3-6 was used to model a dirty filter. With the addition of the particulates in the modeling equation there are six terms summed together which represent: pressure drop due to flow through a porous wall, pressure drop due to particulate (later dependent on particulate wall thickness, permeability and air viscosity and velocity), pressure drop due to inlet and outlet conditions (dependent on particulate wall thickness), pressure drop due to friction effects, second order effects of flow through a porous wall and pressure drop due to expansion and contraction of flow at the inlet and outlet of the DPF, respectively.

$$
\begin{aligned}
& \Delta p=\frac{\mu Q}{2 \forall_{\text {trap }}}(\alpha+w)^{2}\left[\frac{w}{k \alpha}+\frac{1}{2 k_{p}} \ln \left(\frac{\alpha}{\alpha-2 w_{p}}\right)+\frac{4 F L^{2}}{3}\left(\frac{1}{\left(\alpha-2 w_{p}\right)^{4}}+\frac{1}{\alpha^{4}}\right)\right]+ \\
& \frac{\rho Q^{2}(\alpha+w)^{4}}{\forall_{\text {trap }}^{2} \alpha}\left[\frac{\beta w}{4}+2 \varsigma\left(\frac{L}{\alpha}\right)^{2}\right]
\end{aligned}
$$

Equation 3-6

In order to obtain the modeling parameters, the flow bench test with the lowest differential pressure was assumed to be a clean filter. This assumption was necessary because the actual history of the filters was unknown. Using this assumption a nonlinear least squares curve fit was used to obtain the filter permeability and inertial coefficient. The filter permeability and inertial coefficient was expected to be higher than previous models because the differential pressure measurement included the entire DPF system 
(i.e. diffusers and a pre-filter catalyst for filter 6). These values were used to find the particulate wall thickness and permeability for the remaining "dirty" flow bench and engine test cycles. 


\section{RESULTS AND DISCUSSION}

\subsection{Introduction}

The purpose of this work was to investigate cleaning techniques of diesel particulate filters. This section reviews and discusses the results of each stage of the investigation.

\subsection{Profiles of Particulate Filters}

Each of the initial five filters blockage length was investigated by dropping metal rods and wire into individual substrates. This process is time consuming because of the number of passages in each filter and great care must be taken to avoid damaging the filter. The blockage had no particular pattern nor showed any particular area of heavier loading, as can be seen from Figure 3-10 through Figure 3-12 in section 3.12.1 above. Filter 4 did show a small section of lighter loading as shown in Figure 3-10 above and can also be seen from measured values illustrated in Figure 4-1 below.

Table 4-1 Average Filter Passage Measurements for Each Filter

\begin{tabular}{|c|c|r|}
\hline \multicolumn{3}{|c|}{$\begin{array}{c}\text { Average Filter Passage Length } \\
\text { (in) }\end{array}$} \\
\hline \multicolumn{3}{|c|}{ Uncatalyzed Filters } \\
\hline Filter & 1 & 11.05 \\
\hline & 2 & 10.11 \\
\hline \multicolumn{3}{|c|}{ Catalyzed Filters } \\
\hline \multicolumn{3}{|c|}{} \\
\hline Filter & 4 & 3.56 \\
\hline & 5 & 11.25 \\
\hline
\end{tabular}


This indicates that there is no area on the filter that requires additional cleaning. The graphs depicting the filter pass measurements for the remaining filters can be found in Appendix A. A few isolated passages had lost the plugged ends on the outlet face yielding an unobstructed flow path and are indicated as having filter pass measurements equal to the total length of the filter. The average value for each filters passage length is shown in Table 4-1 below. The measuring instrument used had a readability of $+/-0.02$ inches. 


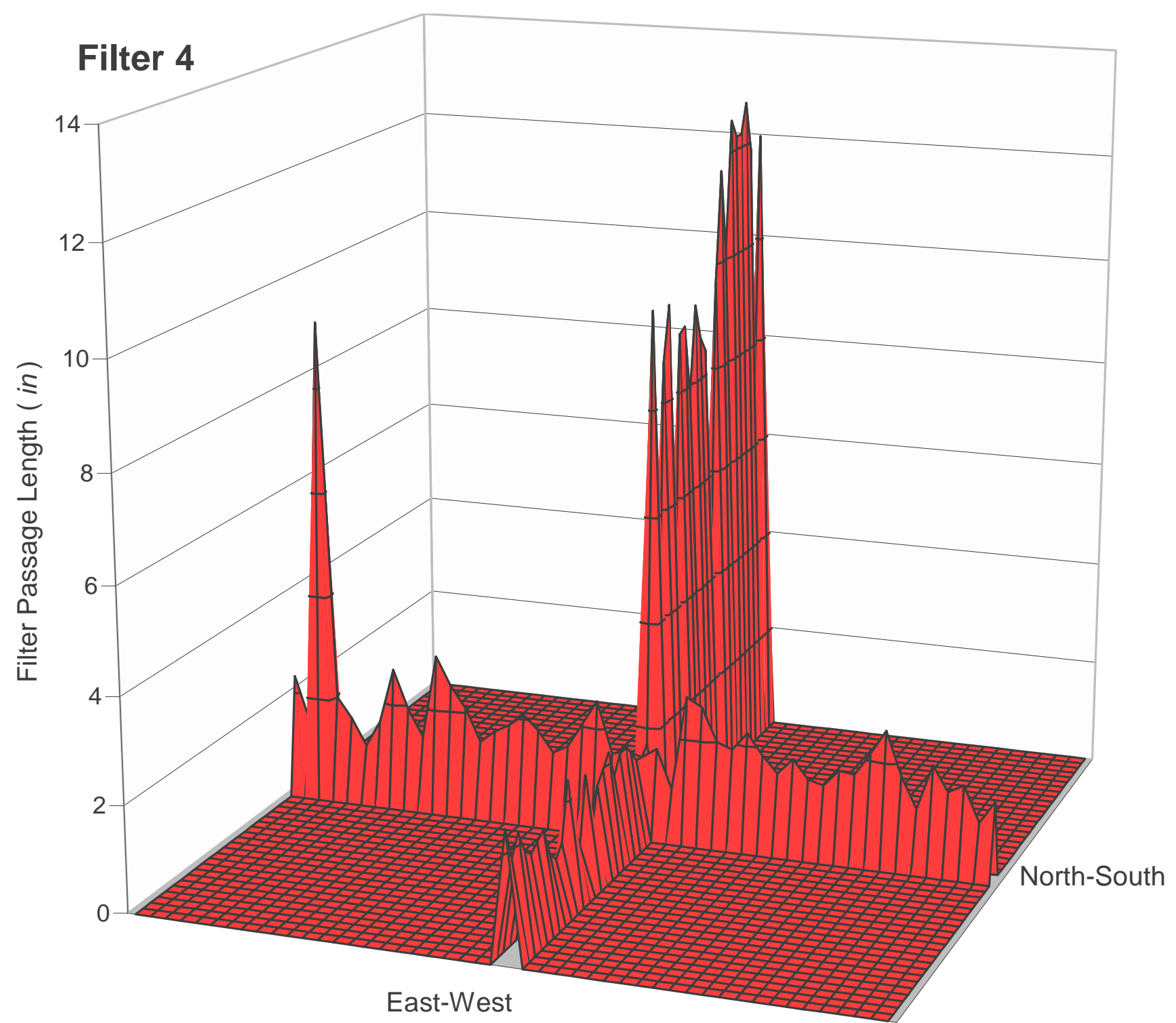

Figure 4-1 Filter Passage Measurements for Filter 4

\subsection{Filter Flow Bench Testing}

The main purpose of the flow bench was to determine the pressure drop as air flowed through the filter. This is important because it relates to the backpressure that the filter would create on an engine's exhaust while in service. This pressure drop was 
recorded and evaluated for several flow rates to evaluate the effects of each cleaning cycle and engine run. The highest standard deviation for all flow bench tests differential pressure measurements was $0.671 \mathrm{in}-\mathrm{H}_{2} \mathrm{O}$.

\subsubsection{Initial Filters Pressure Drop}

Figure 4-2 below is an example of the trends observed through measuring the pressure difference across each of the first five filters. The remaining filters flow bench results can be found in Appendix B. As Figure 4-2 shows, the drop in the filter pressure is parabolic, curving slightly upward as the flow rate is increased. The trends observed from the affects of cleaning are most noticeable for the higher flow rates. The first air cleaning cycle produced a significant reduction in pressure difference. An average of $71 \%$ of the total pressure drop occurred following the first cleaning cycle. Subsequent air cleanings produced much less significant reductions despite the extended time used for some of the cleaning cycles. Each filter that received a water cleaning cycle displayed an additional significant reduction in pressure difference across the filter. This occurred after little progress was shown by additional time for compressed air cleaning (three of the five filters air cleanings totaled over a half hour). 


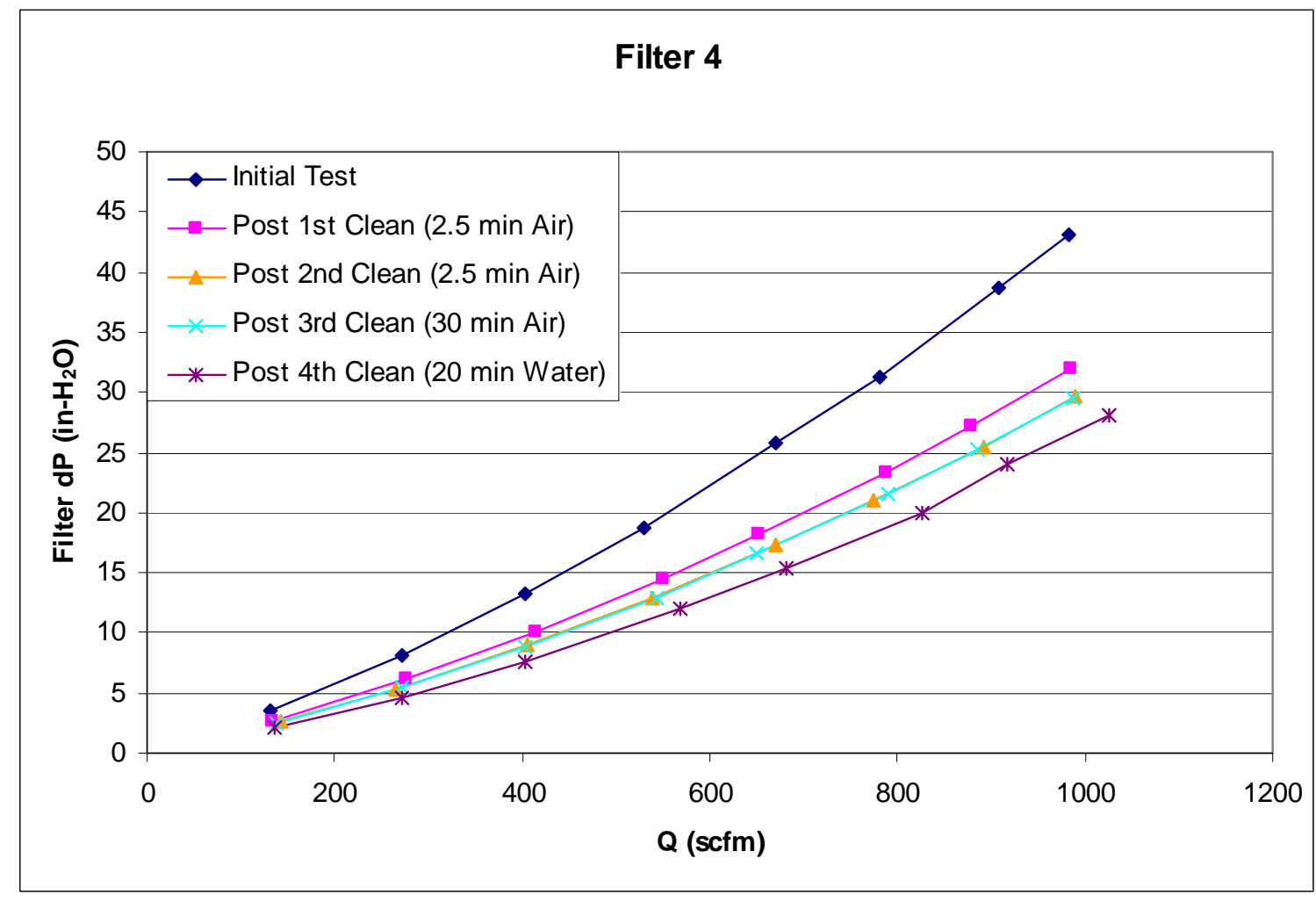

Figure 4-2 Pressure Difference for Each Phase of Flow Bench Testing on Filter 4

\subsubsection{Complete DPF Systems Pressure Drop}

The engine test cycle, for the two complete DPF systems, was a key addition to the flow bench testing. Figure 4-3 below indicates a trend of the pressure difference returning back to the original difference following an engine test run. While this creates problems in determining the effectiveness in the cleaning cycles used, it also indicates that using the differential pressure may not be the best choice of standards to determine how clean a filter is. This trend may be due to the use of an oversized engine or the filters may not have been operated on an engine for an extend period of time prior to receiving them. Both the compressed air cleaning and water cleaning show significant reduction in 
the pressure difference across the filter. The water cleaning did not show as much additional improvement over compressed air cleaning as observed in the initial five filters.

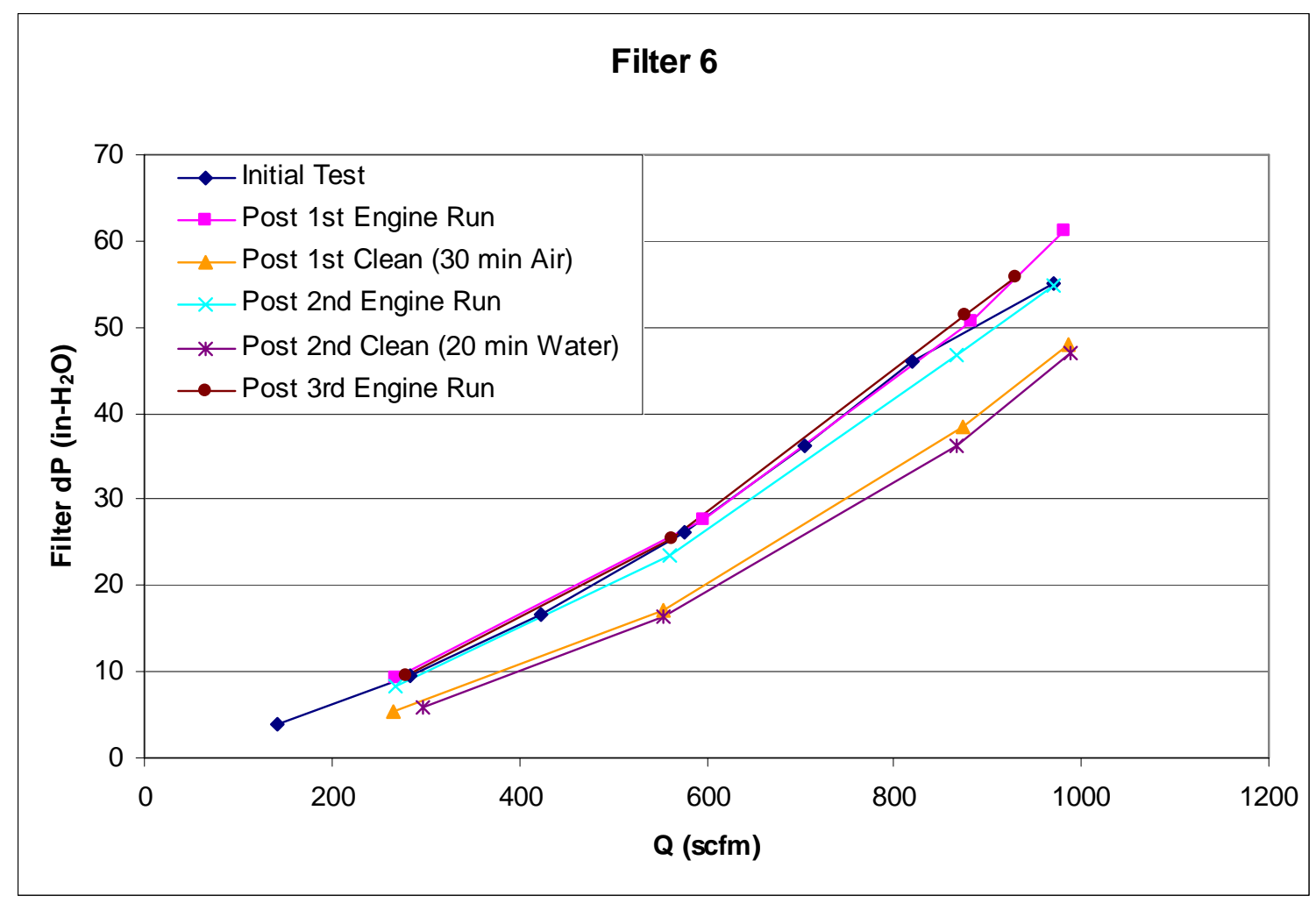

Figure 4-3 Pressure Difference for Each Phase of Testing on Filter 6

Figure 4-4 shows the flow bench results for filter 7 which displays similar trends as shown by filter 6 . Again the trend of the differential pressure returning to the original measurements following an engine test cycle is observed and is even slightly higher than the initial test cycle. The third post engine run flow bench test yielded slightly higher pressure differences compared the first two post engine tests. The differential pressure did not show additional improvements following water cleaning cycle compared with the 
air cleaning. However, the post water clean readings for filter 7 were expected to be slightly higher because the drying cycle was not used due to time constraints.

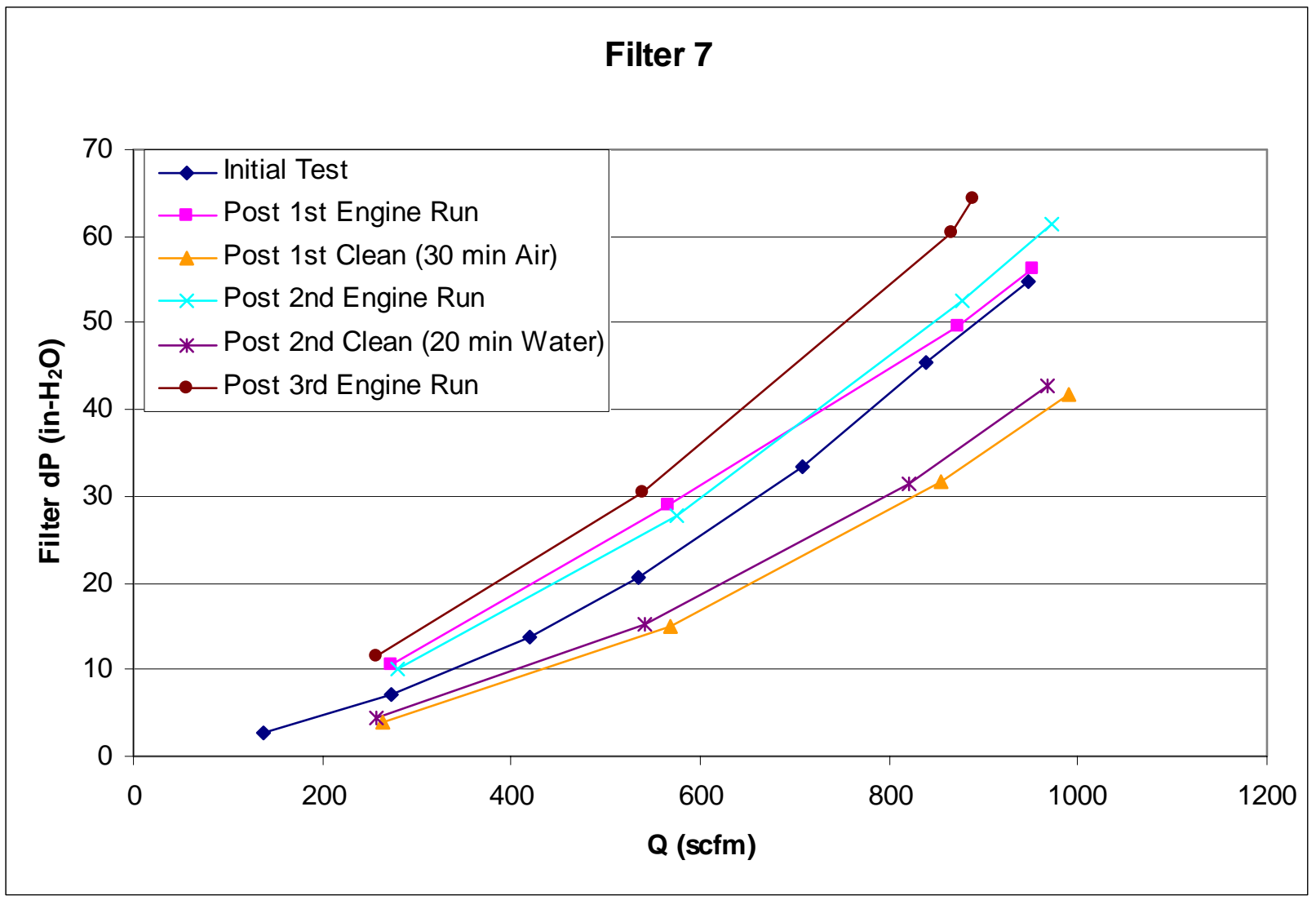

Figure 4-4 Pressure Difference for Each Phase of Flow Bench Testing on Filter 7

\subsection{Filter Weight}

\subsubsection{Introduction}

Before and after every phase of the testing process, the weight of each filter was recorded. This not only indicated the amount of particulate that was removed from each 
cleaning cycle, but also assured that no undesired loading or cleaning of the filter occurred during any of the other testing procedures.

\subsubsection{Initial Filters Weight}

Of the first five filters, filter 3 lost the most weight at $1.03 \mathrm{lbs}$. As shown in Figure 4-5 below, most of the weight loss occurred in the first cleaning cycle. The exception being filter 1 which resulted in a dramatic weight loss following its 3rd cleaning cycle which was a 20 minute water cleaning. Filter 2 gained weight following the final cleaning cycle which was retained even after an extended drying time. The other two filters (number's 3 \& 4) showed a slight reduction in weight following an extended drying time of four months. This is most likely due to the removal of remaining moisture as the filters were allowed to dry to ambient conditions. Filter 4 appears to have little weight loss throughout the testing; however, it lost nearly 6 lbs prior to testing. The filter appeared to have been used with exhaust flowing in both directions and the side chosen for the outlet during testing clearly was not the direction it was last used. 


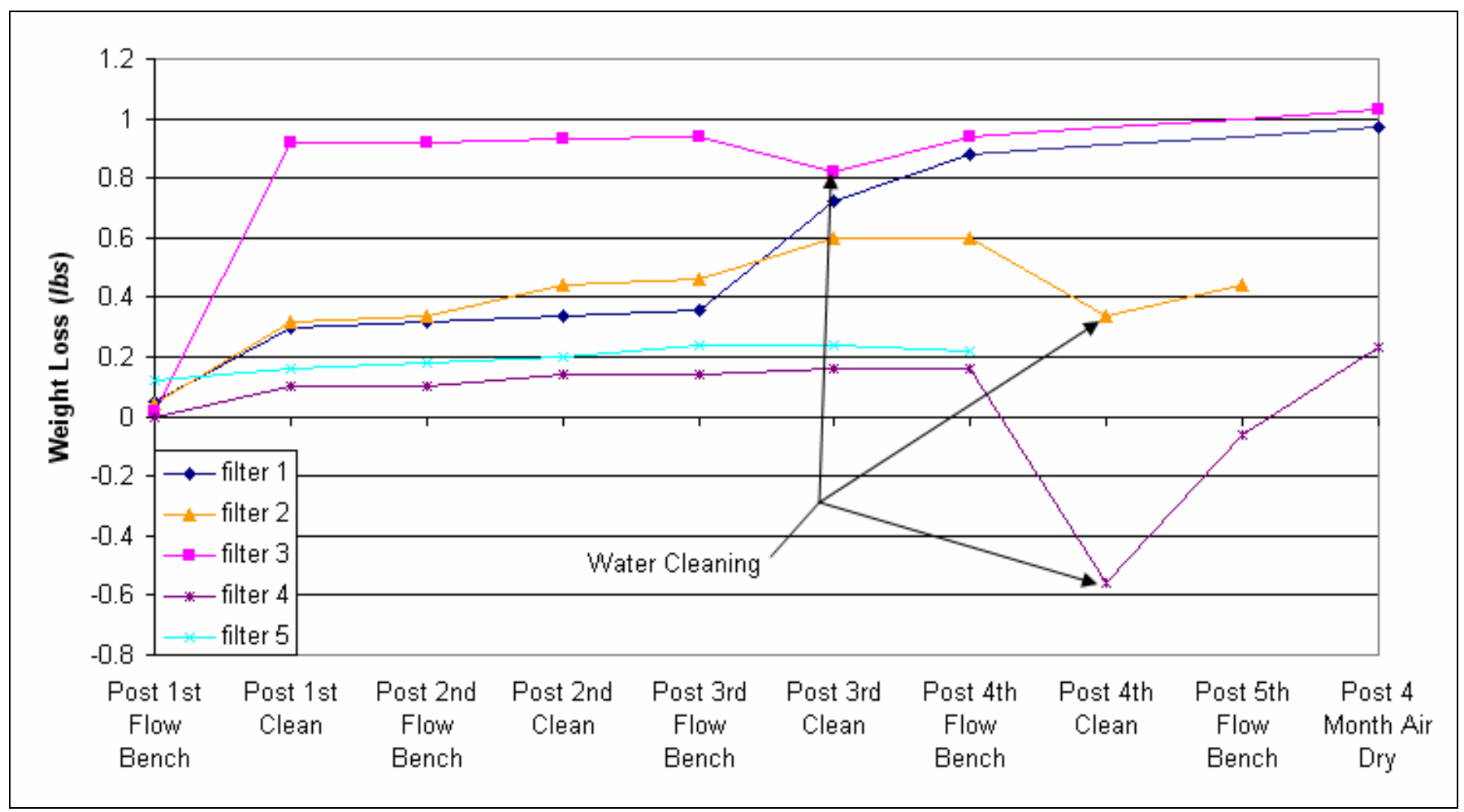

Figure 4-5 Weight Lost During Each Stage of Testing for Initial Five Filters

\subsubsection{Water Retention}

The drying cycle used for the water cleaned filters consisted of operating each filter on the flow bench for one hour, making sure to monitor the humidity level of the exiting air flow. The one hour time frame was well beyond the time required for each of the filters to reach $0 \%$ relative humidity in the exiting air flow. These filters were also allowed to air dry for at least 24 hours and reweighed. There still appeared to be water retained inside the filter as indicated by the increased weight, so the filters were weighed again after a 4 month air drying period.

As mentioned, the water retention and possible associated damage was investigated further by removing the metal sheath from the filter. It was observed that 
water did in fact reach the matting material around the filter and appeared to be slightly damaged. Figure 4-6 below shows the matting which was loosened from the metal to the point of falling off into small sections. It's possible that the matting as well as some small crevasses in the metal sheathing was the cause of this prolonged water retention.

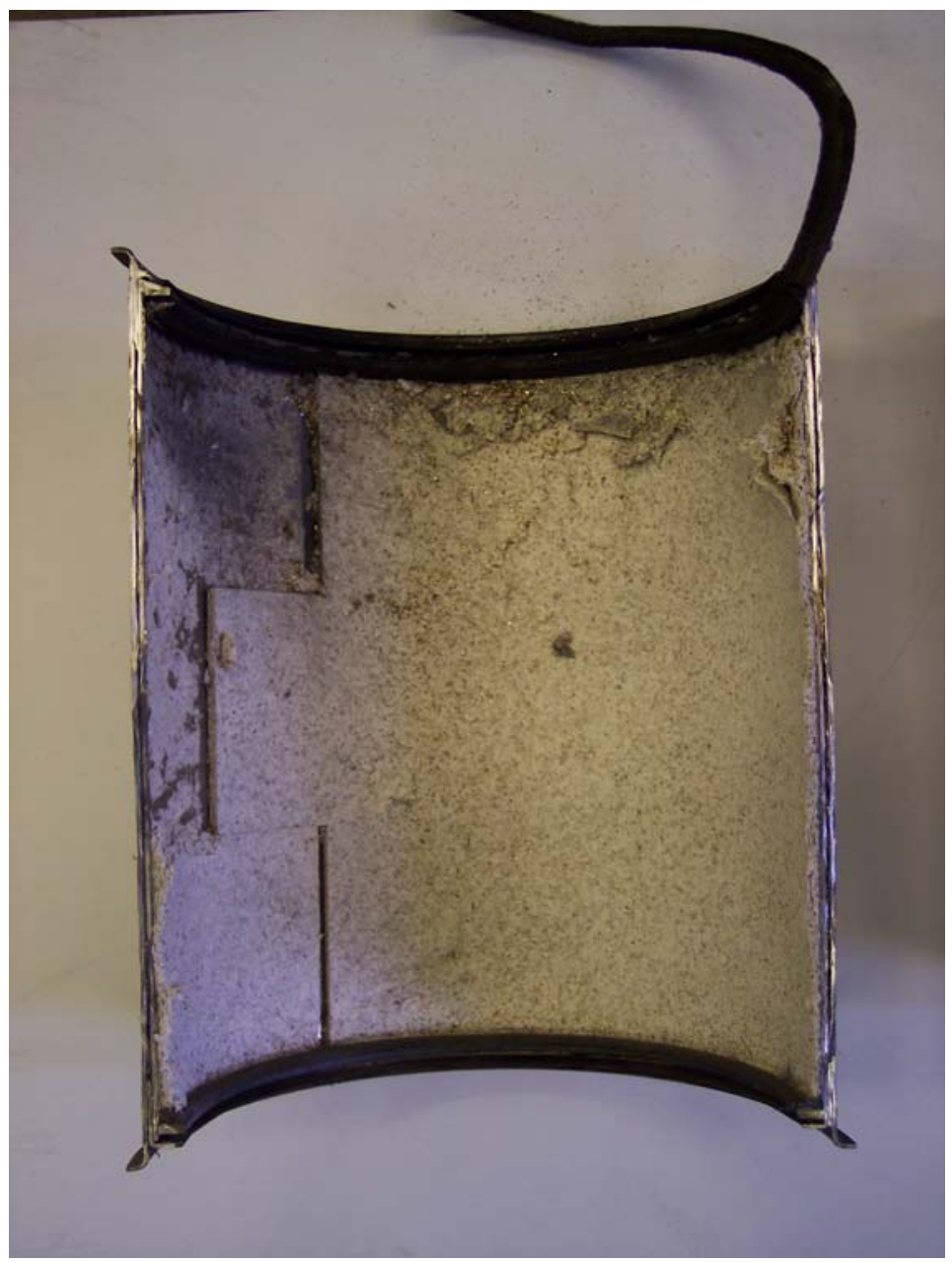

Figure 4-6 Inside View of Half the Metal Sheath Removed From Filter 2

The extent of the water propagation through the filter was also further investigated. After the metal sheath was removed approximately 0.5 liters of water was poured into the center of the filter brick to observe if the water would reach the outer 
edges of the filter. Within a few minutes the entire filter brick became damp beginning at the bottom and quickly propagating outward through the top of the filter. This indicates that water cleaning cannot be used without having water reach the matting material and potentially damaging the filter.

\subsubsection{Complete DPF Weight}

Figure 4-7 below shows the weight loss throughout the testing of the two complete DPF systems. Only the filter itself was weighed; the DPF system was disassembled and the filter section removed before each weighing. Filter 7 shows a considerable weight reduction following the first engine run which may be due to the regeneration of combustible PM remaining in the filter when the appropriate temperature was reached. This was not observed in filter 6 because the filter itself was not catalyzed. Both filters show a large weight loss following their first cleaning cycle nearly equal to the total weight lost by filter 3 . The large amount of weight gained by filter 7 following the second cleaning cycle is due to the water retained from the water cleaning cycle. Because of time constraints this filter did not receive the drying cycle that the other filters underwent following the water cleaning. Following the third engine test cycle, filter 7 showed a significant reduction in weight which could be attributed to the water cleaning cycle; because of the water retention, the effects of this cleaning cycle were not observed until the moisture was removed by the high temperature exhaust. A slight weight reduction in filter 6 following the third engine runs could also be attributed to moisture being removed; again indicating that PM was removed by the previous water cleaning cycle. A slight weight gain occurred in the final weights which were recorded four 
months following the 3rd engine test. The filters were placed on the flow bench immediately following the third engine tests and were still at relatively high temperatures when weighed. Thus this weight gain is likely due to moisture gained after cooling down to ambient air temperatures.

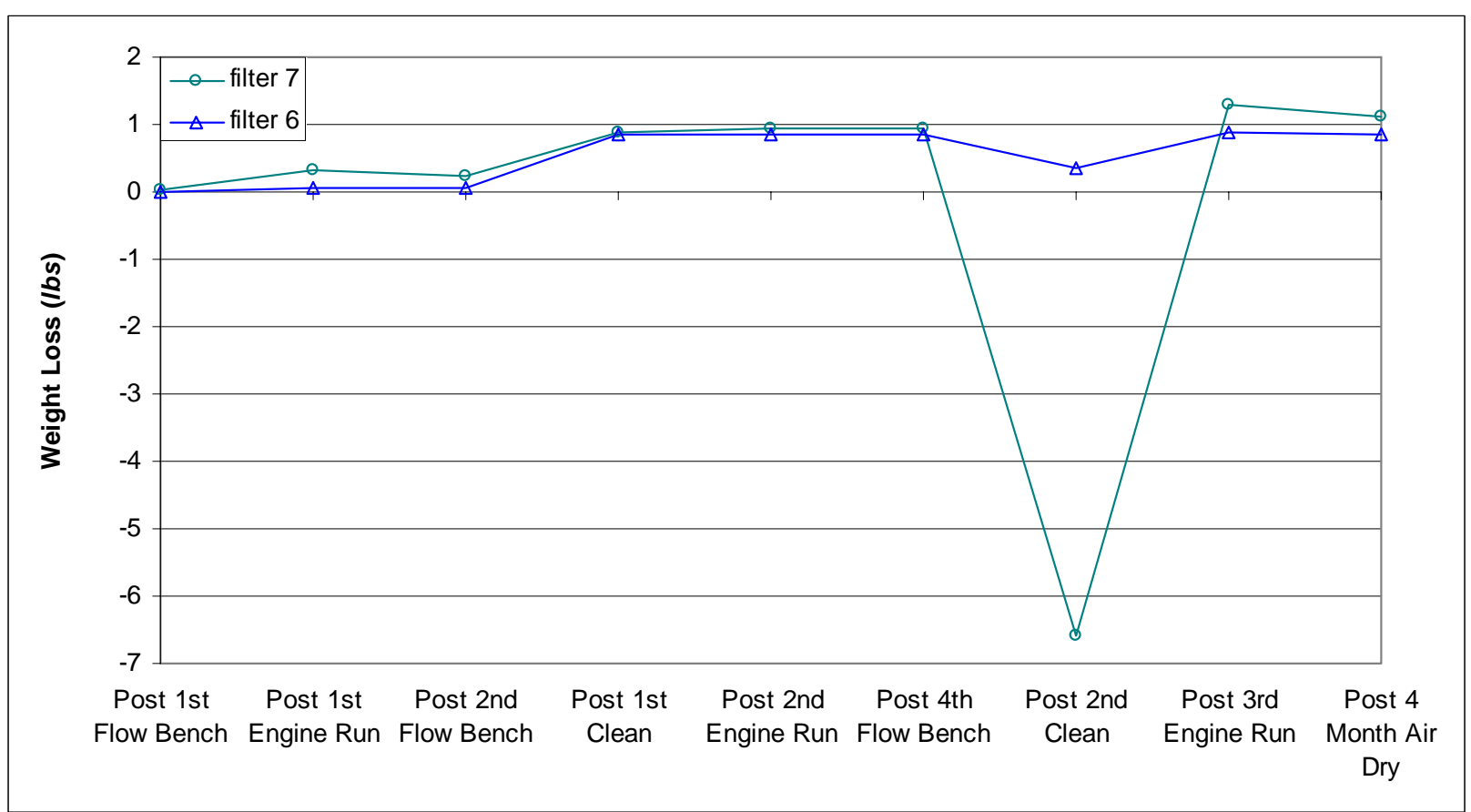

Figure 4-7 Mass Lost During Each Stage of Testing for Two Complete DPF Systems

\subsection{Engine Pressure Difference}

The pressure difference across both complete DPF systems was recorded during each of the engine runs. Figure 4-8 below shows the results of the average differential pressure measurements for each engine run performed on filter 6. The remaining differential pressure graphs for the engine runs can be found in Appendix C. Note that the volumetric flow rate for the differential pressure during engine testing is in $a c f m$ in order 
to keep the data points separated to make the graphs more presentable. The drop in pressure difference across the filter following a cleaning cycle can be seen from Figure 4-8 below. Following the first cleaning cycle it is shown that there is an observable reduction in the differential pressure across the final five modes of testing. The slight increase in the differential pressure following the second cleaning may be do to a small amount of water still contained in the filter brick following the water cleaning, although it is still lower than the initial pressure difference.

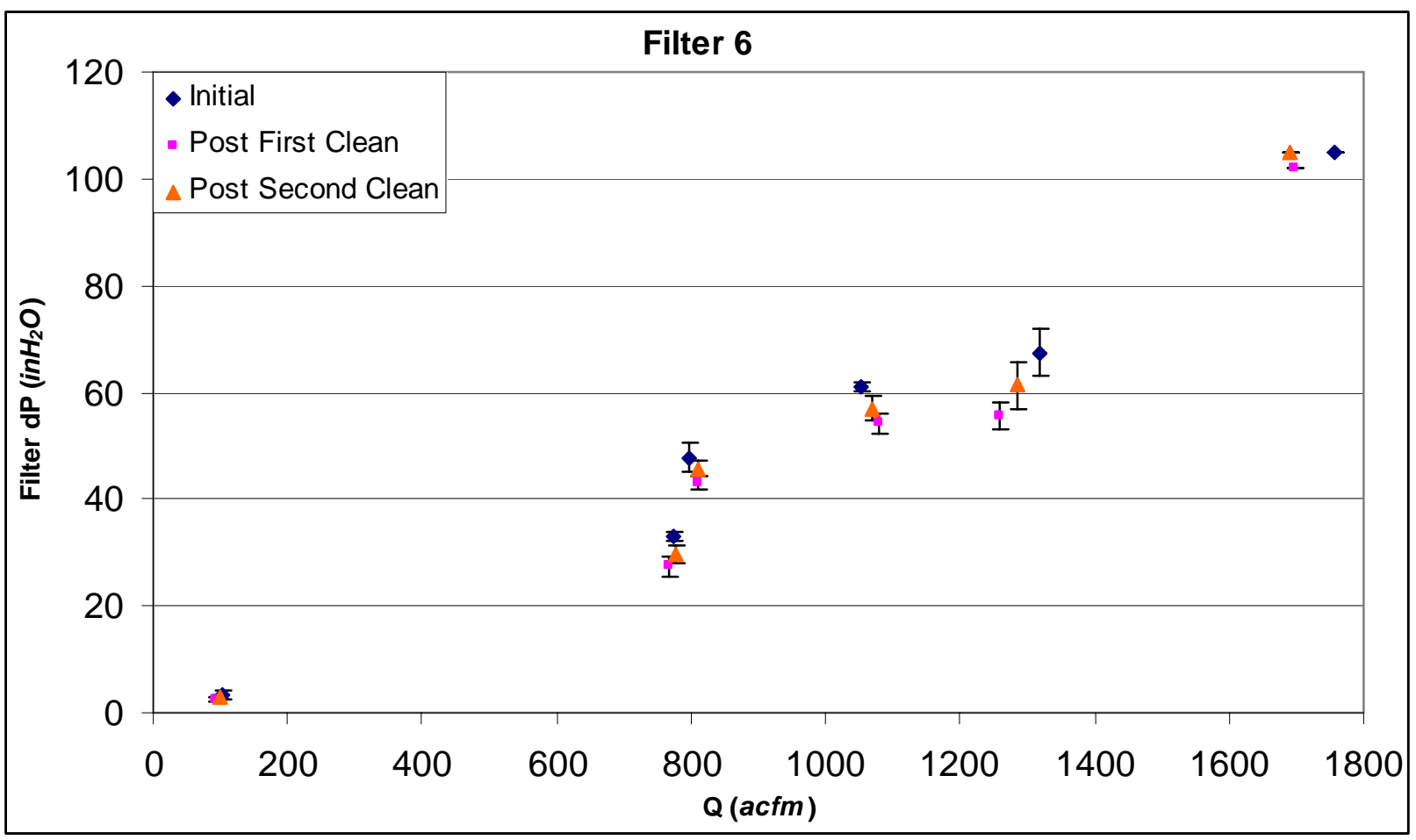

Figure 4-8 Pressure Difference During Engine Testing for Filter 6

The differential pressure produces a linear trend as indicated in Figure 4-9 below. The standard deviation of the differential pressure is indicated in both Figures 4-8 and 49. This partially explains the deviation of the data from the linear trend. 


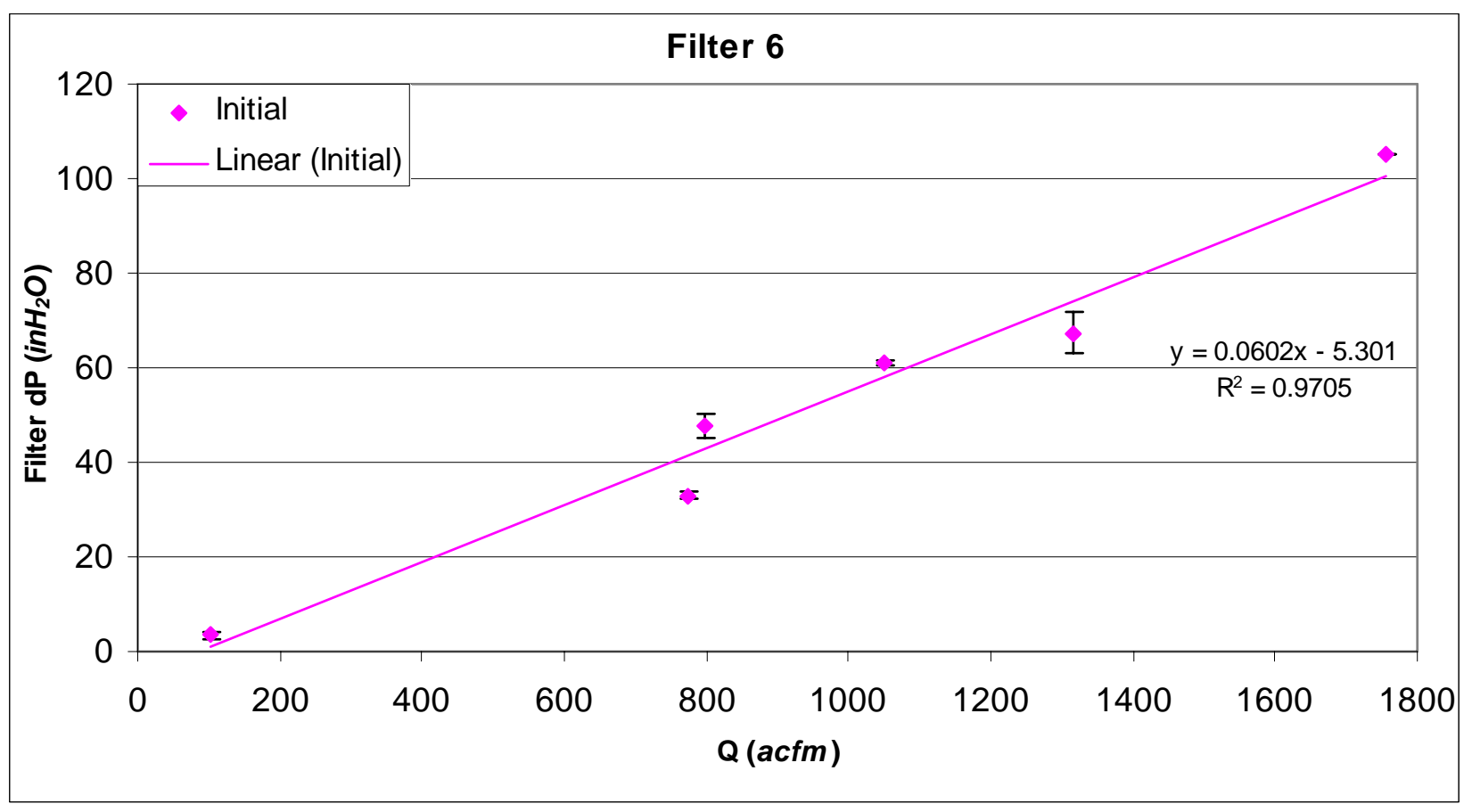

Figure 4-9 Pressure Difference for the Initial Engine Testing for Filter 6

Another possible cause for the deviation from the trend is the error in the actual filter temperature. Temperature probes were placed approximately $5 \mathrm{ft}$ in front and $20 \mathrm{ft}$ behind the DPF, Figure 4-10 below shows representative results from filter 6 . As shown in the figure, the exhaust temperature had not reached steady state due to time and fuel constraints. These variations in the filter temperature could be the cause of the variations of the pressure drop across the filter due to the change in the exhaust gas viscosity. This possibility is drawn from the larger deviation of the pre and post filter temperature measured from the second and third mode which corresponds to the two points significantly lower then the indicated trend line on Figure 4-9. The flow rate calculations were preformed using the pre-filter temperature measurements. 


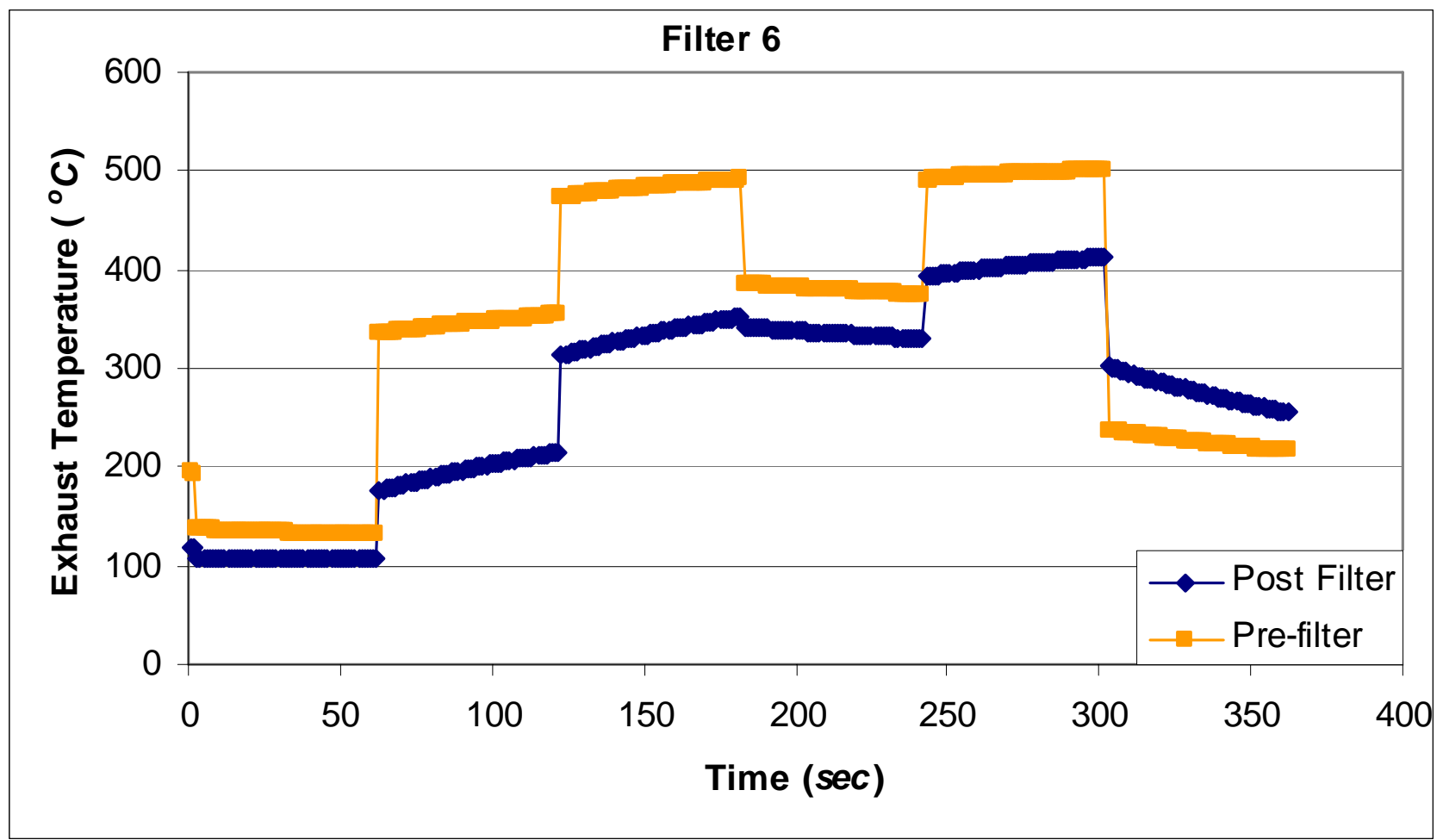

Figure 4-10 Exhaust Temperature Difference During Engine Testing for Filter 6

\subsection{Modeling Results}

The modeling of the compete DPF systems was separated to compare the flow bench and engine test differential pressure data. The model yielded a good fit for both data sets as shown in Figures 4-11 and 4-12 below. The model and experiment number corresponds to the series of flow bench and engine tests performed on filter 6 for Figures 4-11 and 4-12, respectively. The experimental data points shown in the figures are the same as those found in Figures 4-3 and 4-8. 


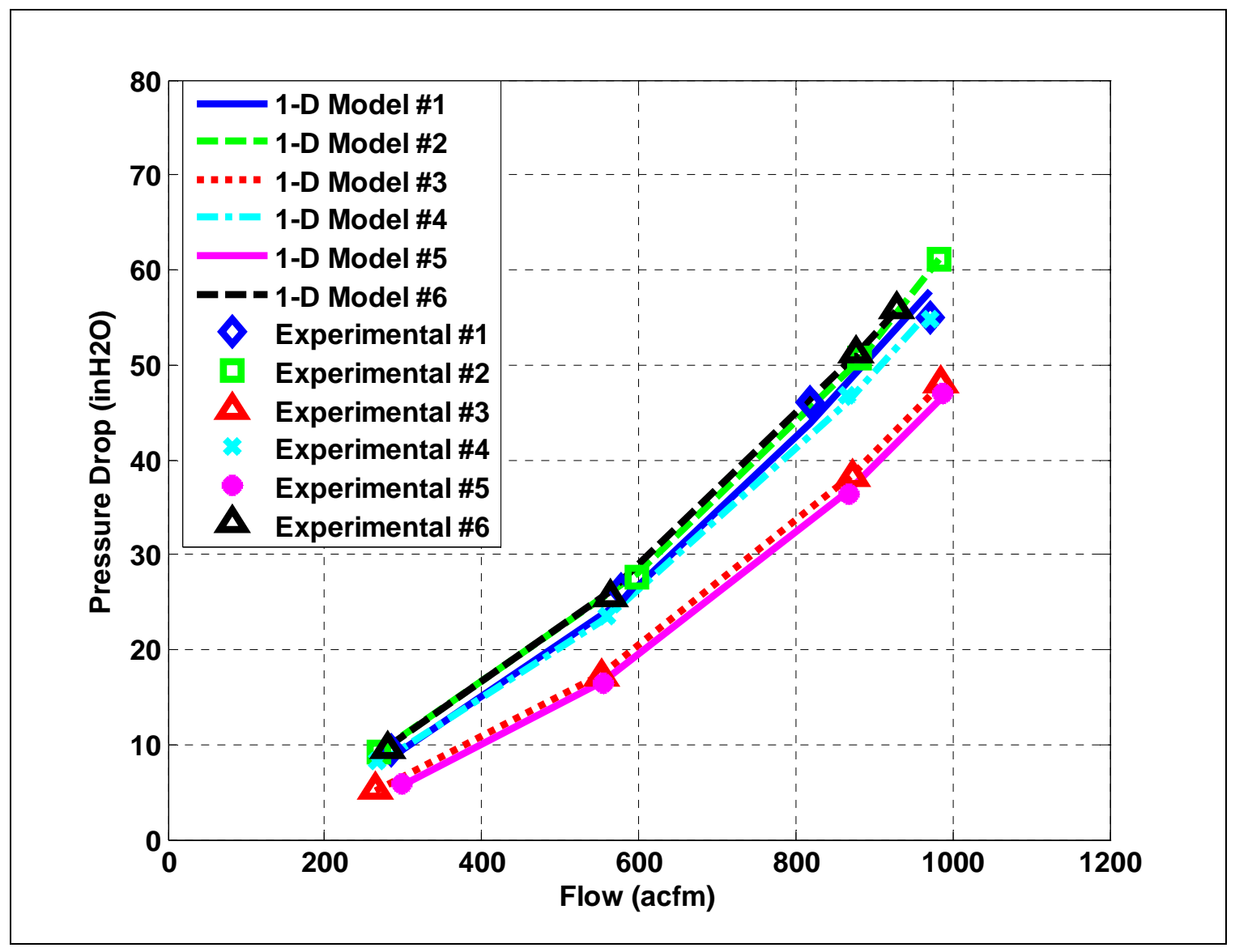

Figure 4-11 Modeling Fit to Filter 6's Flow Bench Results

In Figure 4-12, the model follows the order of the engine test cycle. As discussed in the previous section the variations in the differential pressure may be due to the variation in the actual temperature of the DPF. The modeling results for filter 7 show a similar trend and can be found in Appendix D. 


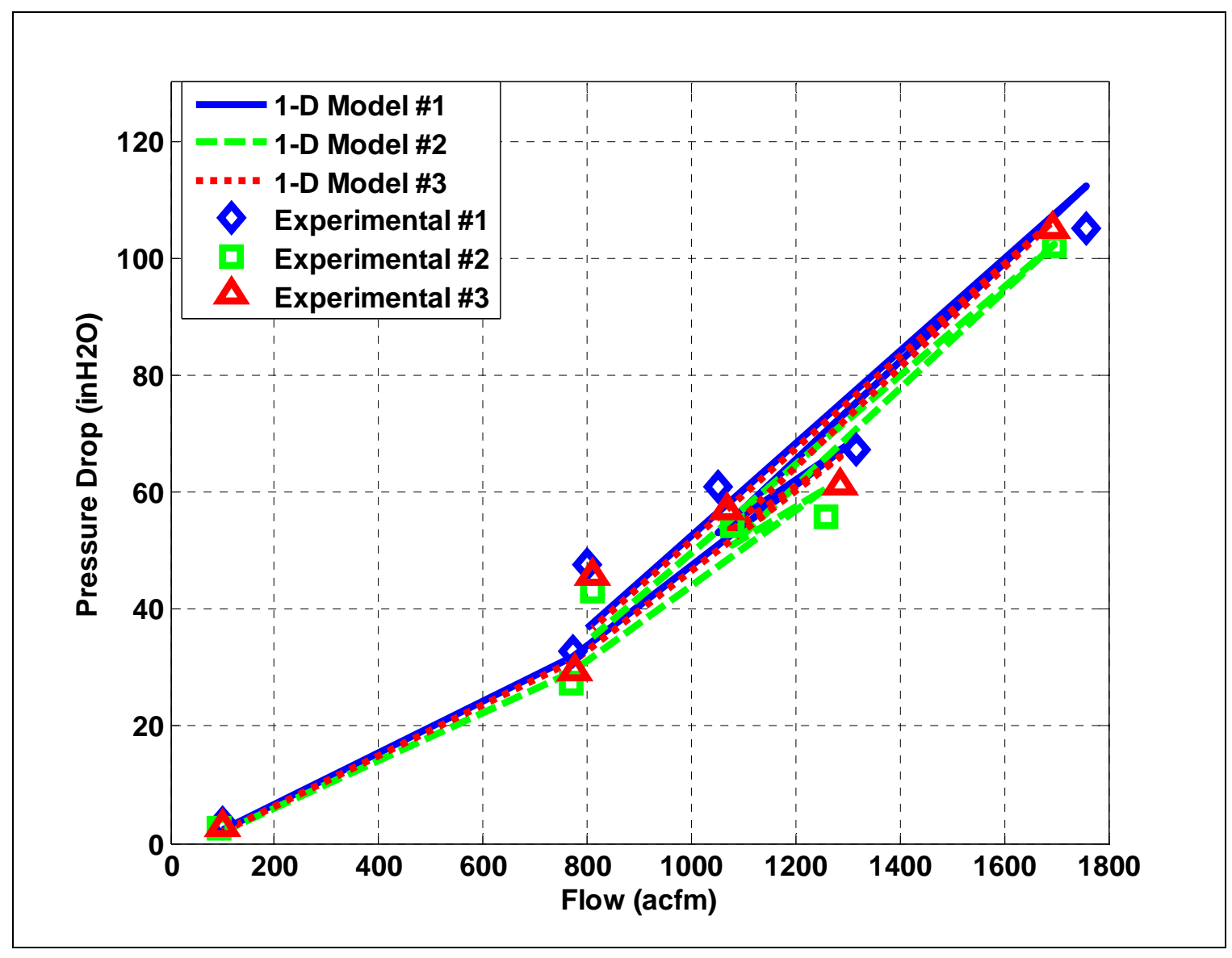

Figure 4-12 Modeling Fit to Filter 6's Engine Test Results

Figure 4-13 below displays the linear fit of the model predicted differential pressure to the experimental differential pressures for both filters. The model had a reasonable fit with an $\mathrm{R}^{2}$ of 0.98203 , as indicated in the figure. Figure 4-14 shows the frequency analysis of the percent difference of the model predicted pressure difference to the experimental pressure difference. The percent difference was within $+/-10 \%$ for $76 \%$ of the experimental points with 18 out of 20 points outside the $+/-10 \%$ range coming from the engine test data. 


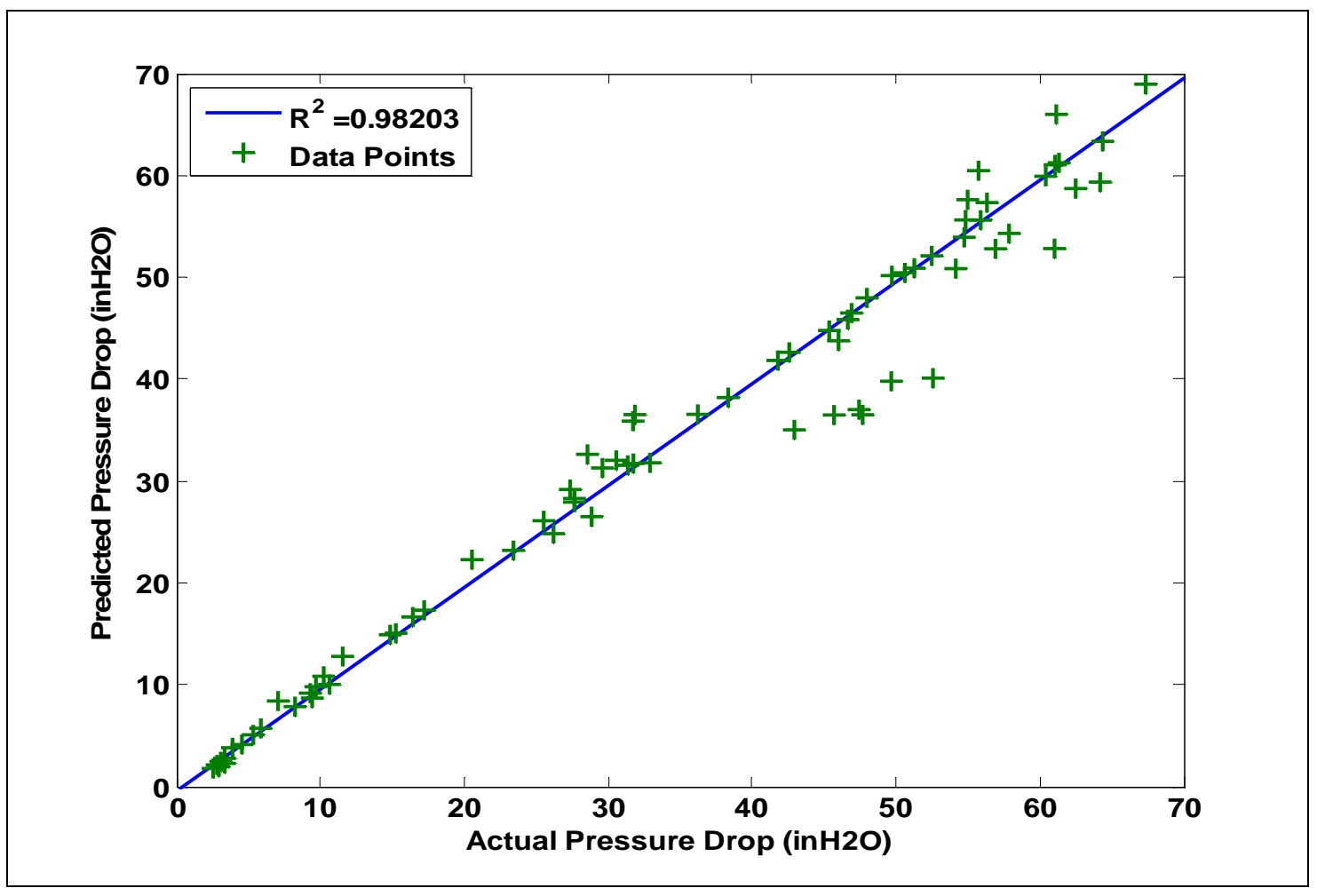

Figure 4-13 Comparison of Modeled and Actual Pressure Drop for Both Filters

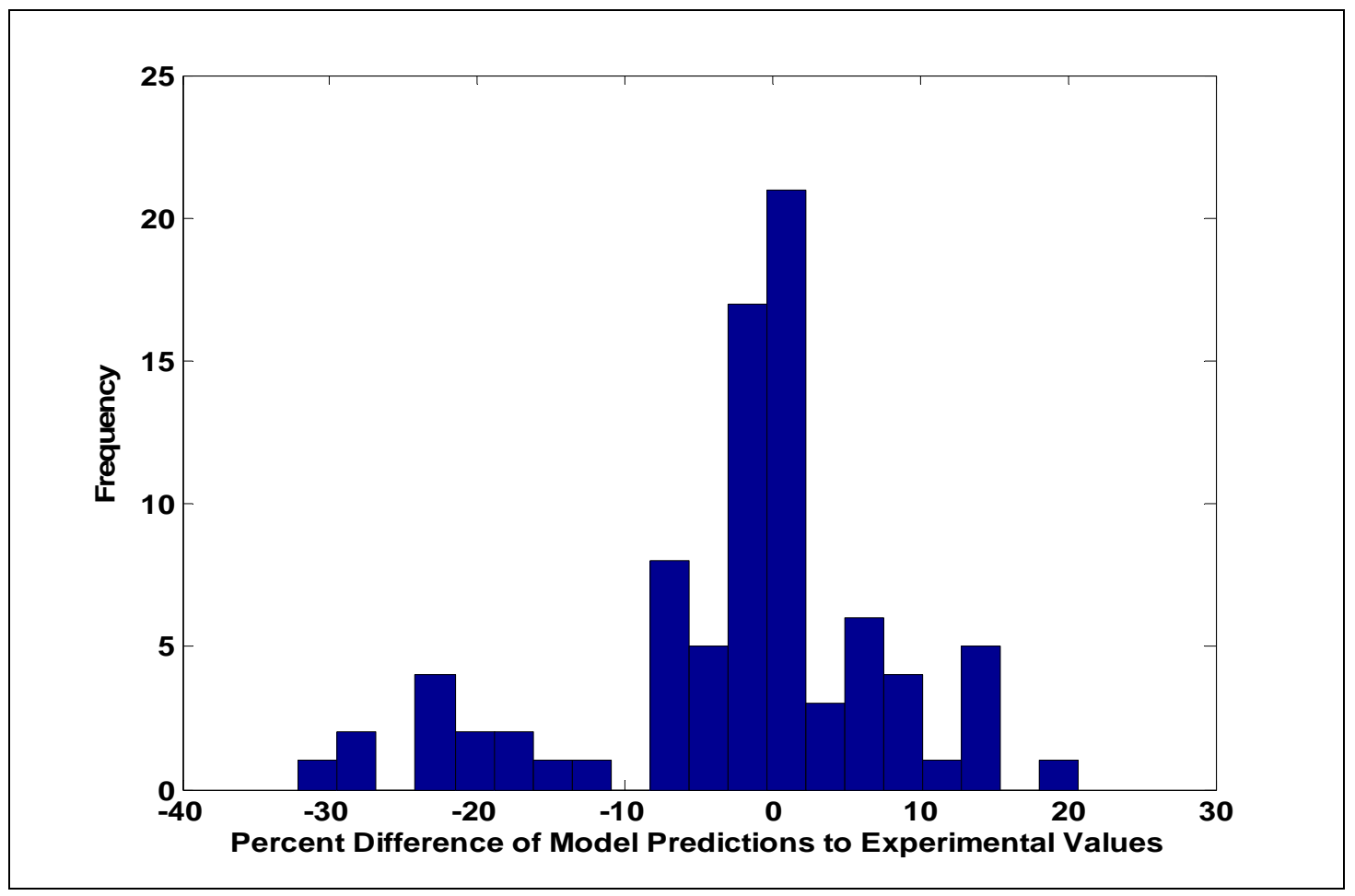

Figure 4-14 Frequency of Percent Error of Predicted to Experimental Pressure Drop 
Table 4-2 below shows the comparison of the range of the modeling parameters obtained from a similar study reported by Konstandopoulos [76], the first five filters [75] and the flow bench and engine models for filters 6 and 7 . As the table shows the modeling ranges for the engine data is within the ranges of the corresponding flow bench data. The permeability of the filter wall was found to on the order of $10^{-11}$ to $10^{-8} \mathrm{in}^{2}$. The larger filter wall permeability for the complete DPFs could be due to the diffusers and pre-filter catalyst, for filter 6, which were included in the differential pressure measurements. The particulates permeability was found to range from $10^{-12}$ to $10^{-11} \mathrm{in}^{2}$. The wall thickness of the particulate was found to be on the order of 0 to $10^{-3} \mathrm{in}^{2}$.

Table 4-2 Comparison of the Range of Modeling Parameters

\begin{tabular}{|c|c|c|c|}
\hline Parameter & $\mathrm{k}\left(\mathrm{in}^{2}\right)$ & $\mathrm{k}_{\mathrm{p}}\left(\mathrm{in}^{2}\right)$ & $\mathrm{w}_{\mathrm{p}}(\mathrm{in})$ \\
\hline $\begin{array}{c}\text { Konstandopoulos } \\
\text { Model Range } \\
{[76]}\end{array}$ & $2.79 \mathrm{E}-10$ & $2.79 \mathrm{E}-11$ & 0 \\
\hline $\begin{array}{c}\text { Initial Five Filters } \\
\text { Modeling Range } \\
{[75]}\end{array}$ & $1.32 \mathrm{E}-10$ & $8.41 \mathrm{E}-11$ & $1.57 \mathrm{E}-02$ \\
\hline Flow Bench & $1.22 \mathrm{E}-09$ & $1.49 \mathrm{E}-10$ & $1.18 \mathrm{E}-02$ \\
\hline Modeling Range & $2.20 \mathrm{E}-09$ & $8.78 \mathrm{E}-11$ & $1.00 \mathrm{E}-03$ \\
\hline Engine Modeling & $2.32 \mathrm{E}-07$ & $1.50 \mathrm{E}-10$ & $1.80 \mathrm{E}-02$ \\
Range & $1.32 \mathrm{E}-07$ & $1.07 \mathrm{E}-10$ & $4.70 \mathrm{E}-03$ \\
\hline
\end{tabular}




\section{CONCLUSIONS AND RECOMMENDATIONS}

\subsection{Conclusions}

This study comprised of several investigations branching from the main task to develop a system for cleaning DPFs in operation. Each investigation was used to help further the development of some or all of the cleaning methods utilized in this study. The data collected from the numerous runs on the flow bench provided an insight into the effects of different cleaning methods as well as the effectiveness of using the pressure drop across each filter as a determination of its cleanliness.

The lack of a pattern found from measuring the depth of the blockage in the substrates of each filter eliminates the possibility of focusing any cleaning methods on a particular area. Although certain areas of the filter may have blockage that is more compact, the effective flow through area of the substrates is reduced throughout the filter. This method is also subject to the diameter of the rod used to obtain the measurements. The results indicate that it is important to perform any cleaning procedure on the entire face of the filter to ensure the best possible results.

Observing the results of the weight loss of filters 1-5, indicates that most of the particulate was removed (an average of $60.6 \%$ of the total mass removed) from the filters during the initial pressurized air cleaning showing almost no improvements after approximately 10 minutes of air cleaning. Similar results were shown by the filter pressure drop with an average of $71.0 \%$ of the total loss in the measured differential pressure across the filter occurring after the first compressed air cleaning. This may be attributed to the initial removal of a built up layer of PM in the filter channels followed 
by a slow removal of remaining PM embedded in the porous filter walls. Another possibility is that air flows through the open ends of the passages and exits through the passage walls downstream. This would allow the air to go around the blocked ends of the passages rather than removing the blockage. Water cleaning may be more effective in removing the blocked ends that air could flow around. This gradual improvement may not justify any further efforts after 30 minutes of pressurized air cleaning despite the knowledge that further improvements were made using a water cleaning method.

Both the filter pressure drop and the weight loss results of filters 1-5 showed that using a water cleaning method was a better alternative to pressurized air cleaning. However, this method may be destructive to the matting material inside the filter canister and is not recommended unless the filter is designed specifically to withstand water cleaning.

The results of the engine tests performed on the complete DPF systems provide only tentative trends due to the lack of repeated trials and the filters unknown history prior to testing. Filter 6, which was uncatalyzed returned to the pre-testing differential pressure across the filter following engine test cycles. Filter 7 also showed a trend similar to this, which may be due to operating the filters on an oversized engine. This trend was not supported by an observed weight loss that occurred for filter 7 following the engine test cycles. This could only be explained by the regeneration processes occurring when the diesel engine exhaust reached the appropriate temperature. This process could not occur in filter 6 because the filter brick was uncatalyzed.

The two measures for how effective the cleaning cycles used were the pressure drop across the filter at various flow rates and the weight loss of the filter. The 
differential pressure measurement appears to be a logical choice since the necessity of cleaning the filters comes from the build up of backpressure while operating on a diesel engine. Following the test results of the filters 6 and 7 indicating how quickly the differential pressures go back the fully loaded range, validates the tracking of the weight loss associated with each testing and cleaning cycle.

The modeled differential pressure closely matched the experimental data collected from the flow bench and engine testing. The parameters found using the modeling analysis agreed with values found in similar studies. The use of these parameters, such as the permeability of the filter wall and PM, can be used to determine the effectiveness of a cleaning method. To obtain the most accurate model and better evaluate the effectiveness of a cleaning procedure, the clean filter model should be acquired before the filter is operated on an engine.

\subsection{Recommendations}

The best cleaning method determined by this study is to use a water cleaning cycle. The use of the water cleaning cycle further improved both the pressure loss across the filter and the weight loss after the pressurized air cleaning method had been almost completely ineffective. Since each of the water cycles used in this study followed a series of pressurized air cleaning cycles the extent of effectiveness of a water cleaning alone was not determined so a 30 minute pressurized air cleaning is recommended before a 20 minute water cleaning cycle. If the DPF is not designed to withstand a water cleaning then only the 30 minute pressurized air cleaning should be used. Monitoring weight loss and the drop in the differential pressure should be used to determine when a filter is clean. The best possibility would be to monitor both of weight and differential pressure 
while the cleaning cycle is performed and stop the cleaning cycle once the changes in these parameters had leveled off.

A further study could be performed for improving the cleaning cycle if water is not a viable option such as utilizing a baking cycle or using pulsating air blasts. For additional studies filter passage measurements could be made following the first pressurized air cleaning to determine if the majority of the substrate blockage is removed in the initial cleaning as indicated by the differential pressure loss in this study. A measured crossing pattern using rods with several diameters could be utilized to get a more detailed record of the effects of cleaning on the passage lengths and reduce the considerable time needed to carefully obtain the profile. An unused or "clean" filter could also be subjected to the same cleaning and testing procedures to determine if the weight and differential pressure is affected by these procedures.

Additional engine testing could also be performed using several filters that the histories of use were known. An appropriate sized engine and DPF systems should also be used to get a better indication of the trends that occurred following an engine test cycle. The specific engine and test cycle used for testing can affect the composition and extent of the soot deposited in the filter as well as the regeneration process. Thus, numerous tests with various testing cycles and engines should be repeated to confirm the trends observed in this study. Also temperature probes should be placed as close as possible to the inlet and outlet of the DPF during engine testing and the exhaust temperature should be monitored closely to ensure that it had time to stabilize.

The additions to the engine tests would also improve the accuracy of the modeling parameters and the differential pressure predictions for the engine cycles. As mentioned 
in the previous section, the clean filter model should be acquired before the filter is operated on an engine to ensure a more accurate filter wall permeability value. A second set of pressure taps should be used to isolate the filter so the differential pressure measurements would not include the diffuser sections and any pre-filter catalysts. 


\section{REFERENCES}

1. National Emissions Standards Act. U.S. Environmental Protection Agency, Washington Office, Washington, DC, 42 U.S.C. 7401.

2. Manufacturers of Emission Controls Association. "Diesel Particulate Filter Maintenance: Current Practice and Experience.” Washington, D.C. 21 Nov. 2005. <www.meca.org>.

3. Igarashi, T., M. Shimoda, T. Otani, K. Tsuchihashi and M. Shigemori. “Development of Diesel Particulate Trap System for City Buses.” SAE 910138, 1991.

4. McMillian, M.H., M. Cui, M. Gautam, M. Keane, T. Ong, W. Wallace, and E. Robey. "Mutagenic Potential of Particulate Matter for Diesel Engine Operation of Fischer-Tropsch fuel as a Function of Engine Operating Conditions and Particle Size.” SAE 2002-01-1699, 2002.

5. Howitt. J.S. "Particulate Control Technology for Light and Heavy Duty Diesel Powered Vehicles.” ASME paper 0402-1215, 1985.

6. “40 CFR Parts 80, 85, 86.” U.S. Environmental Protection Agency, Federal Register. Vol. 65, No. 28, February 10, 2000.

7. Kittelson, D.B. "Engines and Nanoparticles: A Review.” Journal Aerosol Science. 1998a., 5/6 (29): 575-588.

8. "Health Assessment Document for Diesel Engine Exhaust.” U.S. Environmental Protection Agency, Office of Research and Development, National Center for Environmental Assessment, Washington, DC, EPA/600/8-90/057F, 2002.

9. Part B: Health Risk Assessment for Diesel Exhaust.” California Environmental Protection Agency. Office of Environmental Health Hazard Assessment, Sacramento, CA, 1998.

10. Stober, W. "On the Health Hazards of Particulate Diesel Engine Exhaust Emissions.” SAE 871988, 1987.

11. Clark, N., J. Prucz, M. Gautum and D. Lyons. "The West Virginia University Heavy Duty Vehicle Emissions Database as a Resource for Inventory and Comparative Studies.” SAE 2000-01-2854, 2000.

12. Lev-On, M., C. LeTavec, J. Uihlein, K. Kimura, T. Allemen, D. Lawson, K. Vertin, M. Gautam, G. Thompson, W. Wayne, N. Clark, R. Okamoto, P. Rieger, G. Yee, B. Zielinska, J. Sagebiel, S. Chaterjee and K. Hallstrom. "Speciation of Organic Compounds from the Exhaust of Trucks and Buses: Effects of Fuel and After-Treatment on Vehicles Emission Profiles.” SAE 2002-01-2873, 2002. 
13. Tan, P., K. Deng, and J. Lu. "Analysis of Particulate Matter Composition From A Heavy-Duty Diesel Engine.” Automobile Engineering. Vol. 218, November 2004: 1325-1331.

14. Lev-On, M., C. LeTavec, J. Uihlein, T. Alleman, D. Lawson, K. Vertin, G. Thompson, M. Gautam, S. Wayne, B. Zielinska, J. Sagebeil, S. Chatterjee, and K. Hallstrom. "Chemical Speciation of Exhaust Emissions from Trucks and Buses Fueled on Ultra-Low Sulfur Diesel and CNG.” SAE 2002-01-0432, 2002.

15. Harrison. R.M. “Airborne particulate matter in the United Kingdom.” Third report of the quality of urban air review group, The University of Birmingham, Edgbaston England, 1996.

16. Needham, J. "Engine Experience and EPA Regulations." University of Minnesota Short Course "Diesel Particulate Matter. 1991. 11 Nov. 2005 $<$ http://www.dieselnet.com/tech/engine_design.html $>$.

17. Karim, G.A. and G. Ward. "The Examination of the Combustion Processes in a Compression-Ignition Engine by Changing the Partial Pressure of Oxygen in the Intake Charge.” SAE 680767, 1968.

18. Hillard, J.C. and J.A. Levendis. "Effect of Oxygen Enrichment on the Performance and Emissions of I.D.I. Diesel Engines.” SAE 830245, 1983.

19. Ikeya, D., N. Kondoh, D. Ishiehara, T. Tomita, and A. Ohkita. "Hybrid Charging System for Heavy Duty Diesel Engines.” SAE 910419, 1991.

20. Tanin, K., D. Wickman, S. Montgomery, and R. Reitz. "The Influence of Boost Pressure on Emissions and Fuel Consumption of a Heavy-Duty Single-Cylinder D.I. Engine.” SAE 1999-01-0840, 1999.

21. Browning, L.H. "Technologies and Costs for On-Road Heavy-Duty Engines Meeting 2004 Emissions Standards.” SAE 973256, 1997.

22. Zelenka, P., P. Kriegler, W. Herzog, and W. Carellieri. "Ways Toward the Clean Heavy-Duty Diesel.” SAE 900602, 1990.

23. Sobotowski, R., B. Porter, and A. Pilley. "The Development of a Novel Variable Compression Ratio, Direct Injection Diesel Engine.” SAE 910484, 1991.

24. Kazutoshi, M., H. Jyoutaki, K. Kawai, and K. Sakai. "New Quiescent Combustion System for Heavy-Duty Diesel Engines to Overcome Exhaust Emissions and Fuel Consumption Trade-off.” SAE 2000-01-1811, 2000.

25. Pulkrabek, W. Engineering Fundamentals of the Internal Combustion Engine. $2^{\text {nd }}$ Edition. Upper Saddle River, NJ: Prentice Hall, 1997. 
26. Tsuruntani, K., Takei, Y., Fujimoto, Y., Matsudaira, J., and Kumamoto, M. "The Effects of Fuel Properties and Oxygenates on Diesel Exhaust Emissions.” SAE 952349, 1995.

27. Kidoguchi, Y., "Effects of Fuel Cetane Number and Aromatics on Combustion Process and Emissions of a Direct-Injection Diesel Engine.” SAE Review. Vol. 21, 2000: 469-475.

28. Li, X., "Influence of Diesel Fuel Cetane Number and Aromatic Content on Engine Exhaust Emissions.” Journal of Canadian Petroleum Technology. Vol. 37, 1998: 56-60.

29. McCarthy, C., W. Slodowske, E. Sienicki, and R. Jass. "Diesel Fuel Property Effects on Exhaust Emissions from a Heavy Duty Diesel Engine That Meets 1994 Emissions Requirements.” SAE 922267. 19992.

30. Lee, R., J. Pedley, and C. Hobbs. "Fuel Quality On Heavy Duty Diesel Emissions: A Literature Review.” SAE 982649, 1998.

31. Su, T., C. Chang, R. Reitz, P. Farrell, A. Pierpont, and T. Tow. "Effects of Injection Pressure and Nozzle Geometry on Spray SMD and D.I. Emissions.” SAE 952360, 1995.

32. Shimoda, M., K. Funai, K. Shimokawa, T. Otani, and I. Joko. “Application of Heavy Duty Diesel Engine to Future Emission Standards.” SAE 910482, 1991.

33. Shundoh, S., T. Kakegawa, K. Tsujimura, and S. Kobayashi. "The Effect of Injection Parameters and Swirl on Diesel Combustion with High Pressure Fuel Injection.” SAE 910489, 1991.

34. Verbeek, R., "DAF Euro-4 Heavy-Duty Diesel Engine with TNO EGR System and CRT particulate Filter.” SAE 2001-01-1947, 2001.

35. Sher, E.E. Handbook of Air Pollution from Internal Combustion Engines. Academic Press, Boston, 1998.

36. Khair, M. and D. McKinnon. "Performance Evaluation of Advanced Emissions Control Technologies for Diesel Heavy-Duty Engines.” SAE 1999-01-3564, 1999.

37. Ambs, J. and B. McClure, "The Influence of Oxidation Catalysts on NO2 in Diesel Exhaust.” SAE 932494, 1993.

38. "CRT." Johnson Matthey Catalytic Systems Division. 2002. 21 Nov. 2005 $<$ www.jmcsd.com>. 
39. Hammerle, R., D. Ketcher, R. Horrocks, G. Lepperhoff, G. Huthwohl and B. Luers. "Emissions from Diesel Vehicles with and without Lean NOx and Oxidation Catalysts and Particulate Traps." SAE 952391, 1995.

40. Khair, M. "Technical and Synergistic Approaches Towards the Twenty-First Century Diesel Engine." SAE 972687, 1997.

41. "21st Century Diesel: A Clean Future." Auto Emissions Magazine, Number 14. Fall 1999.

42. Levin, M. and R. Baker. "Co-Fueling of Urea for Diesel Cars and Trucks”, SAE 2002-01-0290, 2002.

43. Hoard, J., "Plasma-Catalysts for Diesel Exhaust Treatment: Current state of the Art." SAE 2001-01-0185, 2001.

44. Levendis, Y., T. Panagiotou and M. Taslim. "Development of a Self-Cleaning Particle Trap for Diesel Engine Particulate Control.” SAE 900601, 1990.

45. Barris, M., “Durability Studies of Trap Oxidizer Systems.” SAE 900108, 1990.

46. "Wall-Flow Monoliths." Revision 2005.09. Ecopoint Inc. 30 June 2006 < http://www.dieselnet.com/tech/dpf_wall-flow.html>.

47. Wade, W. “Diesel Particulate Trap Regeneration Techniques.” SAE 810118, 1981.

48. Horiuchi, M., K. Saito, and S. Ichihara. "The Effects of Flow-through Type Oxidation Catalysts on the Particulate Reduction of 1990's Diesel Engines.” SAE 900600, 1990.

49. Francois, G., W. Cheng, C. Cheng. M. Sztenderowicz, J. Heywood, and N. Collings. "In-Cylinder Measurements of Residual Gas Concentration in a Spark Ignition Engine.” SAE 900485, 1990.

50. Fox, J., W. Cheng, and J. Heywood. "A Model for Prediction Residual Gas Fraction in SI Engines.” SAE 931025, 1993.

51. Sandquist H., J. Wallensten, K. Enwald, and S. Stromberg. "Influence of Valve Overlap Strategies on Residual Gas Fraction and Combustion in a SI Engine at Idle.” SAE 972936, 1997.

52. Adams T. "Effect of Exhaust System Design on Engine Performance." SAE 800319, 1980.

53. Takesa, K., T. Uchiyama, and S. Enamito. "Development of Particluate Trap System with Cross Flow Ceramic Filter and Reverse Cleaning Regeneration.” SAE 910326, 1991. 
54. Levendis, Y., T. Panagiotou, and M. Taslim. "Development of a Self-Cleaning Particle Trap for Diesel Engine Particulate Control.” SAE 900601, 1990.

55. Khalil, N. and Y. Levendis. "Development of a New Diesel Particulate Control System with Wall-Flow Filters and Reverse Cleaning Regeneration.” SAE 920567, 1992.

56. Cleaire Filter Cleaning System Manual, Cleaire Advanced Emission Controls, LLC., San Leandro, CA, 2005.

57. Fleetguard Diesel Particulate Filter Automated Cleaing System Manual, Fleetguard Emissions Solutions, Nashville, TN, 2005.

58. CombiClean Manuel, Lubrizol Engine Control Systems, Newmarket, ON, 2005.

59. Correspondence with Cummins and Fleetguard Emissions Solutions, Nashville, TN, 2005.

60. Correspondence with Donaldson Company, Inc., Minneapolis, MN, 2005.

61. Correspondence with Faurecia Exhaust Systems, Toledo, OH, 2005.

62. Alvesteffer, W. and L. Eget. "A Laminar Flow Element with a Linear Pressure Drop versus Volumetric Flow.” Teledyne Hastings Technical Papers. Proceedings of FEDSM, 1998.

63. Mariam’s Laminar Flow Element Manual, Meriam Process Technologies, Cleveland, OH. 21 Nov. $2005<$ www.meriam.com>.

64. Fluke 714 Thermocouple Calibrator Manual, Fluke Corporation, Everett, WA. 21 Nov. $2005<$ www.fluke.com>.

65. Heise PTE-1 Digital Calibrator Manual, Ashcroft Inc., Stratford, CT. 21 Nov. $2005<$ www.hiese.com>.

66. Fluke 713 G30 Pressure Calibrator Manual, Fluke Corporation, Everett, WA. 21 Nov. $2005<$ www.fluke.com>.

67. Omega Digital Thermo-hygrometer Manual, Omega Engineering Inc., Stamford, CT. 21 Nov. $2005<$ www.omega.com>.

68. Omega Differential Pressure Transducer Manual, Omega Engineering Inc., Stamford, CT. 21 Nov. $2005<$ www.omega.com>.

69. Viatran Differential Pressure Transducer Manual, Viatran Corp., Grand Island, NY. 21 Nov. $2005<$ www.viatran.com>. 
70. Validyne Differential Pressure Transducer Manual, Validyne Engineering Corp., Northridge, CA. 21 Nov. 2005 <www.validyne.com>.

71. Magnehelic Differential Pressure Gages Manual, Dwyer Instruments Inc., Michigan City, IN. 21 Nov. 2005 <www.dwyer-inst.com>.

72. Gibble, J. “Comparison of Heavy-Duty Diesel Engine Emissions Between an On-Road Route and Engine Dynamometer Simulated On-Road Cycle,” M.S. Thesis, Department of Mechanical and Aerospace Engineering, West Virginia University, Morgantown, WV, 2003.

73. Vellaisamy, R., “Assessment of $\mathrm{NO}_{\mathrm{x}}$ Destruction in Heavy-Duty Diesel Engines by Injecting Nitric Oxide into the Intake," M.S. Thesis, Department of Mechanical and Aerospace Engineering, West Virginia University, Morgantown, WV, 2005.

74. Model CD-11 Indicator Instruction Manual, Ohaus Corp., Pine Brook, NJ. 21 Nov. $2005<$ www.ohaus.com>.

75. Nuszkowski, J., G. Thompson, N. Moles, M. Chiaramonte, and J. Hu. "Pressure Drop and Cleaning of In-Use Ash Loaded Diesel Particulate Filters.” Paper Submitted to SAE: May, 2006.

76. Konsandopoulos, A., M. Kostoglou, E. Skaperdas, E. Papaioannou, D. Zarvalis and E. Kladopoulou. "Fundamental Studies of Diesel Particulate Filters: Transient Loading, Regeneration and Aging.” SAE 2000-01-1016, 2000. 


\section{APPENDIX A}

Filter Passage Measurement Graphs 
Each of the initial five filters blockage length was investigated by dropping metal rods into individual substrates and measured. The blockage had no particular pattern nor showed any particular area of heavier loading as can be seen in the figures included in this appendix. This indicates that there is no area on the filter that requires additional cleaning. Figures A-1 through A-4 depict the filter passage measurements for filters 1, 3 and 5. Each measurement had a readable accuracy of $+/-0.02$ inches. 


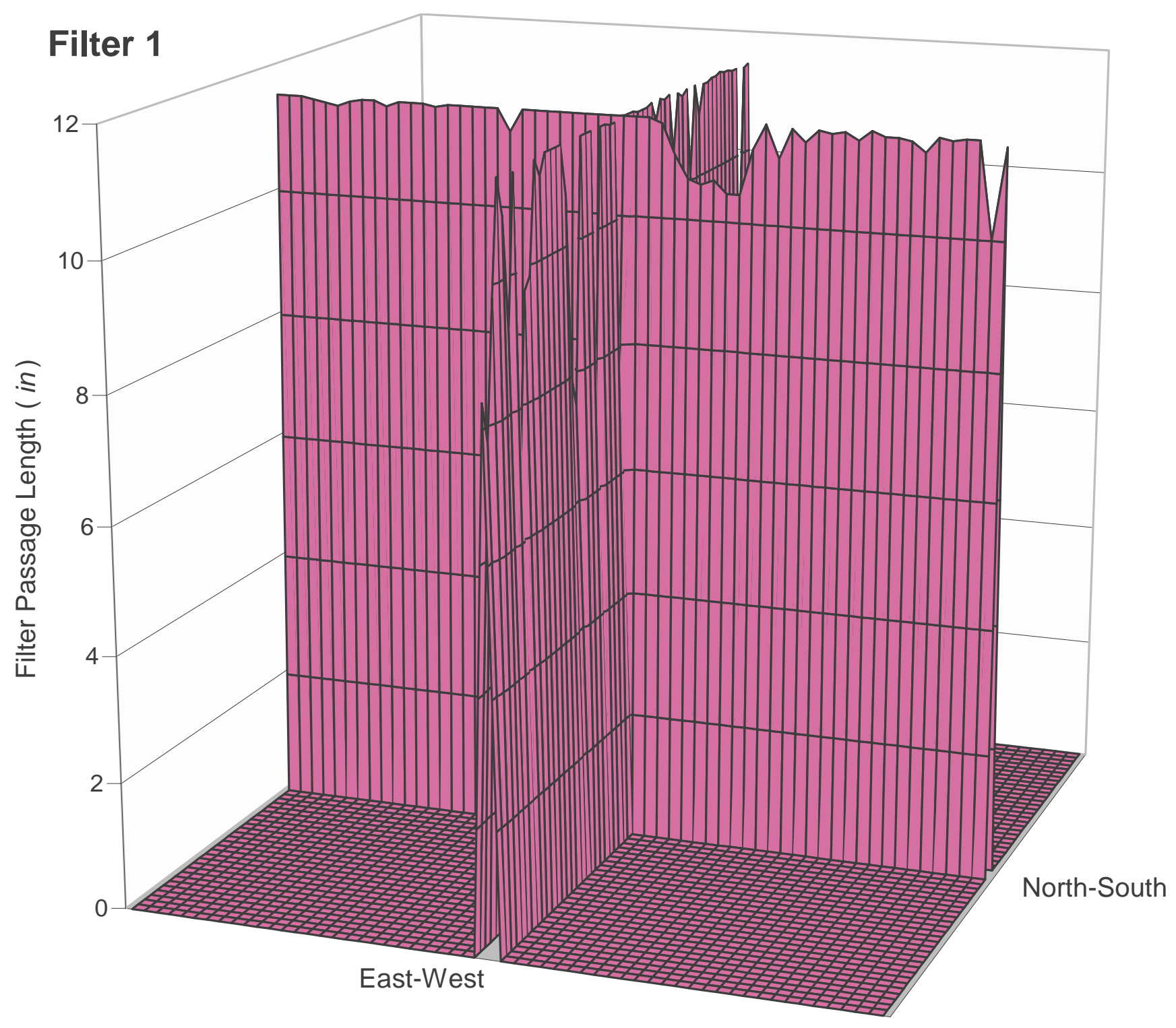

Figure A-1 Filter Passage Measurements for Filter 1 


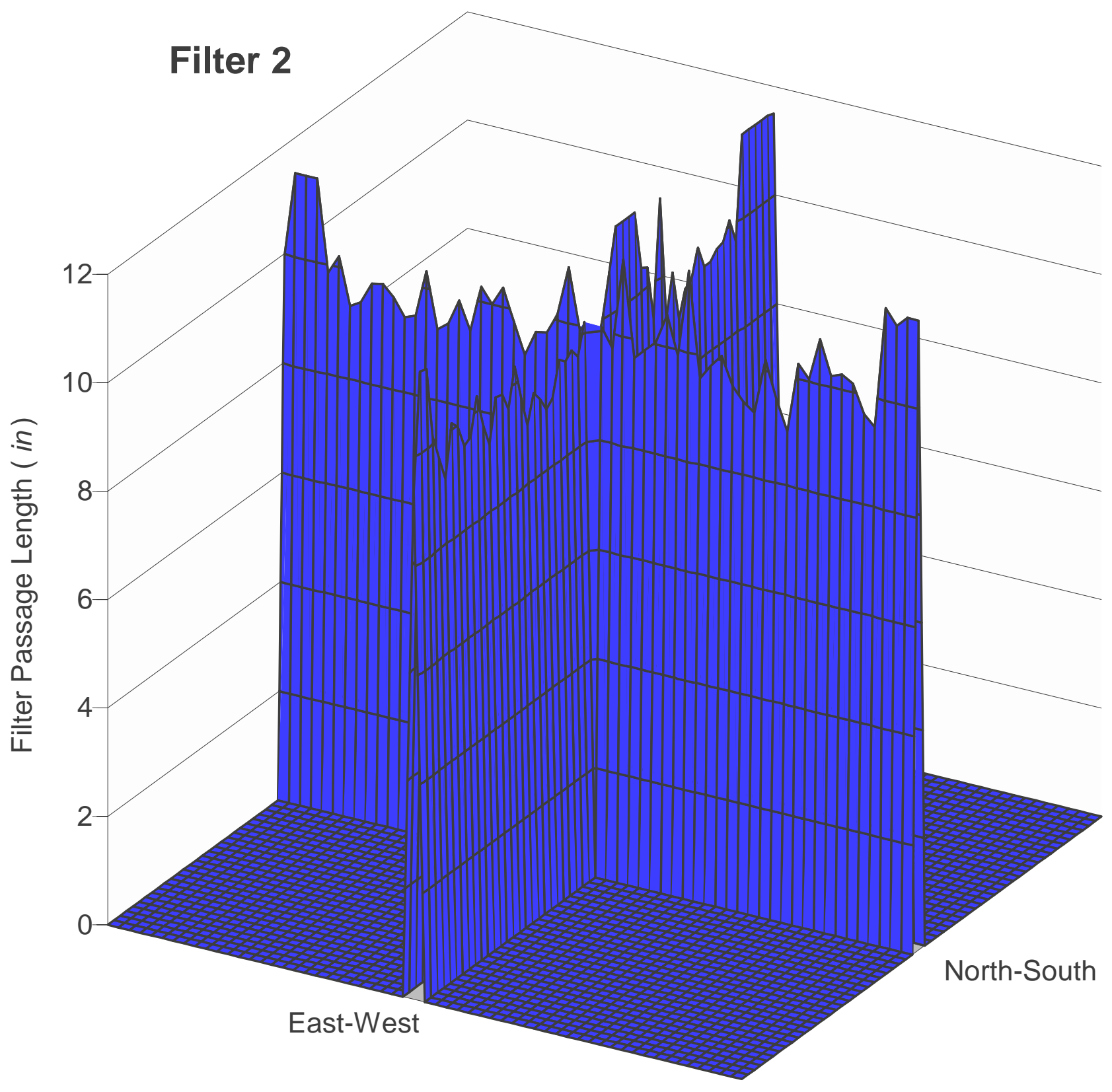

Figure A-2 Filter Passage Measurements for Filter 2 


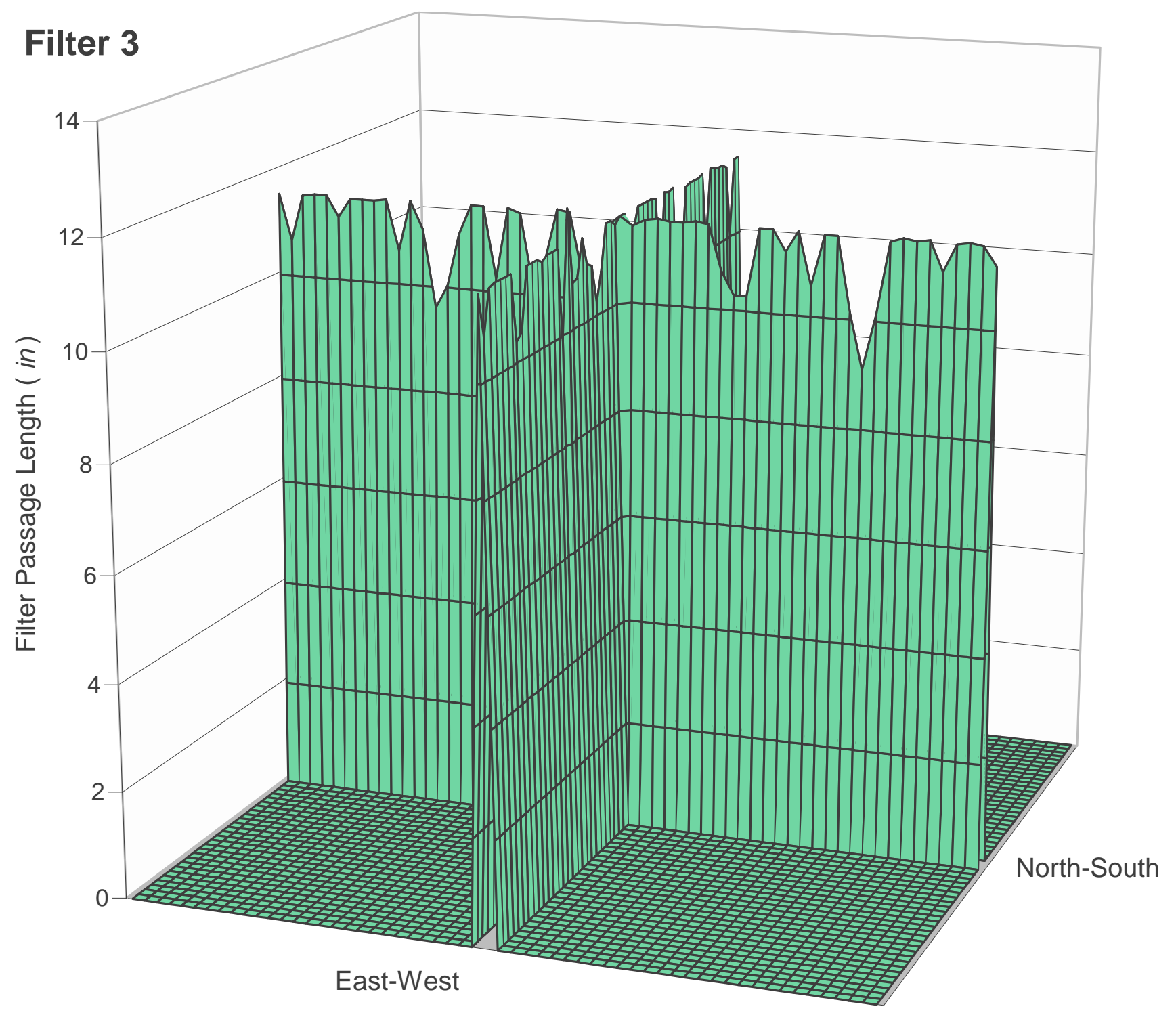

Figure A-3 Filter Passage Measurements for Filter 3 


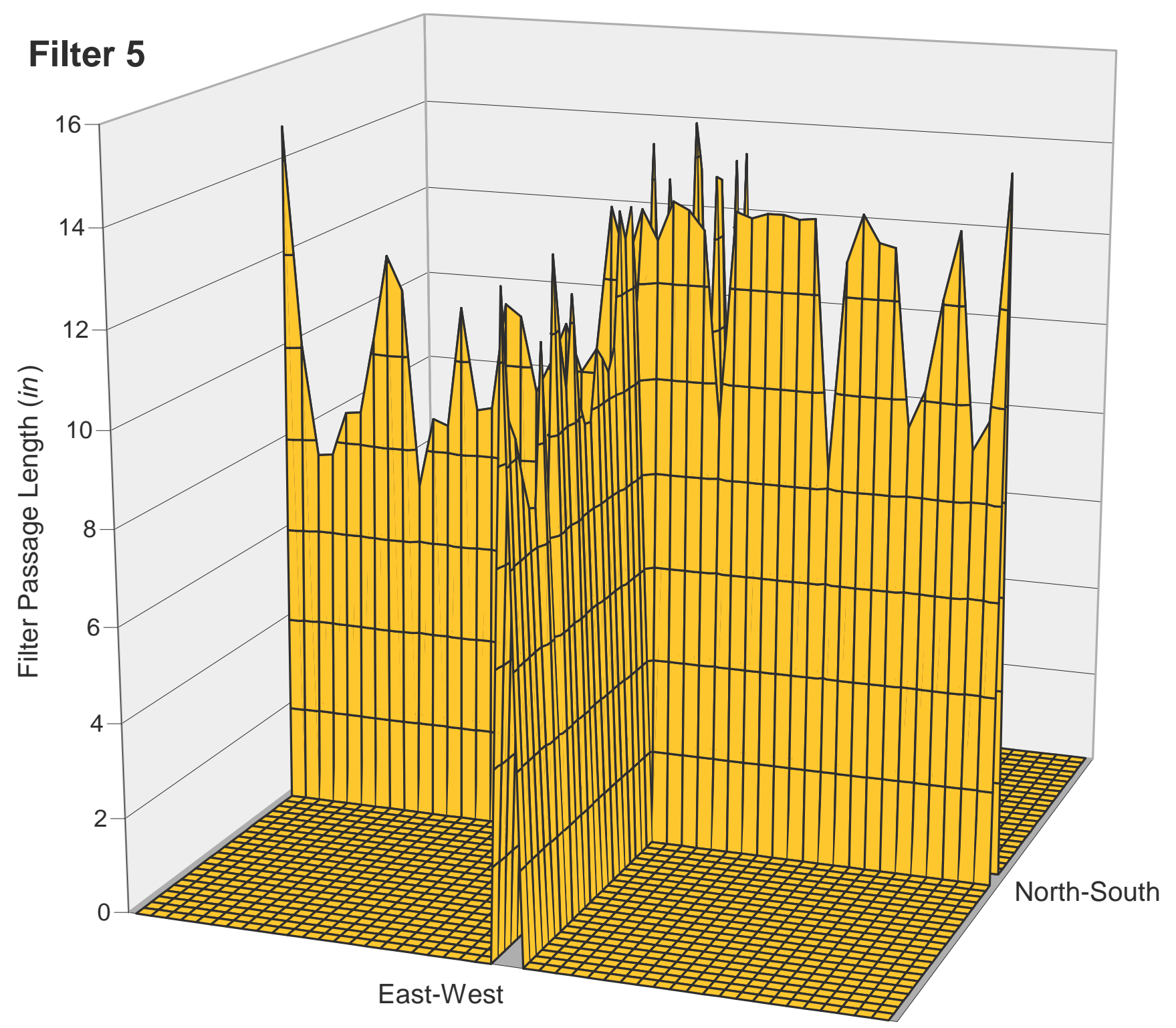

Figure A-4 Filter Passage Measurements for Filter 5 


\section{APPENDIX B}

Flow Bench Differential Pressure Graphs 
Figures B-1 through B-5 below show the trends observed through measuring the pressure difference across each filters 1-4 and the muffler on the flow bench. The drop in the filter pressure is parabolic, curving slightly upward as the flow rate is increased. The trends observed from the affects of cleaning are most noticeable for the higher flow rates. The first air cleaning cycle produced a significant reduction in pressure difference. Subsequent air cleanings produced much less significant reductions despite the extended time used for some of the cleaning cycles. Each filter that received a water cleaning cycle displayed an additional significant reduction in pressure difference across the filter. This occurred after little progress was shown by additional time for compressed air cleaning (three filters air cleanings totaled over a half hour). 


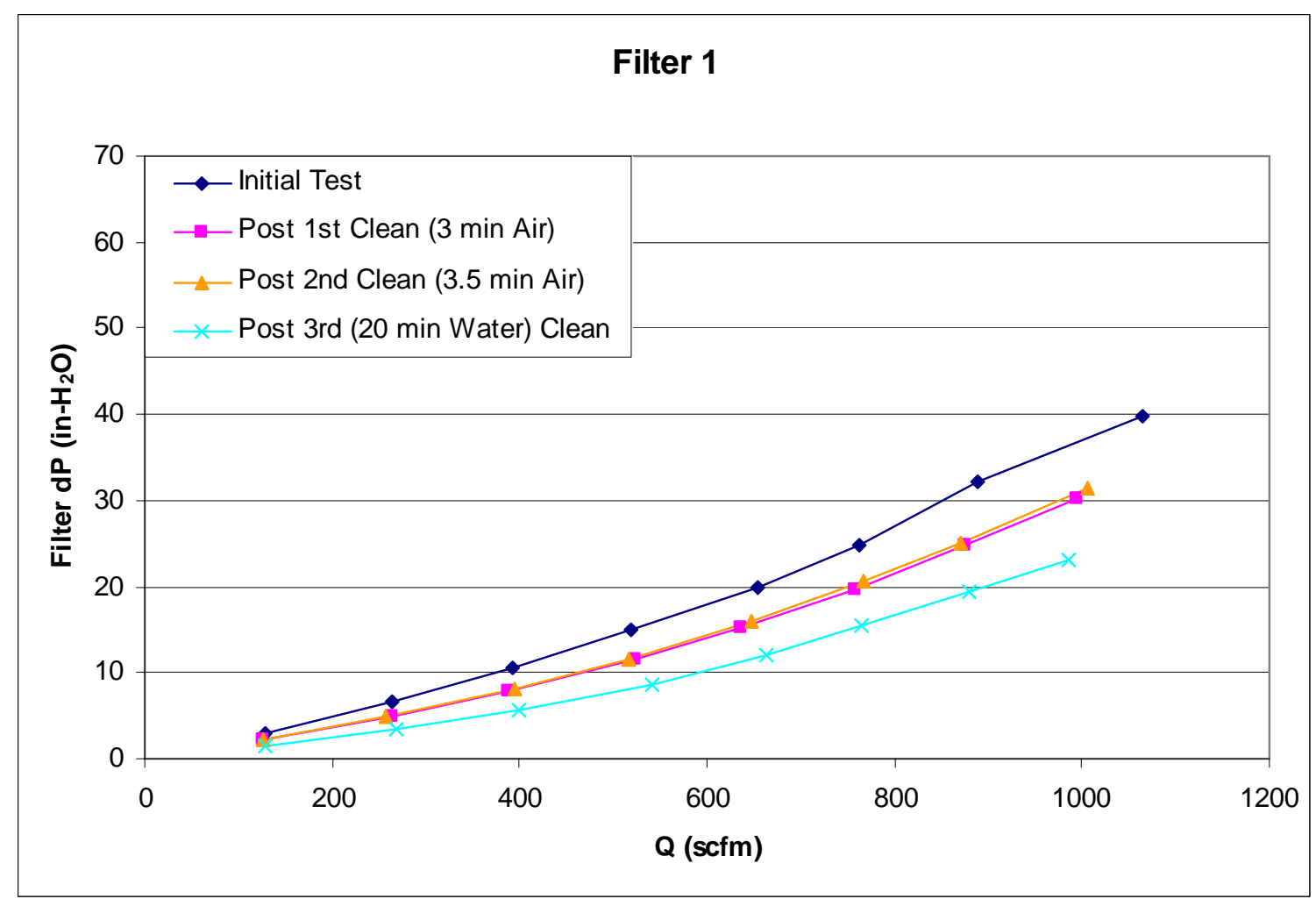

Figure B-1 Pressure Difference for Each Phase of Flow Bench Testing on Filter 1

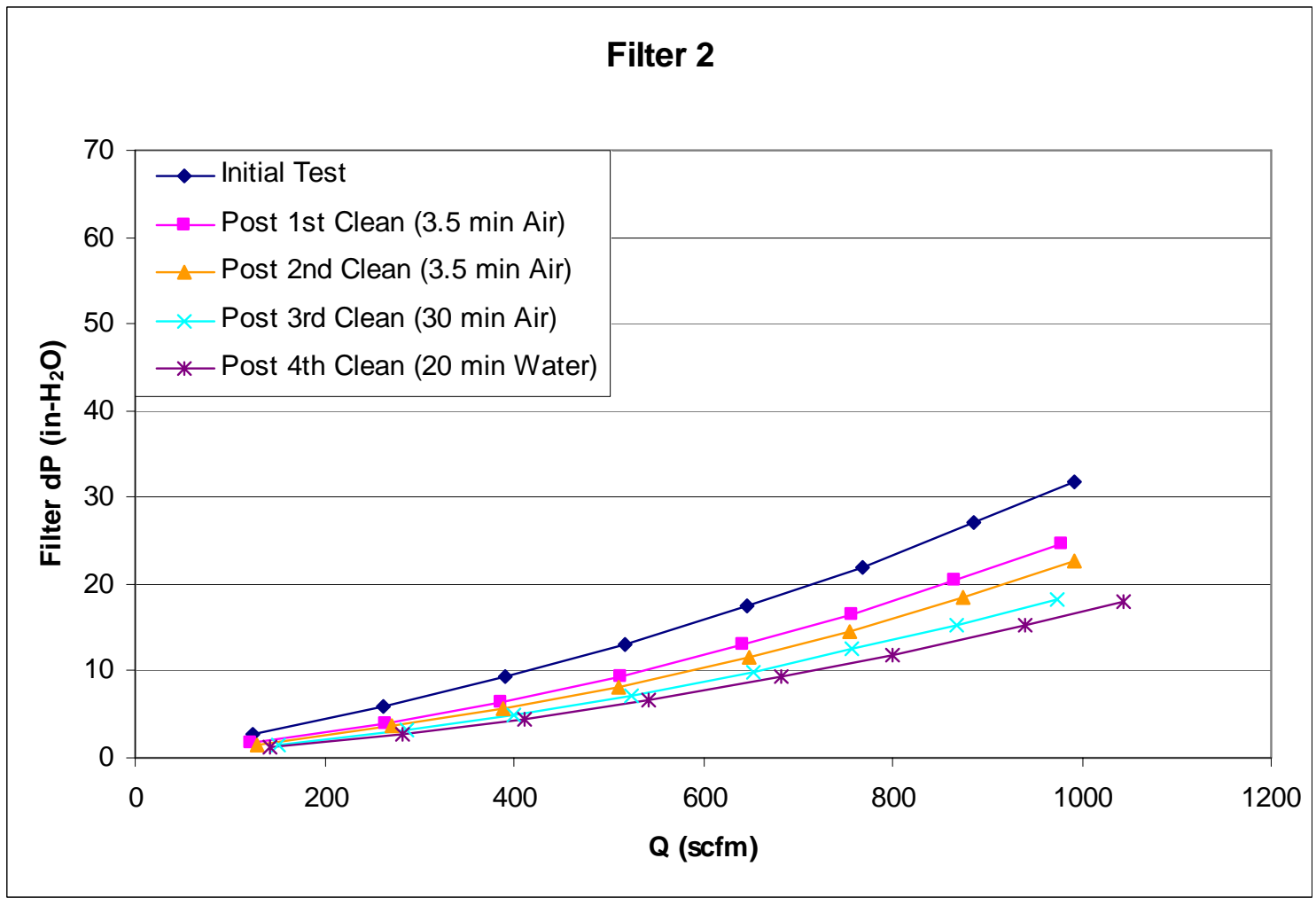

Figure B-2 Pressure Difference for Each Phase of Flow Bench Testing on Filter 2 


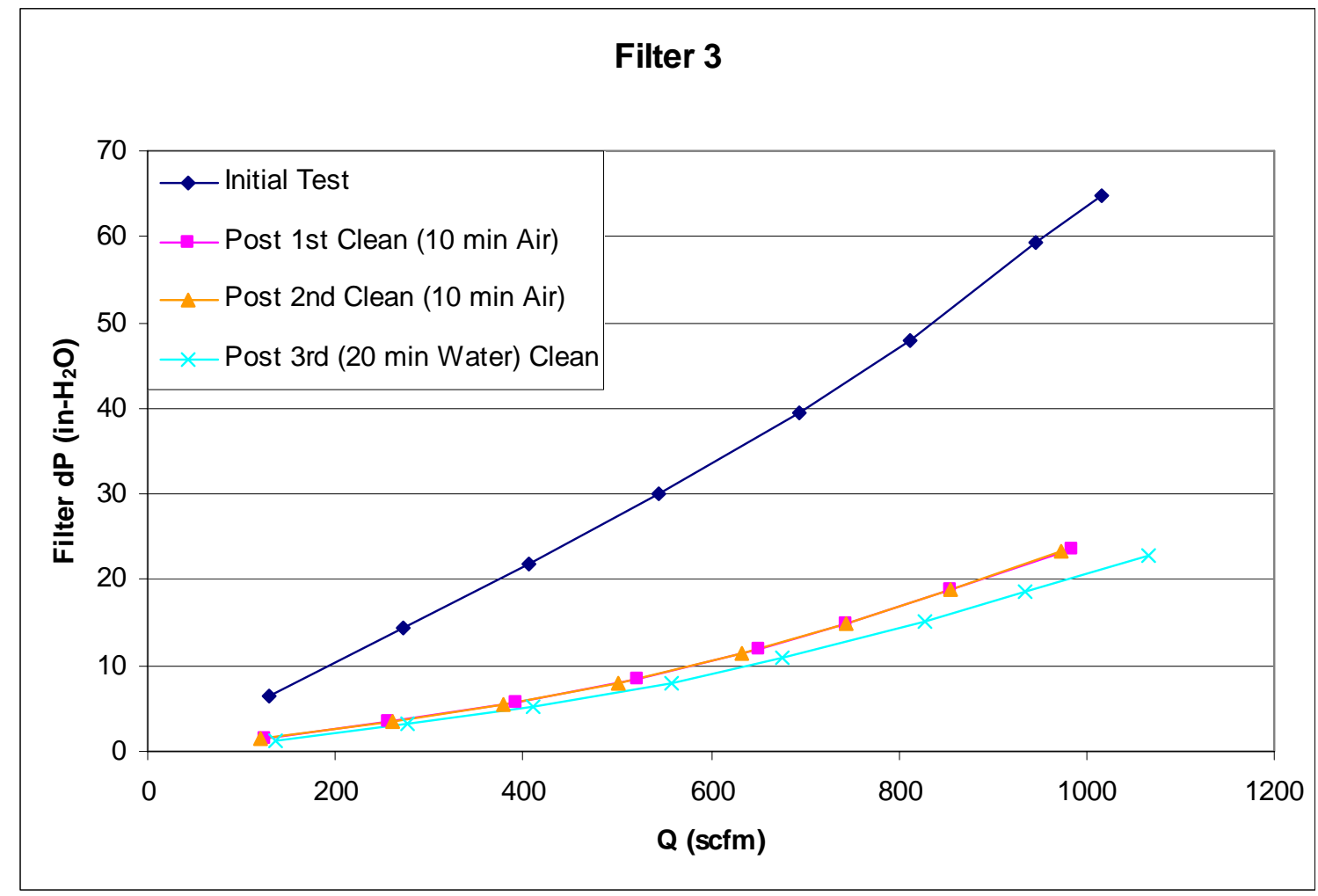

Figure B-3 Pressure Difference for Each Phase of Flow Bench Testing on Filter 3

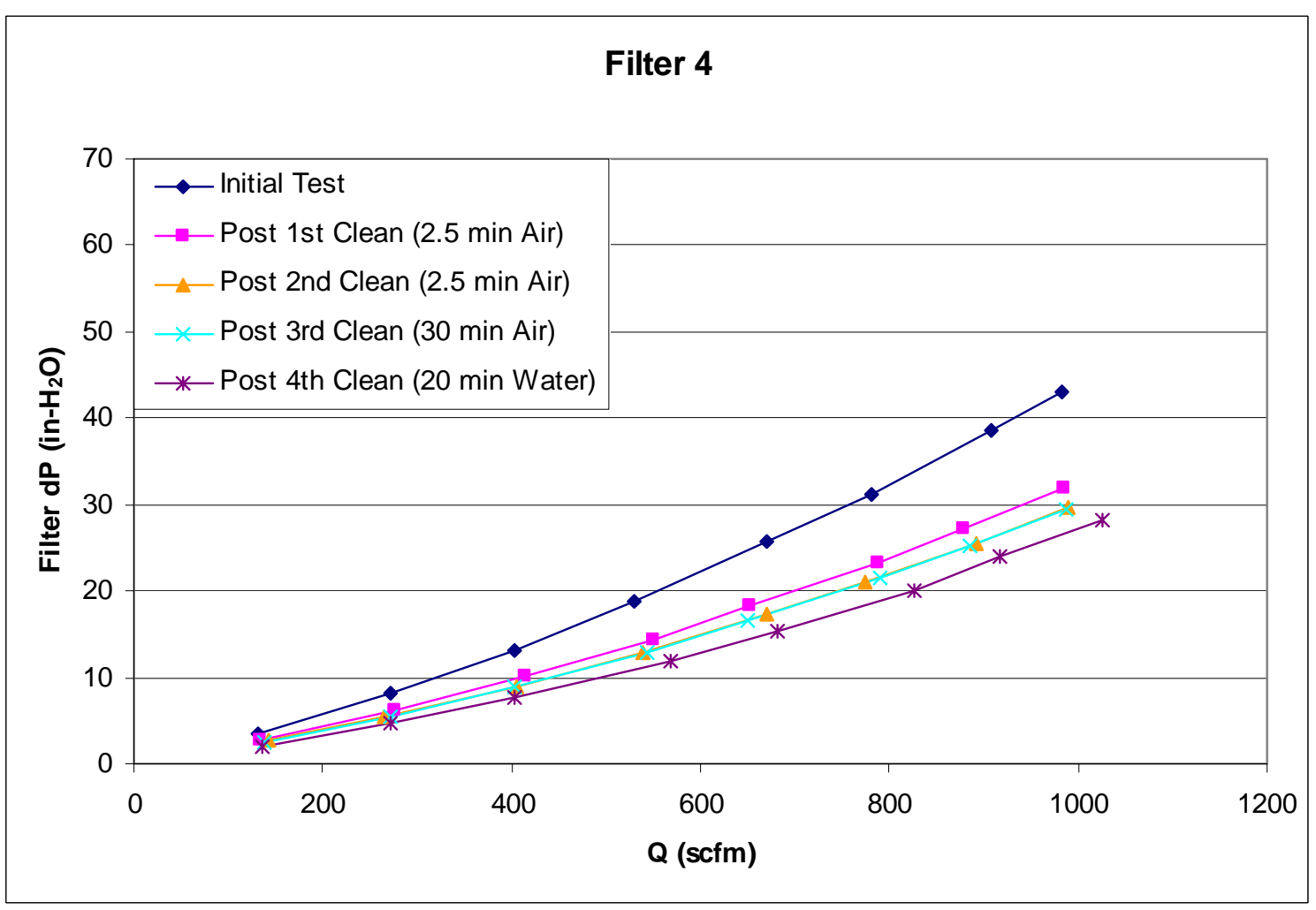

Figure B-4 Pressure Difference for Each Phase of Flow Bench Testing on Filter 5 


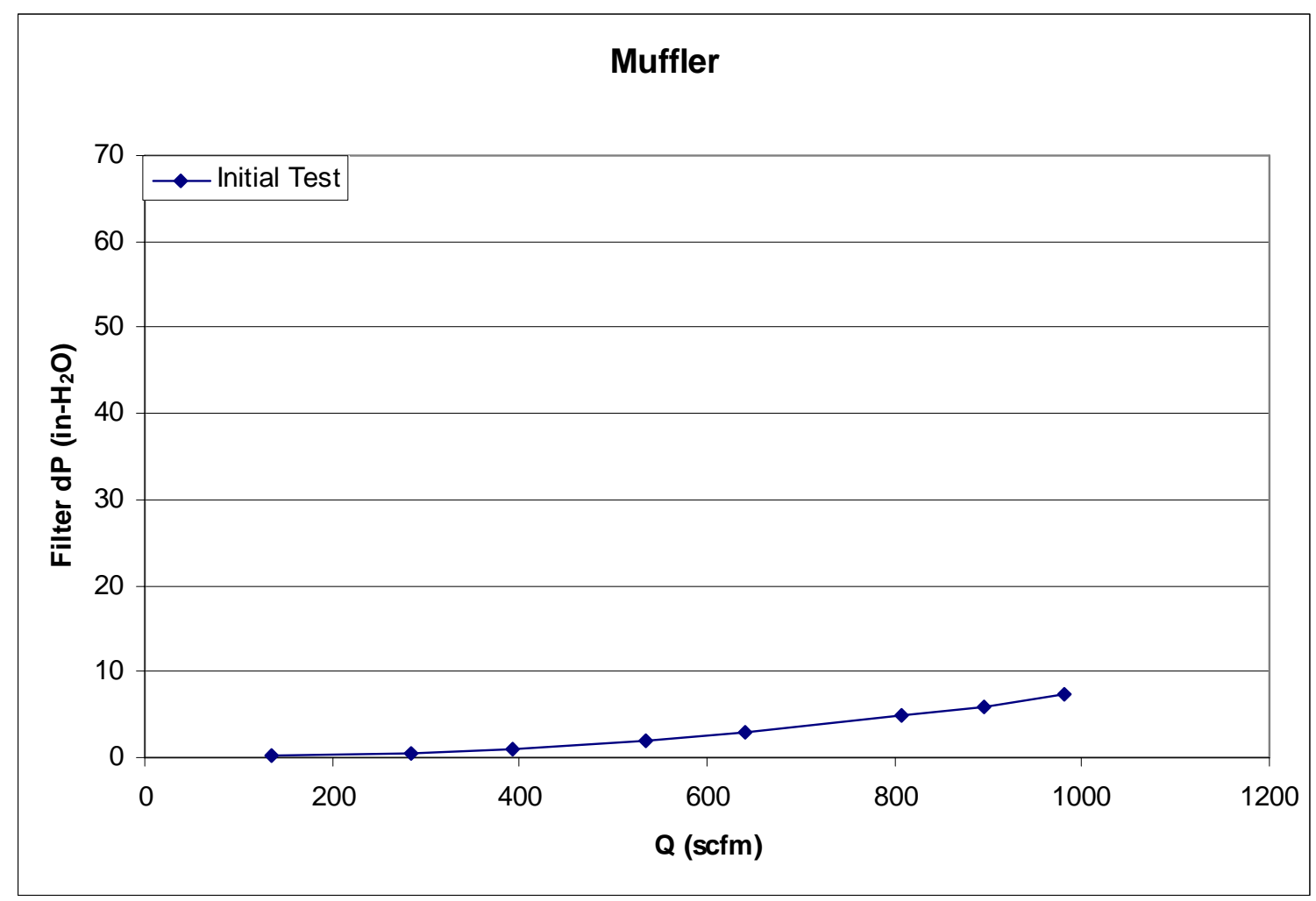

Figure B-5 Pressure Difference for the Flow Bench Testing on the Muffler 


\section{APPENDIX C}

Engine Pressure Differential Graphs 
Figures C-1 and C-2 below show the pressure drop measured across filter 7 and the muffler during the engine testing cycle. Each value is the average of three test cycles consecutively run for each of the six modes of operation. Figure C-1 shows the differential pressure as a function of the exhaust flow rate for the initial run and after the first and second cleaning cycles of a 30 minute pressurized air and 20 minute water cleanings, respectively. Figure C-2 shows the muffler test cycle which was used to compare an exhaust system retrofit with a DPF system with a standard muffler. This figure also has the linear approximation to fit the pressure drop as a function of exhaust flow rate. The standard deviation of the differential pressure is indicated in both figures which again partially explains the deviation of the data from the linear trend. Another possible cause for the deviation from the trend is the error in the actual filter temperature. The exhaust temperature had not reached a steady state condition and the variations in the filter temperature could be the cause of the variations of the pressure drop across the filter due to the change in the exhaust gas viscosity. 


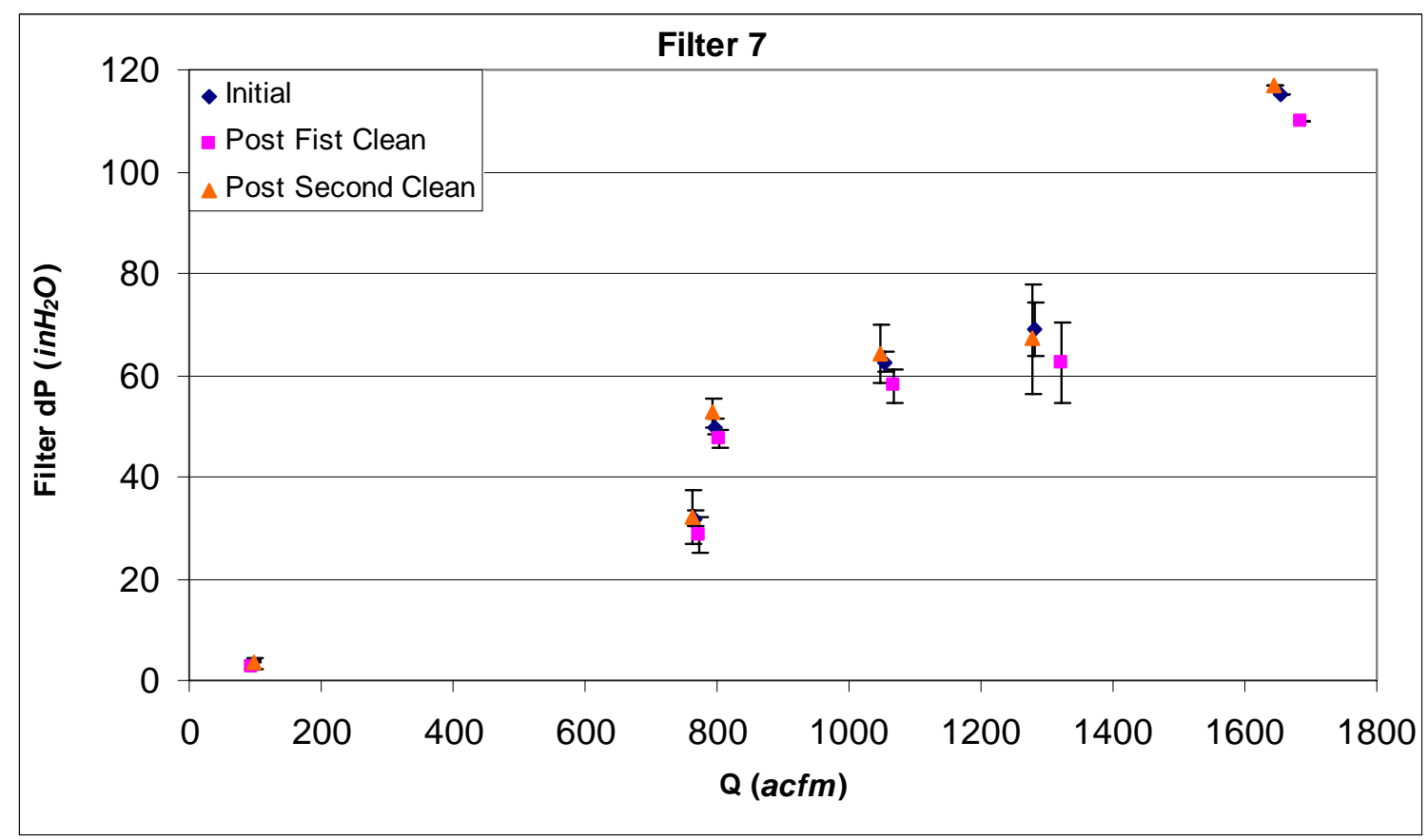

Figure C-1 Pressure Difference During Engine Testing for Filter 7

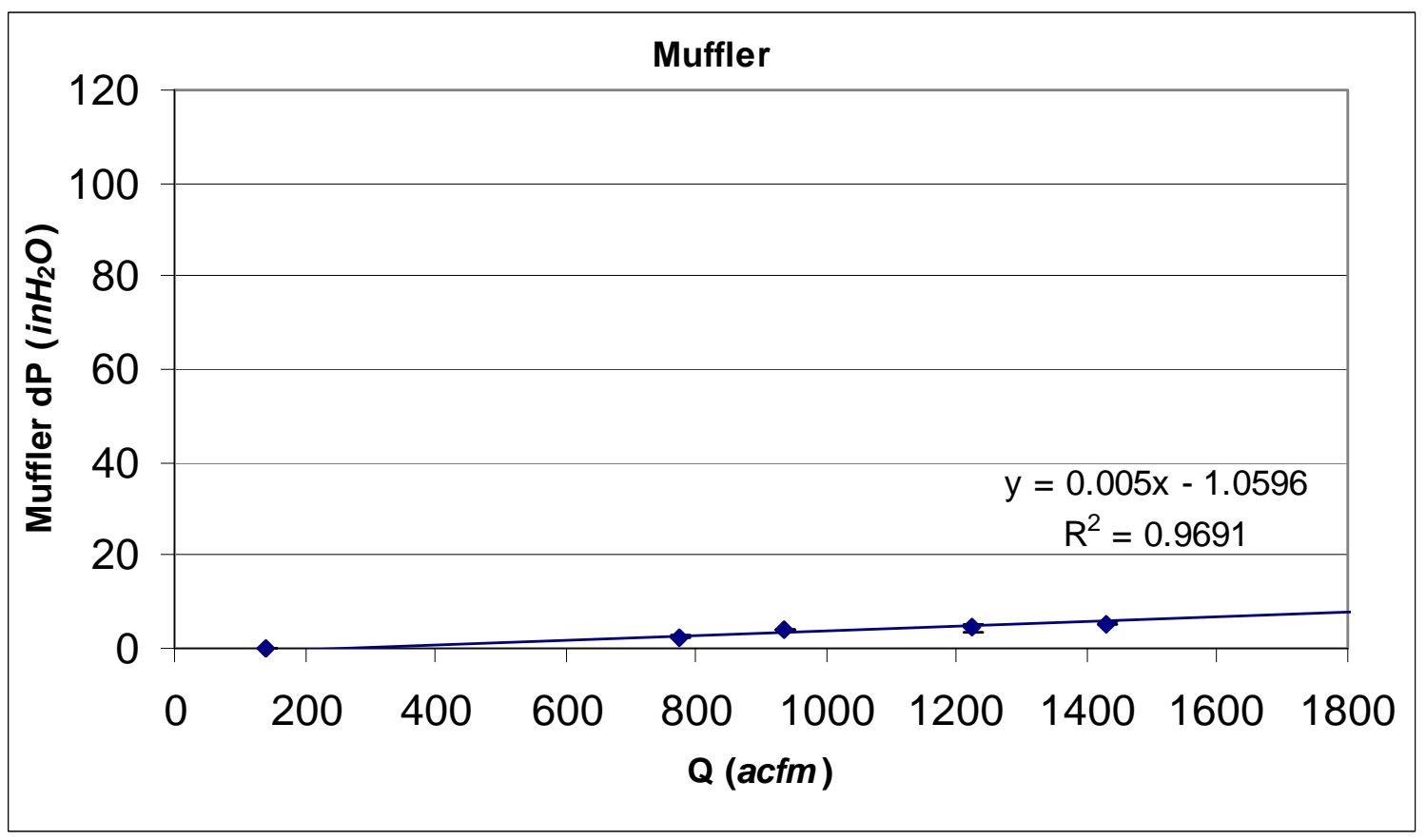

Figure C-2 Pressure Difference During Engine Testing for the Muffler 


\section{APPENDIX D}

Modeling Fit to Filter 7 
Figure D-1 below shows the modeling of the flow bench results for filter 7 . The data points on the figure represent the actual data collected and are the same points that are found in Figure 4-4 and the lines represent the modeling results. Figure D-2 shows the engine test modeling results. The data points on the figure represent the actual data collected and are the same points that are shown in Figure C-1 and the lines represent the modeling results. The modeling follows the order of the testing cycle thus the line does not follow a linear increase for flow rate and differential pressure. Both models yielded a good fit for both flow bench and engine tests. 


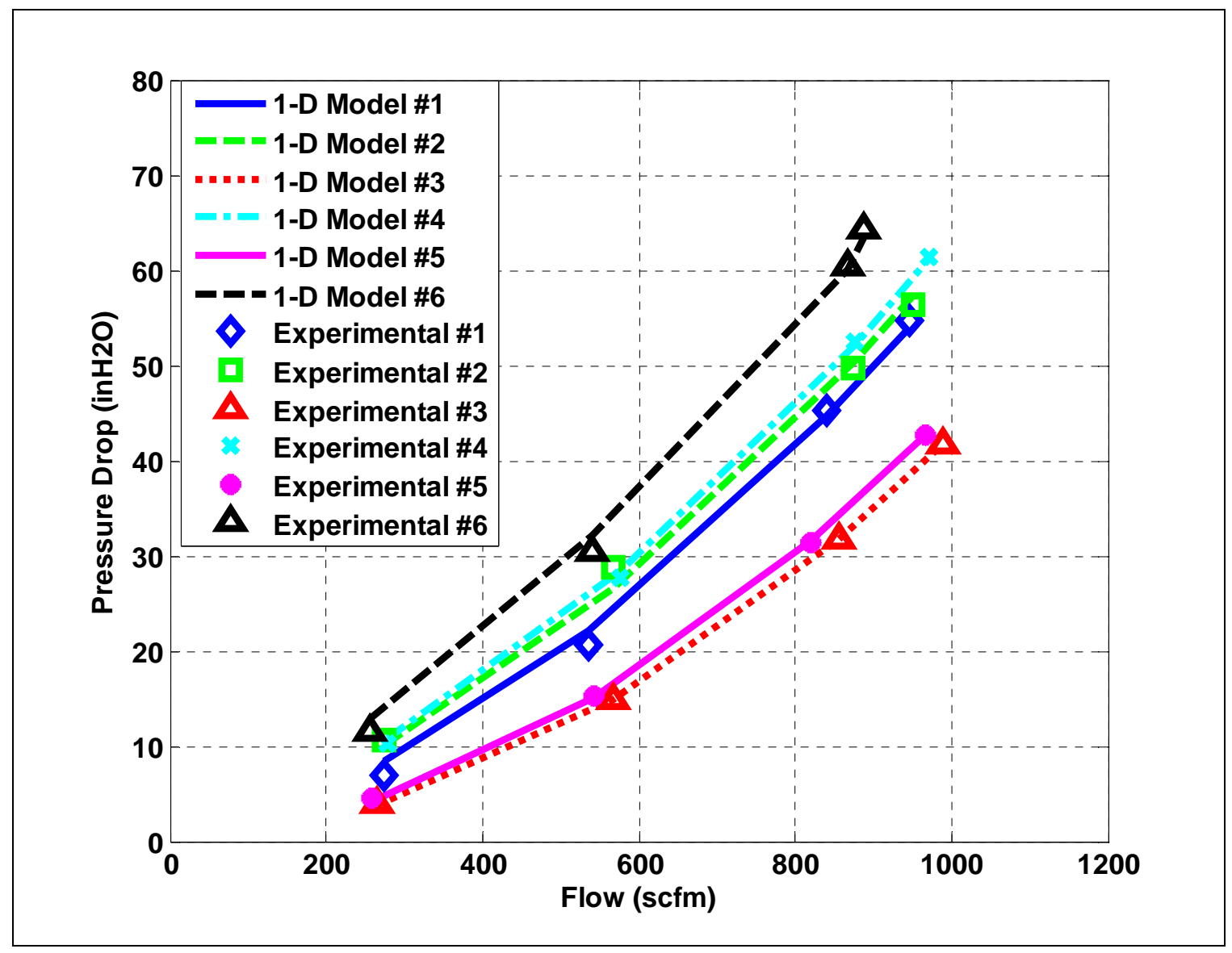

Figure D-1 Modeling Fit to Filter 7's Flow Bench Results 


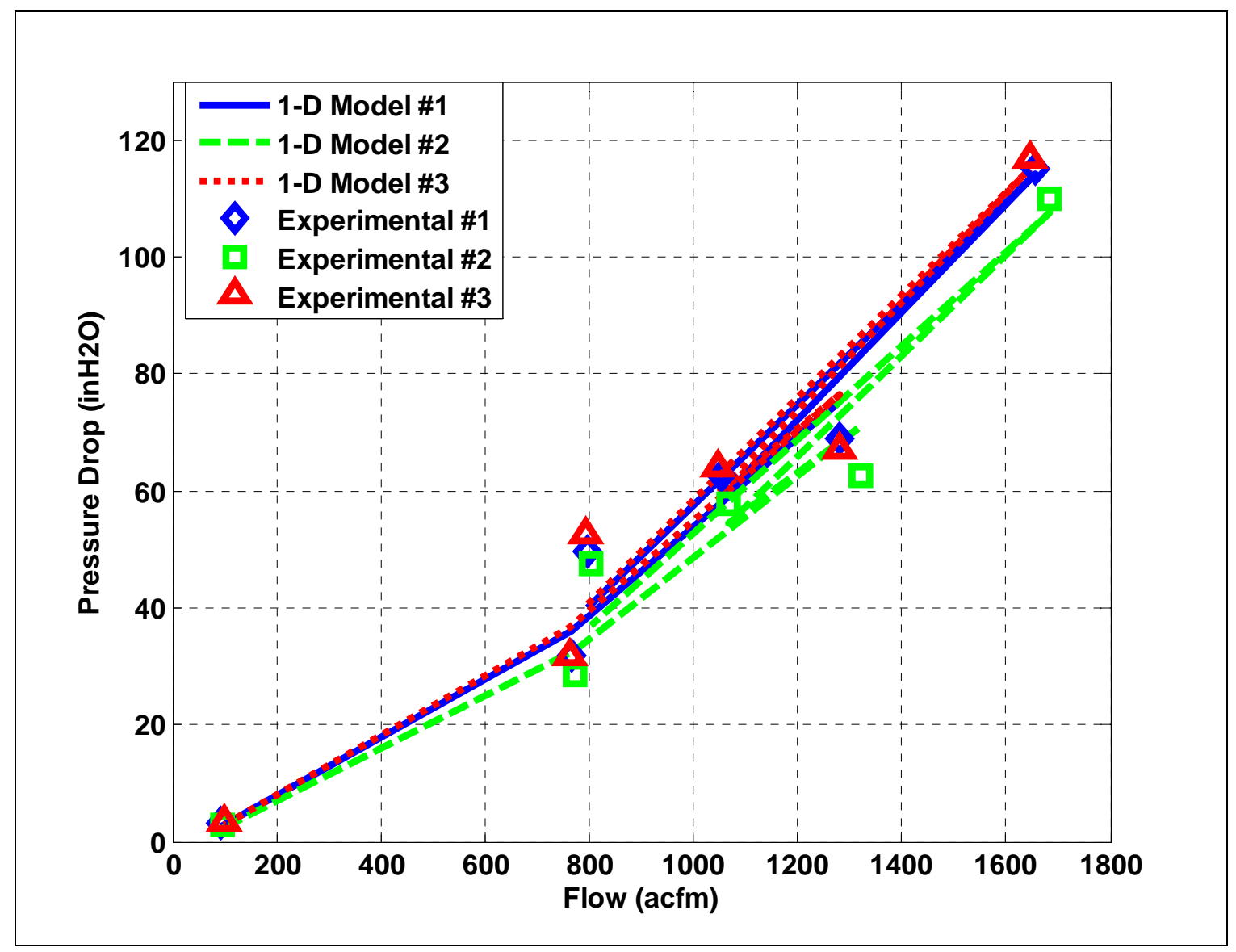

Figure D-2 Modeling Fit to Filter 7's Engine Test Results 